University of Louisville

ThinkIR: The University of Louisville's Institutional Repository

Electronic Theses and Dissertations

$12-2014$

\title{
Investigation of transmission loss through double wall structures with varying small air gaps using modal analysis.
}

Richard Michael Phillips 1988-

University of Louisville

Follow this and additional works at: https://ir.library.louisville.edu/etd

Part of the Mechanical Engineering Commons

\section{Recommended Citation}

Phillips, Richard Michael 1988-, "Investigation of transmission loss through double wall structures with varying small air gaps using modal analysis." (2014). Electronic Theses and Dissertations. Paper 1760. https://doi.org/10.18297/etd/1760

This Master's Thesis is brought to you for free and open access by ThinkIR: The University of Louisville's Institutional Repository. It has been accepted for inclusion in Electronic Theses and Dissertations by an authorized administrator of ThinkIR: The University of Louisville's Institutional Repository. This title appears here courtesy of the author, who has retained all other copyrights. For more information, please contact thinkir@louisville.edu. 
INVESTIGATION OF TRANSMISSION LOSS THROUGH DOUBLE WALL STRUCTURES WITH VARYING SMALL AIR GAPS USING MODAL ANALYSIS

\author{
By
}

Richard Michael Phillips

B.S. in Mechanical Engineering, University of Maryland Baltimore County 2011

\author{
A Thesis \\ Submitted to the faculty of the \\ University of Louisville \\ J.B. Speed School of Engineering \\ In Partial Fulfillment of the Requirements \\ For the Degree \\ Master of Science \\ Department of Mechanical Engineering \\ University of Louisville \\ Louisville, Kentucky
}

December 2014 
Copyright (C) by Student Richard Phillips 2014

All Rights Reserved 

INVESTIGATION OF TRANSMISSION LOSS THROUGH DOUBLE WALL STRUCTURES WITH VARYING SMALL AIR GAPS USING MODAL ANALYSIS

\author{
Submitted by: Richard M. Phillips
}

A Thesis Approved on

November 24, 2014

By the following Thesis Committee

Dr. Christopher Richards (Associate Professor and Advisor - Mechanical Engineering)

Dr. Kevin Murphy (Chairman and Professor - Mechanical Engineering)

Dr. Robert Cohn (Professor - Electrical and Computer Engineering) 


\section{ACKNOWLEDGEMENTS}

I would like to dedicate this thesis to my family; to my wife, Stephanie, who has been forever supportive of my work and education despite the long hours, and to my mother, father and brother who have continuously encouraged me throughout my life.

I would like to thank my University of Louisville advisor Dr. Chris Richards for helping me through the process of completing this thesis, and the thesis committee, Dr. Murphy and Dr. Cohn for their direction and consultation. I would also like to extend my gratitude to Avi Patil for his tutelage and support. Additionally, I would like to thank Tim O'Connell, Rob LaFleur, Sam DuPlessis, Mark Shah, Rajan Parbhoo and Rob Bollman for giving me the opportunity to complete graduate school while working full time. Lastly, thank you John Quirk and Jason Gulczewski for helping me collect the acoustics data included in this thesis. 


\title{
ABSTRACT \\ INVESTIGATION OF TRANSMISSION LOSS THROUGH DOUBLE WALL STRUCTURES WITH VARYING SMALL AIR GAPS USING MODAL ANALYSIS
}

\author{
Richard M. Phillips
}

November 24, 2014

Noise reduction testing is completed for two single steel plate constructions with different thicknesses and for two double wall constructions with different air gap thicknesses that include the same two plates used in the single plate constructions. Results compare favorably with known theory and experimental results from previous literature. These favorable comparisons include the direct relationship between mass per unit area and transmission loss for single plate constructions, the presence of a noise reduction valley near the mass-air-mass frequency, the dependency of the mass-air-mass frequency on the air gap thickness, and the existence of a bridge frequency. Despite the similarities between theory and experimental results, there are discrepancies. Both the mass-air-mass and bridge frequencies for the double wall constructions were over predicted by equations offered in the literature. Additionally, the theory over predicted the bridge frequency, and the bridge frequency did not shift with changing air gap thickness. To uncover if these discrepancies are a result of structural dynamics not accounted by theory, experimental modal analysis was conducted on the single and double plate constructions. Investigation into the mode shape behavior reveals that the 
double wall noise reduction minimum attributed to the mass-air-mass frequency occurs in a region containing mode shapes where the two plates display synchronous motion and an unexpected noise reduction peak occurs in a frequency region where the double wall construction mode shapes exhibit asynchronous motion. Finally, acceleration plots of the constructions when excited by sound reveals that the bridge frequency occurs at a transition when the plate vibration reduces significantly. 
TABLE OF CONTENTS

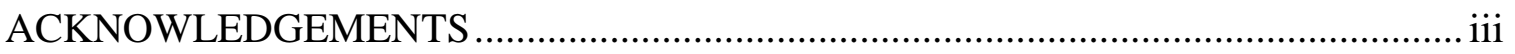

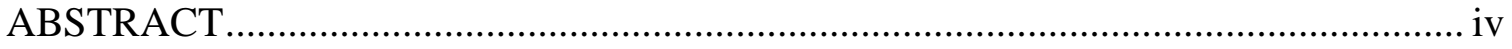

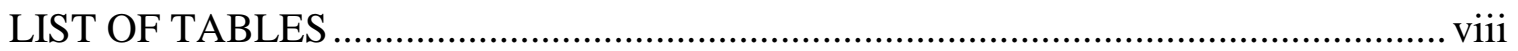

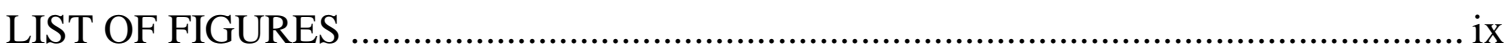

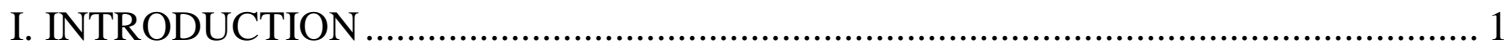

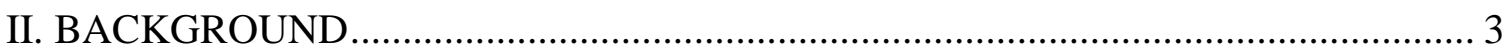

A. Sound Transmission - Terminology and Common Testing Techniques .....................3

B. Government Regulations and Customer Requirements............................................6

C. Common Methods to Increase Sound Transmission Loss ..........................................

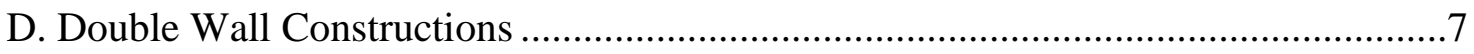

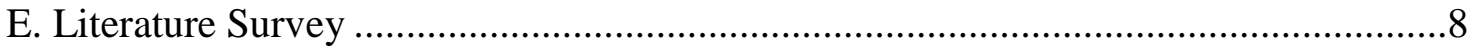

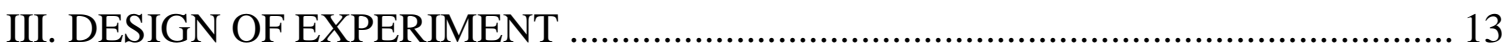

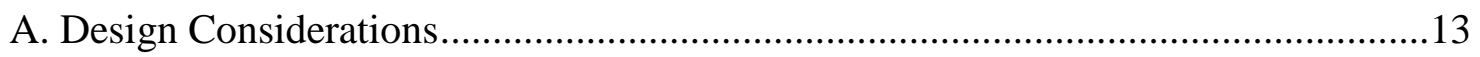

B. Construction of Experiment...............................................................................16

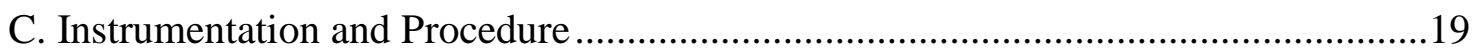

IV. TRANSMISSION LOSS THEORY AND EXPERIMENTAL RESULTS ................ 26

A. Single Wall Transmission Loss Theory ………………..........................................26

B: Double Wall Transmission Loss Theory .............................................................

C. Single Wall Experimental Noise Reduction .............................................................

D: Double Wall Experimental Noise Reduction ........................................................38

E. Discrepancies Between Theory and Experiment Explained Through Structural

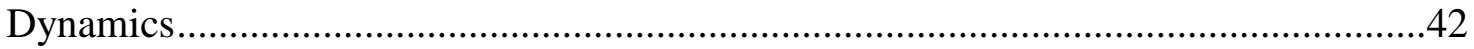

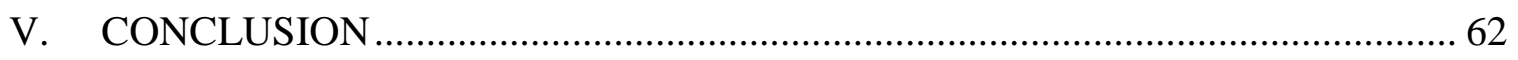

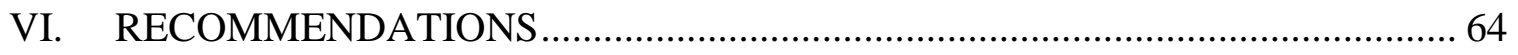




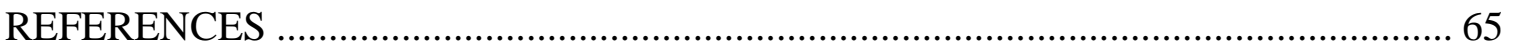

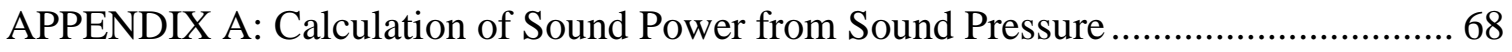

APPENDIX B: One Third Octave Band Ranges and Center Frequencies ...................... 69

APPENDIX C: Method of Calculating STC [1] ..................................................... 70

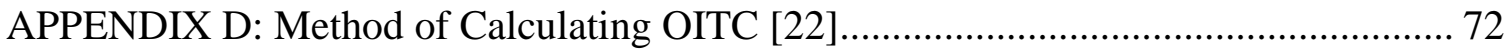

APPENDIX E: Drawings Used to Create the Test Specimen and Frame ...................... 74

APPENDIX F: Values of the Constants for Equations 6 and 7 .................................. 75

APPENDIX G: FEM Mode Shapes (First 4 Mode Shapes of Single Plates) and Experimental Modal Analysis (First 4 Mode Shapes of all Configurations).................... 76

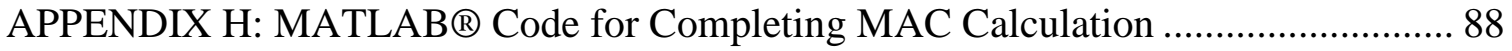

APPENDIX I: MAC Values for 1.9 mm Air Gap Mode Shapes.................................... 89

APPENDIX J: MAC Values for 3.8 mm Air Gap Mode Shapes .................................... 90

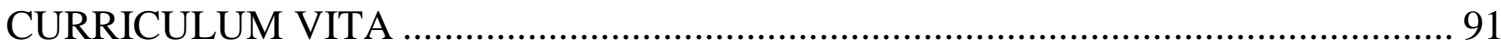




\section{LIST OF TABLES}

Table 1. Excerpt from shock and vibration handbook [18] ........................................ 28

Table 2. Theoretical and numerical results for the first natural frequency of the

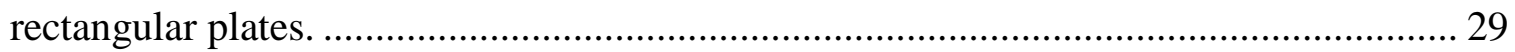

Table 3. Mass-air-mass resonant frequencies of experimental configurations................ 34

Table 4. One third octave band ranges and center frequencies..................................... 69

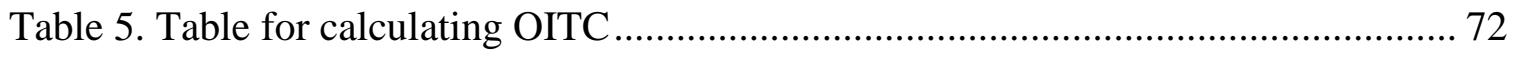

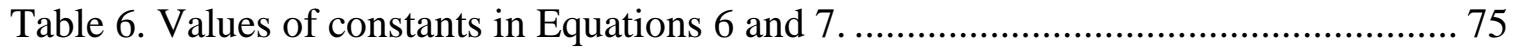

Table 7. MAC values for $1.9 \mathrm{~mm}$ air gap configurations mode shapes.......................... 89

Table 8. MAC values for $3.8 \mathrm{~mm}$ air gap configuration mode shapes. .......................... 90 


\section{LIST OF FIGURES}

Figure 1. Typical sound transmission loss testing setup................................................. 4

Figure 2. Single plate configurations (specimen in gray and frame in blue)................... 14

Figure 3. Double wall configurations (specimen in gray, frame in blue)......................... 15

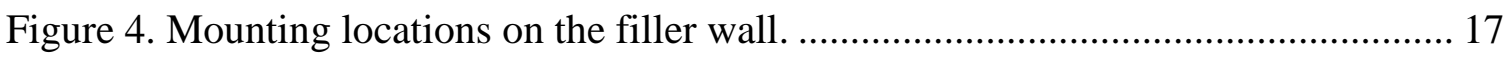

Figure 5. View of the filler wall from the source room................................................ 18

Figure 6. View of the filler wall from the receiving room............................................. 18

Figure 7. Discretization of the specimen, accelerometer location (blue), impact locations

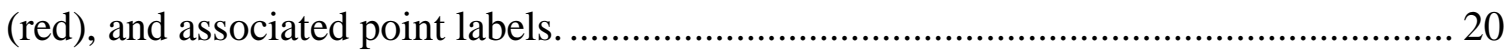

Figure 8. Top view of configurations for noise reduction testing................................... 21

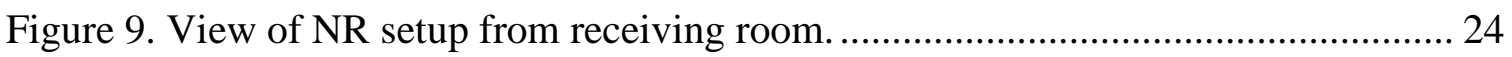

Figure 10. View of NR setup from the source room.................................................. 24

Figure 11. View of NR setup - sound source and source room microphone. .................. 25

Figure 12. Theoretical transmission loss plot for single plate constructions.................... 27

Figure 13. Theoretical transmission loss plot for double plate configurations................. 32

Figure 14. Mass spring system analogous to double wall mass-air-mass resonance........ 33

Figure 15. Measured NR and predicted TL for the two single plates.............................. 36

Figure 16. NR curves for all 4 test configurations........................................................ 39

Figure 17. Double wall NR shows that an air gap increase corresponds to mass-air-mass

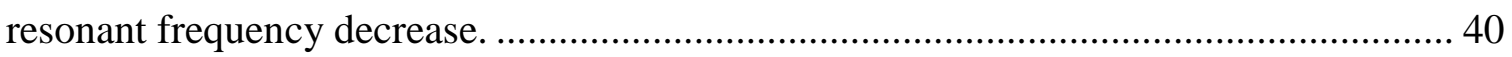

Figure 18. Double wall NR critical frequency is independent of the air gap. ................. 41

Figure 19. Double wall NR and predicted slopes. ......................................................... 42

Figure 20. Mass-air-mass frequency predicted by Equation 12..................................... 43

Figure 21. Mode shape of double plate configuration with $1.9 \mathrm{~mm}$ air gap at $434 \mathrm{~Hz}$... 44

Figure 22. Predicted mass-air-mass frequency and frequency of observed synchronous

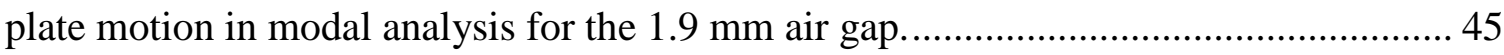

Figure 23. Mode shape of double plates with $3.8 \mathrm{~mm}$ air gap at $402 \mathrm{~Hz}$........................ 46

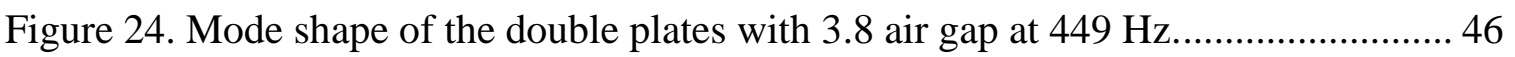

Figure 25. Predicted mass-air-mass frequency and frequency of observed synchronous plate motion in modal analysis for $3.8 \mathrm{~mm}$ air gap.......................................................... 47

Figure 26. NR and MAC values for the $1.9 \mathrm{~mm}$ air gap double plate configuration. ...... 49

Figure 27. MAC value for observed mass-air-mass resonance in modal analysis, indicated

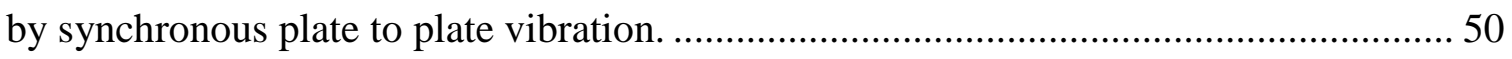

Figure 28. NR and MAC for the $3.8 \mathrm{~mm}$ air gap double plate configuration.................... 51 
Figure 29. MAC value for observed mass-air-mass resonance in modal analysis, indicated

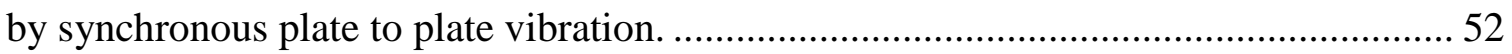

Figure 30. Predicted bridge frequency for $1.9 \mathrm{~mm}$ and $3.8 \mathrm{~mm}$ air gap configurations... 53

Figure 31. NR and plate acceleration of double plates with $1.9 \mathrm{~mm}$ air gap................... 54

Figure 32. NR and plate acceleration of double plates with $3.8 \mathrm{~mm}$ air gap................... 56

Figure 33. Mass dependent NR between bridge frequency and critical frequency for the

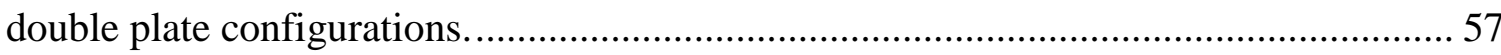

Figure 34. NR and acceleration of $0.6 \mathrm{~mm}$ single plate and frame. ...............................59

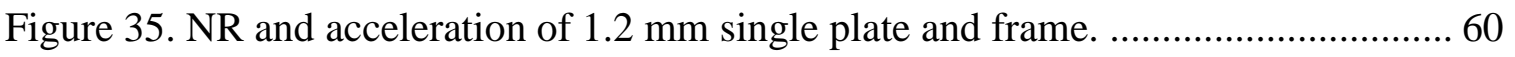

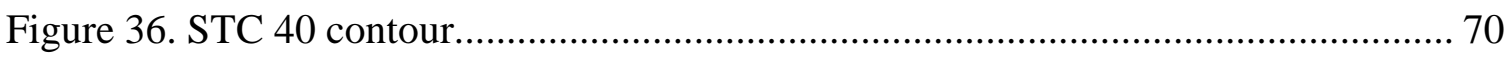

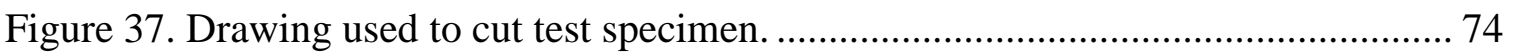

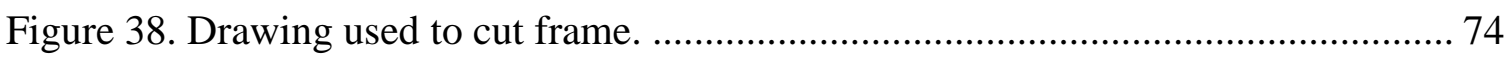

Figure 39. FEM first mode shape for $0.6 \mathrm{~mm}$ plate $(36.8 \mathrm{~Hz})$...................................... 76

Figure 40. EMA first mode shape for $0.6 \mathrm{~mm}$ plate $(34.2 \mathrm{~Hz})$....................................... 76

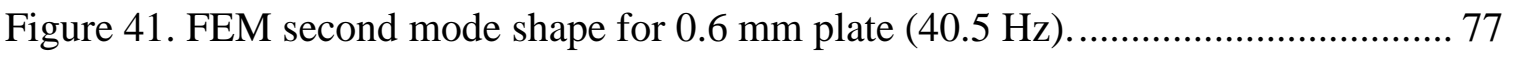

Figure 42. EMA second mode shape for $0.6 \mathrm{~mm}$ plate $(43.1 \mathrm{~Hz})$.................................. 77

Figure 43. FEM third mode shape for $0.6 \mathrm{~mm}$ plate $(47.4 \mathrm{~Hz})$.................................. 78

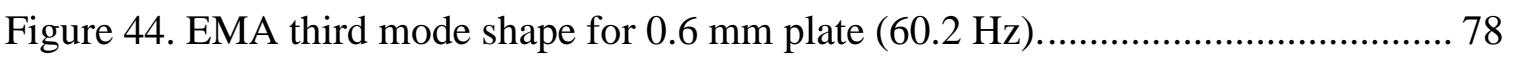

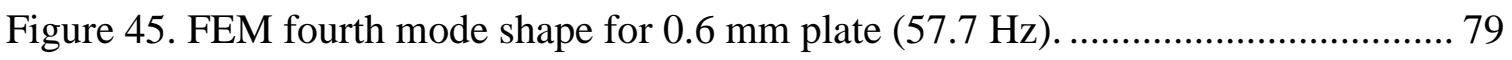

Figure 46. EMA fourth mode shape for $0.6 \mathrm{~mm}$ plate $(74.5 \mathrm{~Hz})$................................. 79

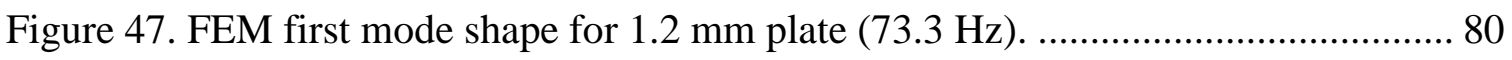

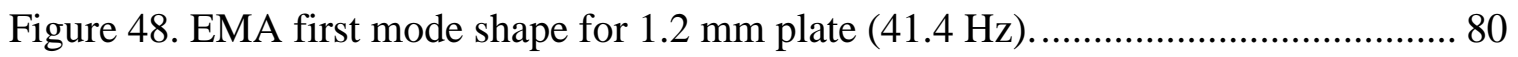

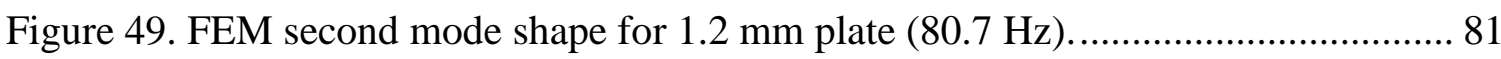

Figure 50. EMA second mode shape for $1.2 \mathrm{~mm}$ plate $(76.3 \mathrm{~Hz})$.................................. 81

Figure 51: FEM third mode shape for $1.2 \mathrm{~mm}$ plate $(94.3 \mathrm{~Hz})$. ................................... 82

Figure 52. EMA third mode shape for $1.2 \mathrm{~mm}$ plate (130.2)....................................... 82

Figure 53. FEM fourth mode shape for $1.2 \mathrm{~mm}$ plate $(114.9 \mathrm{~Hz})$................................ 83

Figure 54. EMA fourth mode shape for $1.2 \mathrm{~mm}$ plate $(261.6 \mathrm{~Hz})$................................ 83

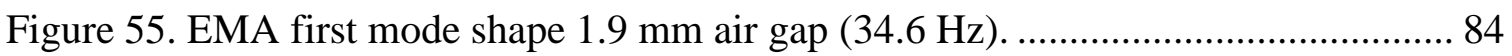

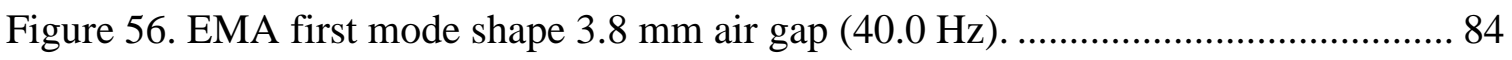

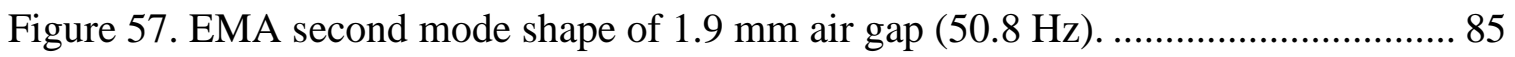

Figure 58. EMA second mode shape of $3.8 \mathrm{~mm}$ air gap $(58.2 \mathrm{~Hz})$.............................. 85

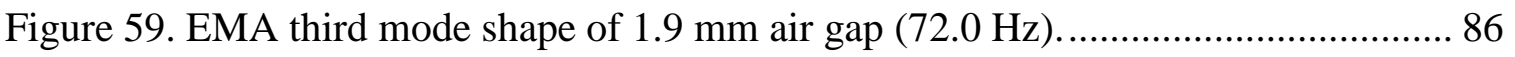

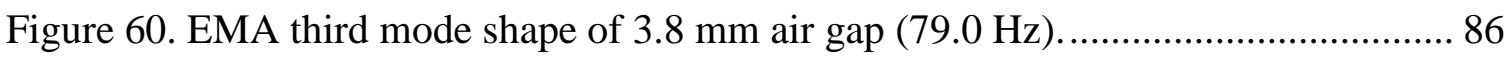

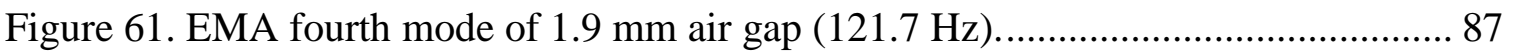

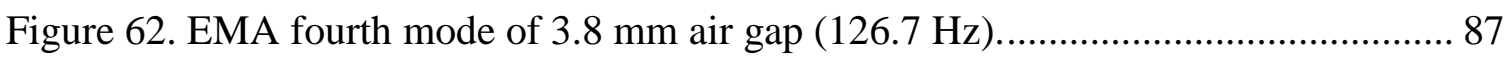




\section{INTRODUCTION}

The literature contains numerous theoretical predictions that can be made regarding the transmission loss (TL) performance for double wall constructions. Traditionally, acoustics textbooks simplify the discussion of double wall structures to yield generalizations that can be used to predict trends in performance [1-3]. To extend the theory, numerous papers have been published describing the effects of the different variables that drive the performance of the double wall structures [4-8]. These variables

are experimentally studied in the literature and include but are not limited to the thickness of the individual walls, material of the wall, thickness of the gap between walls, composition of the gap, stud locations, stud material and screw spacing [4,8]. Typically, the research in the area of double wall transmission loss has been centered around the construction industry, focusing on relatively large wall areas and gap spacings [4,8-9]. Additionally, there is a concentration in the literature on building materials such as wood,

fiberboard, and gypsum boards [8-9]. There are studies that have investigated metal wall constructions including steel studs, and either steel or aluminum wall faces, but the focus on larger gap spacing has remained [4]. A few studies have been published regarding small gaps between double walls, concentrating on the performance of glass window applications $[5-6,10]$.

To perform sound transmission loss experiments, extensive laboratories that include large acoustic rooms, sound source equipment and microphones are required 
[11]. Additionally, mounting of the test specimen must be closely monitored due to the major effect that mounting and flanking paths can have on transmission loss [12].

Alternatively, experimental modal analysis is a tool that can be used to understand the structural dynamics of a system without extensive laboratories. However, limited literature exists regarding correlation between modal analysis and transmission loss [13], or how structural dynamics may cause discrepancies between existing transmission loss theory and experimental results.

In this study four steel plate configurations are considered: two single plate constructions that vary in thickness by double, and two double plate configurations, which use the two plates from the single plate constructions, with air gaps that vary by double. Noise reduction testing and experimental modal analysis is conducted on all four constructions. In addition, accelerometers are placed on the test specimen in each noise reduction test. The noise reduction results are compared to transmission loss theory for both the single and double plate configurations. The single plate noise reduction tests will be compared to the field incidence mass law. For the double wall constructions, the mass-air-mass frequency and bridge frequency in the noise reduction experiments will be compared to the frequencies predicted from theory $[1,4]$.

The similarities and discrepancies between transmission loss theory and the noise reduction experimental results are discussed. Modal analysis and plate acceleration data measured during the noise reduction tests are presented to explain these discrepancies. 


\section{BACKGROUND}

\section{A. Sound Transmission - Terminology and Common Testing Techniques}

When sound impacts a barrier, it is referred to as incident sound [1]. There are three categories of sound incidence; diffuse incidence, normal incidence, and field incidence. Diffuse incidence is the term used to describe when incident sound strikes the barrier at all angles from $0^{\circ}$ to $90^{\circ}$. Normal incidence is when incident sound strikes the barrier at a $0^{\circ}$ angle only. Field incidence is a common ground between diffuse and normal incidence. Field incidence assumes sound is striking the barrier at angles between $0^{\circ}$ and $78^{\circ}$. The omission of sound waves incident at angles between $78^{\circ}$ and $90^{\circ}$ allows for better correlation of theory to experimental results with finite sized rooms and barriers [1].

After incident sound strikes a barrier, three mechanisms occur simultaneously. A portion of the incident sound is reflected back toward the source, a portion is absorbed by the barrier, and the remaining sound is transmitted to the space on the opposing side of the barrier. Transmission loss is the term used to describe the performance of the barrier as sound insulation between the two spaces, with increasing transmission loss corresponding to increasing sound barrier performance. It is given by

$$
\mathrm{TL}=10 \log _{10} \frac{\mathrm{W}_{\mathrm{I}}}{\mathrm{W}_{\mathrm{T}}}
$$


where $W_{I}$ is the sound power (watts) incident on the wall, and $W_{T}$ is the sound power transmitted to the space on the opposing side of the barrier [1]. Sound power is defined as acoustic energy divided by time, and is independent of measurement location [1].

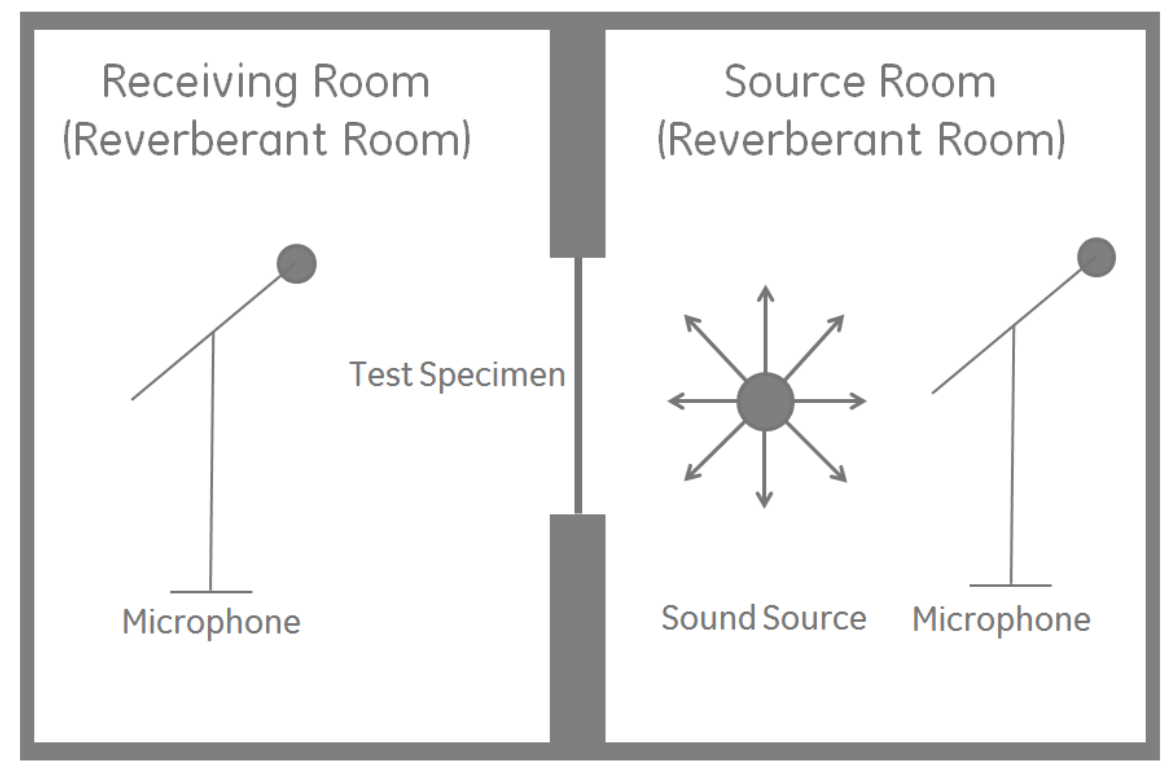

Figure 1. Typical sound transmission loss testing setup.

Testing for measuring transmission loss is conducted following ASTM E90: Standard Method for Laboratory Measurement of Airborne Sound Transmission Loss of Building Partitions [11]. This method for determining transmission loss is generally conducted utilizing two adjacent and isolated reverberant rooms, with an opening in the walls between the two rooms (Figure 1). The test specimen is placed in the opening between the two rooms. One of the rooms contains a speaker that produces pink noise that typically ranges from $80 \mathrm{~Hz}$ to $10,000 \mathrm{~Hz}$ and has amplitude of $100 \mathrm{~dB}$ or higher. This room is appropriately called the source room. 
Also located in the source room is a rotating microphone boom. The microphone measures the sound pressure in the reverberant field of the source room, and data acquisition software converts the pressure into sound power for the specific room. The adjacent room, named the receiving room, contains an additional rotating microphone. Similar to the source room, the rotating microphone measures the sound pressure in the receiving room and data acquisition software converts the sound pressure to sound power for the specific room. The calculation for converting sound pressure to sound power is available in APPENDIX A.

It is typical to convert the narrow band measurements to third octave bands, resulting in sound power measurements in both rooms. With these two measurements, Equation (1) can be used to calculate transmission loss in each third octave band. After completing the testing and determining the transmission loss in each third octave band, it is typical to plot transmission loss vs frequency from center frequencies $100 \mathrm{~Hz}$ to 5000 Hz. The third octave band ranges and center frequencies from $100 \mathrm{~Hz}$ to $5000 \mathrm{~Hz}$ are offered in APPENDIX B.

Another common practice is to synthesize the transmission plot into a single number rating. The two most common ratings used to characterize transmission loss performance are Sound Transmission Class (STC) and Outdoor Indoor Transmission Class (OITC). Methods for calculating STC and OITC are offered in APPENDIX C and APPENDIX D respectively. 


\section{B. Government Regulations and Customer Requirements}

Although single number classifications like STC and OITC can be misleading since they synthesize broadband performance into a single number, they are commonly used by governments and architects when determining sound transmission regulations and requirements. Since the passing of the United States Noise Control Act of 1972, many local and state governments has passed additional ordinances and regulations related to noise pollution and control. Additionally, the U.S. Green Building Council (USGBC) which is responsible for the qualification of Leadership in Energy and Environmental Design (LEED) buildings has created numerous noise requirements for workspaces and classrooms. One example that is specifically relevant to this discussion is the requirement of classroom construction materials other than windows to have an STC of at least 35 [14].

In addition to government regulation and special interest group qualifications, customers in many industries have STC and OITC requirements. As expected, one of the most competitive industries with regards to STC and OITC is the building materials industry. This includes companies that make drywall, insulation, roofing, doors and windows. Typically, these products will have their ratings for STC published, as this is a major consideration for the potential customer. Additionally, some other applications for the use of STC include office cubical dividers and drop ceiling tiles. Architects of buildings will often specify the STC or OITC requirement for building exteriors, as well as interior walls, floors and ceilings. 


\section{Common Methods to Increase Sound Transmission Loss}

There are multiple methods that engineers and building designers use to increase transmission loss of building components and sound barriers. An important factor in improving transmission loss is to ensure that there is no flanking path around the barrier, and that there are no holes, or cracks within the barrier to allow sound to pass through unobstructed [15]. Next, in the case of a common stud wall, decoupling the two sheets of drywall from the studs (using fewer screws) and utilizing double stud construction to decouple the two sheets of drywall from each other prove advantageous. Another common technique is to use insulation materials in the cavity between two walls. Lastly, a simple, but highly effective technique is to increase the mass per unit area of the barrier. In the case of the standard stud wall, doubling the thickness of the drywall on each side of the wall has proven an effective method to increase transmission loss [15].

Unfortunately in many applications, these methods are not practical or cost effective. For instance, doubling the mass per unit area or the thickness of insulation materials of the barrier in cars or airplanes will negatively affect the fuel consumption and compete with space constraints. Additionally, there are numerous products on the market that claim to increase transmission loss (foams, insulations, rubbers, etc), but these products are often not affective at dominant sound source frequencies and are not cost effective.

\section{$\underline{\text { D. Double Wall Constructions }}$}

One technique that increases the transmission loss of a barrier but requires little space and minimal additional cost is to utilize double wall constructions with a small air 
gap. This technique is used heavily in the construction material industry, clearly evident in the construction of walls and of windows. The theory states that two barriers with a small air gap will have improved transmission loss over a majority of frequencies when compared to that of a single barrier of mass per unit area equal to that of the two barriers [1]. This is due to the change in acoustic impedance as the sound travels through solid, then air, and then another solid. Each time the sound reaches a change in acoustic impedance, a percentage of the sound is reflected, thus reducing the amount of sound transmitted through the barrier. In addition to the sound that is reflected, a percentage of the sound energy is dissipated by the barrier in the form of heat.

\section{E. Literature Survey}

Various papers have been published regarding transmission loss of flat panels, including numerous publications concerning double wall transmission loss [4-7,9-10,1213,16-17]. Included in these studies are experimental results of single, double and triple walls of steel, aluminum, glass, gypsum and plywood. Experiments range from large walls with large gaps (simulating home wall constructions) to relatively small walls and small air gaps (window constructions).

One study was completed by London [9] in 1950, in which theory and experiment are both presented regarding double wall transmission loss. London is credited with the derivation of the equation for the mass-air-mass resonant frequency, in which he explains that there exists a frequency in which the mass reactance of the walls exactly equal to the stiffness reactance of the air space. At this frequency the incident sound will be efficiently transmitted, resulting in a sharp reduction in transmission loss. His 
experiments with aluminum and plywood wall faces with air gaps ranging from $3 / 8$ " to 12 " displayed good agreement with the theory developed. The experiments also showed that there exists a gap thickness at which the two walls become decoupled from one another, resulting in a transmission loss of double that of a single wall. London also briefly discusses the effect of studs on the wall, showing that the addition of studs within the air gap reduces the transmission loss of the double wall.

Sewell developed formal solutions for both single wall [16] and double wall partitions [7]. These solutions are plotted numerically and are shown to agree somewhat with experimental data outlined in previous articles. However, the agreement is limited to frequencies below the critical angular frequency, which is defined by Sewell as

$$
\omega_{c}=c^{2} \sqrt{m / D}
$$

where $c$ is the speed of sound, $m$ is the mass per unit area of the plate and $D$ is the bending stiffness. Sewell's results are in best agreement for walls of relatively high mass per unit area and with the assumption that the walls are mounted in an infinitely rigid baffle.

Quirt followed with extensive experimental work comparing experiments with available theory and to determine the dependence of transmission loss on wall thickness and gap spacing [5]. Due to the study being concentrated on widow design, many of the experiments were conducted on double glass walls with small air gaps. It is confirmed the mass-air-mass resonance plays a major role in the performance of the double wall constructions, with experimental data exhibiting sharp reductions in transmission loss 
near the mass-air-mass resonance. It was also explained that there is a reduction in transmission loss near the critical frequency of the single pane of glass. Additionally, the limited effect of the air gap to transmission loss at frequencies below the mass-air-mass resonance is displayed. The results develop general rules that mass law will over predict the transmission loss improvement with the doubling of the wall thickness, and that doubling the air gap will increase the transmission loss by approximately $3 \mathrm{~dB}$. Quirt also studied the effect of non-parallel double walls, showing no major difference between parallel double walls when compared to non-parallel walls with the same mean spacing.

In later work by Quirt [6] it is presented that the theory of mass law correlates well with the transmission loss of double wall structures below half of the mass-air-mass resonance and that the valley at the mass-air-mass resonance a can be reduced in depth and sharpness by adding absorptive materials to the cavity perimeter. Additionally, results within reference [6] show that the mass-air-mass resonance calculation developed by London [9] predicts the general frequency in which the reduction in transmission loss will occur, however the calculation is not perfect in predicting the location of the valley.

Utley and Fletcher also completed transmission loss work regarding window construction, focusing on the effect of the edge conditions [10]. Two edge conditions were studied for single walls, putty and wood beading sealed, or neoprene gasket sealed. For single wall constructions the neoprene gasket exhibited significant transmission loss improvement at the critical frequency $(5-10 \mathrm{~dB})$, while only minimally improving performance at the frequencies below the critical frequency. Similar tests were conducted with double pane windows, comparing sealing methods. The improvement the critical frequency was even larger for double windows (approximately $15 \mathrm{~dB}$ ) and there 
was noticeable improvement at frequencies below the critical frequency $(3-5 \mathrm{~dB})$. The results clearly show that design of the interface between the glass and the frame can affect the transmission loss, however, the general shape (slopes and minima locations) remain the same regardless of mounting.

Extensive description of the transmission loss curve of double wall constructions was offered by Hongisto, et al [4]. A large experimental test matrix was compiled to create a broad parametric study that includes the major parameters that can be changed in design to effect transmission loss. The paper offers a single source to use for predicting the frequencies in which the slope of the transmission loss curve for double walls will change, and also provides guidance as to what those slopes will be. Included in these guidelines are the effect of point or line connections within the double wall structure vs uncoupled (no studs) double walls, the effects of rigid (wood) or flexible (steel) studs within the structure, and the effects of absorptive materials within the cavity. It is concluded that the air gap and the insulation material are more critical in uncoupled double walls, and that the valley near the critical frequency is independent of gap spacing.

Recently, Xin and Lu [13] investigated the implications of boundary conditions (clamped vs simply supported) on double wall transmission loss. The experiments were conducted using relatively small aluminum panels ( $0.3 \mathrm{~m} \mathrm{x} 0.3 \mathrm{~m}$ square structure) without the use of supporting material (studs) in the interior of the double wall. The typical 3,3 mode shape of square plates, with both simply supported and clamped boundary conditions were presented and discussed. The 3,3 mode shape frequency corresponded well to valleys in the experimental narrow band transmission loss plot 
offered, with the narrow band valleys occurring within approximately $50 \mathrm{~Hz}$ of the theoretical 3,3 mode shape. Conclusions show that theoretically, the transmission loss of double walls will be equal for both mounting conditions if the wall is infinitely large. For the finite sized plate studied, the clamped boundary condition yields higher resonant frequencies when compared to simply supported boundaries.

Nilsson and Kihlman [17] lists six factors that can influence transmission loss differences between laboratories. The work is further extended in reference [12], which examined the differences in transmission loss due to boundary condition, apertures, and baffles. Data from experiments conducted at 5 different laboratories is examined and it is concluded that the transmission loss of common specimen can differ greatly due to different laboratory conditions. However, after review of the plots, it is evident that the trends (slopes and frequencies of slope change) exhibited at each laboratory show agreement. 


\section{DESIGN OF EXPERIMENT}

\section{A. Design Considerations}

The material choice was made due to the vast use of sheet steel in many industries including automotive, agricultural and HVAC ducting. The following readily available,

commonly used sheet steel gages where used: $0.6 \mathrm{~mm}$ ( $24 \mathrm{ga}-0.024 \mathrm{in})$ and $1.2 \mathrm{~mm}$ (18 ga -0.048 in). Choosing plates that vary in thickness by approximately double will yield an appreciable difference in transmission loss between the two plates, with theory predicting approximately $6 \mathrm{~dB}$ increase in transmission loss [1]. This allows for the dependence of mass per unit area to be more easily observed than using two plates whose thicknesses do not vary drastically.

Due to the space constraints in many applications of sheet steel (automotive, aerospace, etc.) it was decided to use air gaps smaller than $4 \mathrm{~mm}$. The overall width and height of the double wall specimen used for these experiments was chosen based on the ease of installation in the laboratory used. The filler wall used in the laboratory already contained an aperture measuring $406 \mathrm{~mm}$ by $1067 \mathrm{~mm}$. For this reason the overall size of the specimen (including the frame used for attaching the plates) will be this size.

Although difficult (if not impossible) to achieve, clamped edge conditions were chosen for this study due to the ease of maintaining consistently between individual experiments. Additionally the fixture needed to achieve simply supported boundary conditions was more complicated than the fixture for creating a clamped boundary [13]. 
The frame was constructed out of sheet steel of considerably more thickness than the transmission loss specimen to ensure high stiffness. To create the air gap, either one or two frames were placed between the two plates. The readily available thickness for the frame sheet steel was $1.9 \mathrm{~mm}$ (14 ga - $0.075 \mathrm{in})$, allowing for an air gap of $1.9 \mathrm{~mm}$ and $3.8 \mathrm{~mm}$.

Figure 2 and Figure 3 show the constructions, utilizing the aforementioned designs.
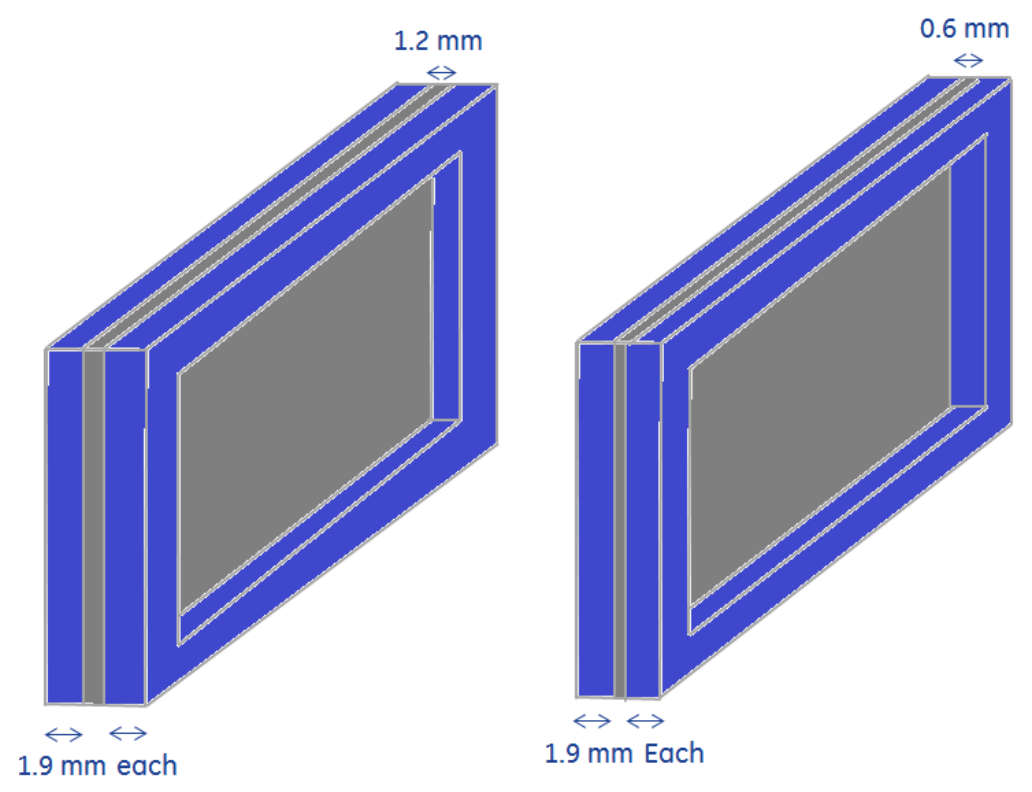

Figure 2. Single plate configurations (specimen in gray and frame in blue). 

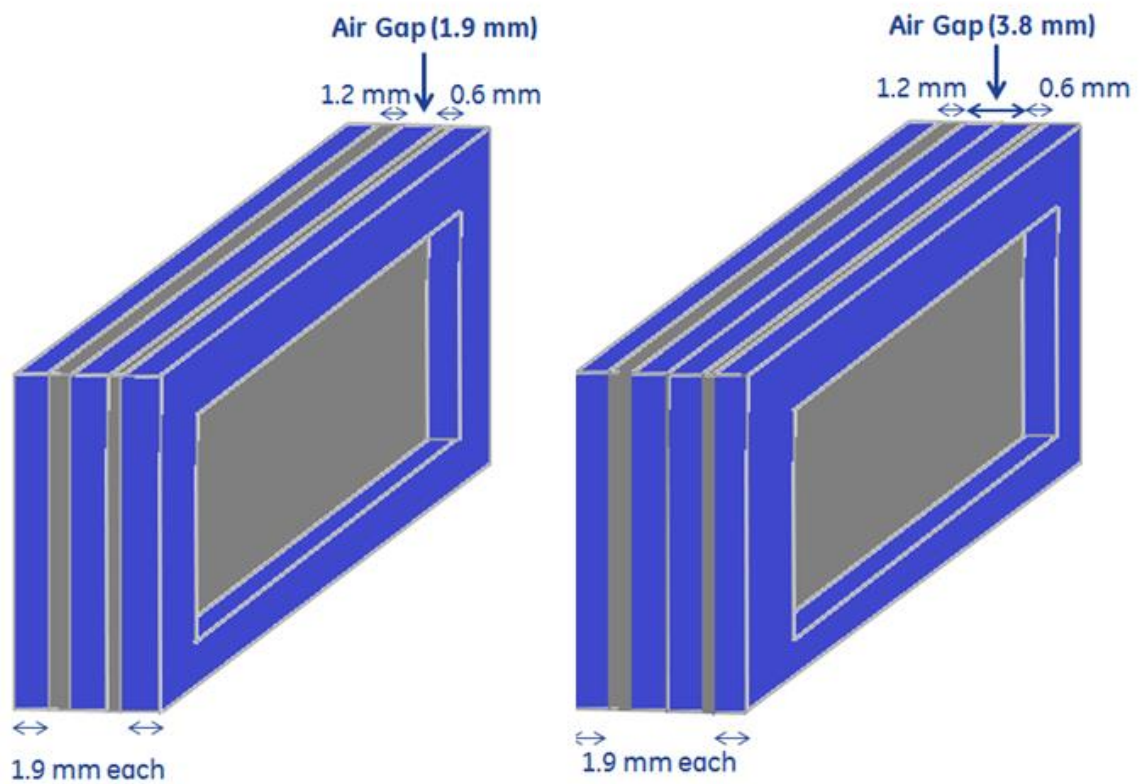

Figure 3. Double wall configurations (specimen in gray, frame in blue).

To create clamped boundary conditions, a bolt pattern around the perimeter of the specimen was used to hold the constructions together. Bolts were placed through holes on the receiving side of the frame, traversing through the frame and test specimen, while nuts were tightened on the source side of the frame. Bolts were chosen, rather than welding or riveting, due to the availability, ease of assembly, and convenience of reusing the frame for each configuration. 


\section{B. Construction of Experiment}

After the experiment was designed, the first step in construction was to order sheet steel of the appropriate thickness $(0.6 \mathrm{~mm}$ and $1.2 \mathrm{~mm}$ for the test specimen and 1.9 $\mathrm{mm}$ for the frame) and to buy all of the hardware. For the test specimen, the overall geometry (406 mm x $1067 \mathrm{~mm}$ ) and the bolt pattern consisting of 5 bolts along the 406 mm sides and 10 bolts along the $1067 \mathrm{~mm}$ sides was modeled in SoildWorks $®$ and cut from oversized sheet steel using a Flow Mach $2^{\mathrm{TM}}$ water jet. The same method was used to create the frame components for the assembly, creating the same overall geometry and hole pattern, while removing a $305 \mathrm{~mm}$ by $965 \mathrm{~mm}$ rectangle from the center of the frame blanks. The drawings used to make the specimen and the frames using the water jet are available in APPENDIX E.

Next, the filler wall mount was attached to the filler wall using hex head fasteners. The fit of the filler wall mount was relatively tight, but extra care was taken to reduce flanking paths. First, isolation rubber mats were cut to fill he small gaps around the perimeter of the mount, between the mount and the filler wall. Next, on the source room side of the filler wall the joint between the mount and the filler wall (which had isolation rubber in between) was sealed using Parker Virginia Sealing Gum ${ }^{\text {TM }}$ (also known as permagum).

Next, the frames and specimen were bolted together to create the test configurations. As seen in Figure 4 below, the filler wall has four mounting points (circled in red), two on the right and two on the left of the aperture. 


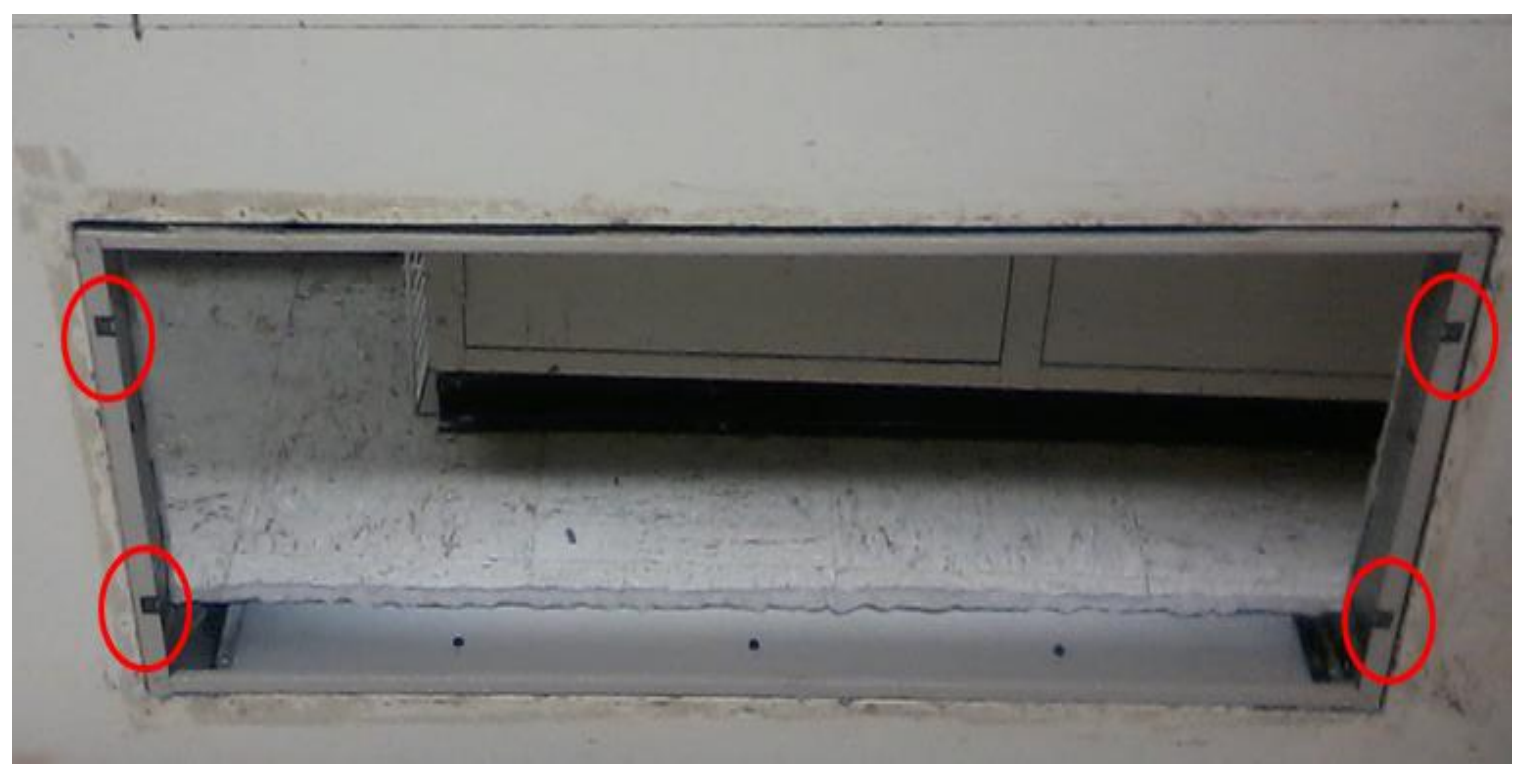

Figure 4. Mounting locations on the filler wall.

The test configuration was mounted using nuts and bolts through these four

mounting points. To reduce flanking paths for sound, similar measures of sealing were taken on the receiving room side of the fixture. Figure 5 and Figure 6 show the filler wall from the source room and the receiving room, displaying the permagum used to ensure minimal flanking sound. 


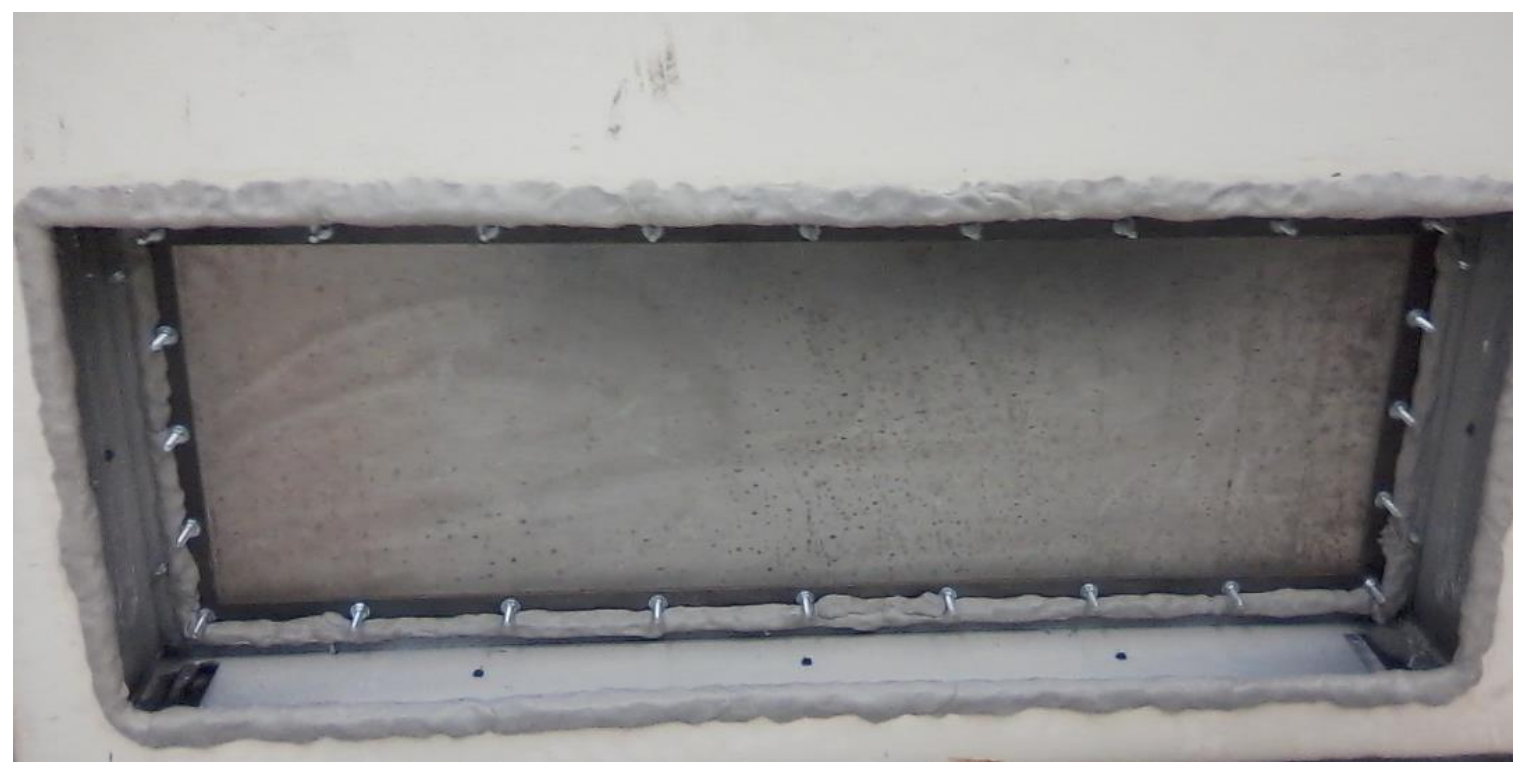

Figure 5. View of the filler wall from the source room.

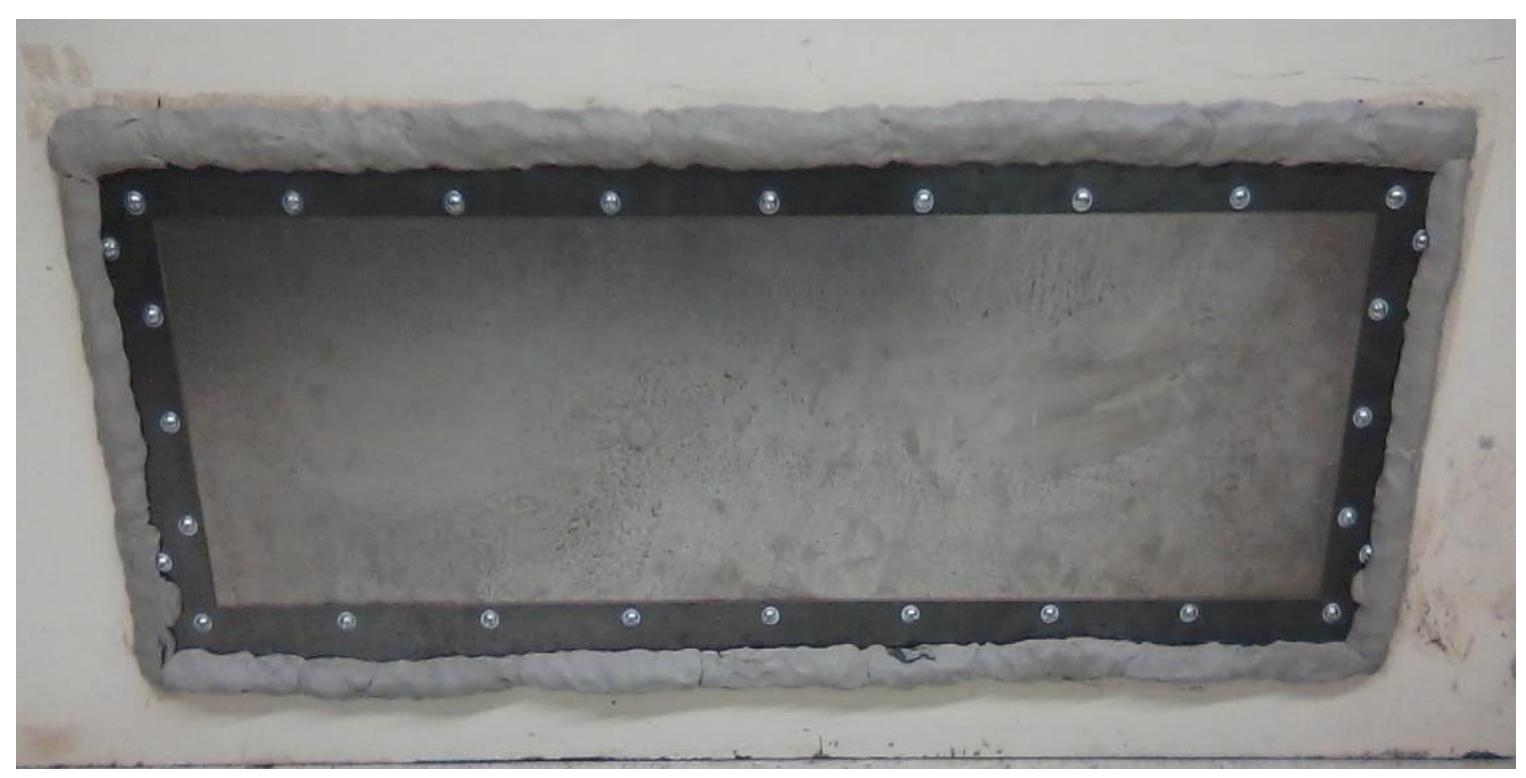

Figure 6. View of the filler wall from the receiving room.

It is important to note that the same test setup, mounting, and sealing treatments were used in both the modal analysis experiments and the transmission loss experiments. Therefore the correlations between the two sets of experiments can be observed without speculation of mounting or boundary condition differences. 


\section{Instrumentation and Procedure}

\section{Modal Analysis}

Modal analysis was completed on four wall configurations; two single panel constructions of varying thickness and two double panel constructions of varying gap thickness. To ensure that the modal analysis was conducted under the same boundary condition as the specimen would experience during sound transmission loss (TL) testing, the specimen was mounted to the same resilient test fixture (filler wall) for all modal and TL testing. The modal analysis was completed using LMS Test Lab 11 and accompanying accelerometer and impact hammer. To begin, the specimen width and height must be discretized to develop a grid in which the mode shapes will be fit to. For these experiments, each specimen is discretized to contain a grid of 7 divisions horizontally and 3 divisions vertically. Figure 7 shows the set-up of the grid, accelerometer, and impact locations. 


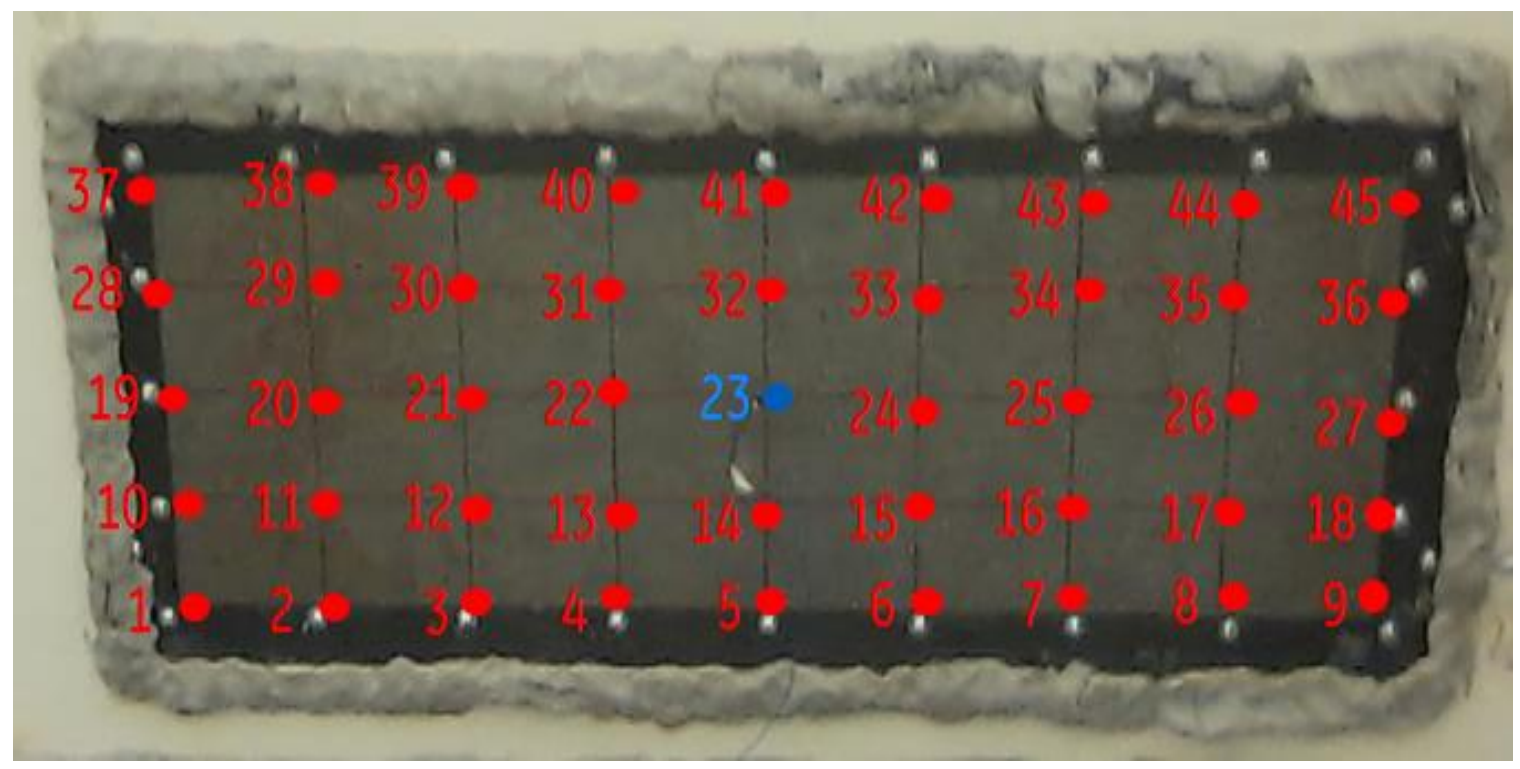

Figure 7. Discretization of the specimen, accelerometer location (blue), impact locations (red), and associated point labels.

There are two common approaches to conducting modal analysis with regards to accelerometer and impact hammer usage. In this experiment it was decided to use the roving hammer method, keeping the accelerometer placed in the center of the receiving room side of the plate (location 23) while impacting the plate in all locations on the receiving room side of the plate. The alternative would be to impact the same point on the specimen while roving the accelerometer. This would theoretically yield the same results, but would require more time as the accelerometer would have to be re-adhered to the plate 45 times for the single plate configuration, and 90 times for the double plate configuration. In instances of double plate configurations, the accelerometer was placed on the receiving side of the receiving plate and the hammer was used to impact the receiving plate on the receiving side and impact the source plate on the source side. 


\section{Noise Reduction}

Due to laboratory constraints, the standardized method used to conduct transmission loss testing in which a specimen is placed between two reverberation rooms (Figure 1) could not be completed. The laboratory that was readily available (Figure 8) included a reverberant room next to a hemi-anechoic room, with a removable filler wall that can be used to create an opening between the two rooms.

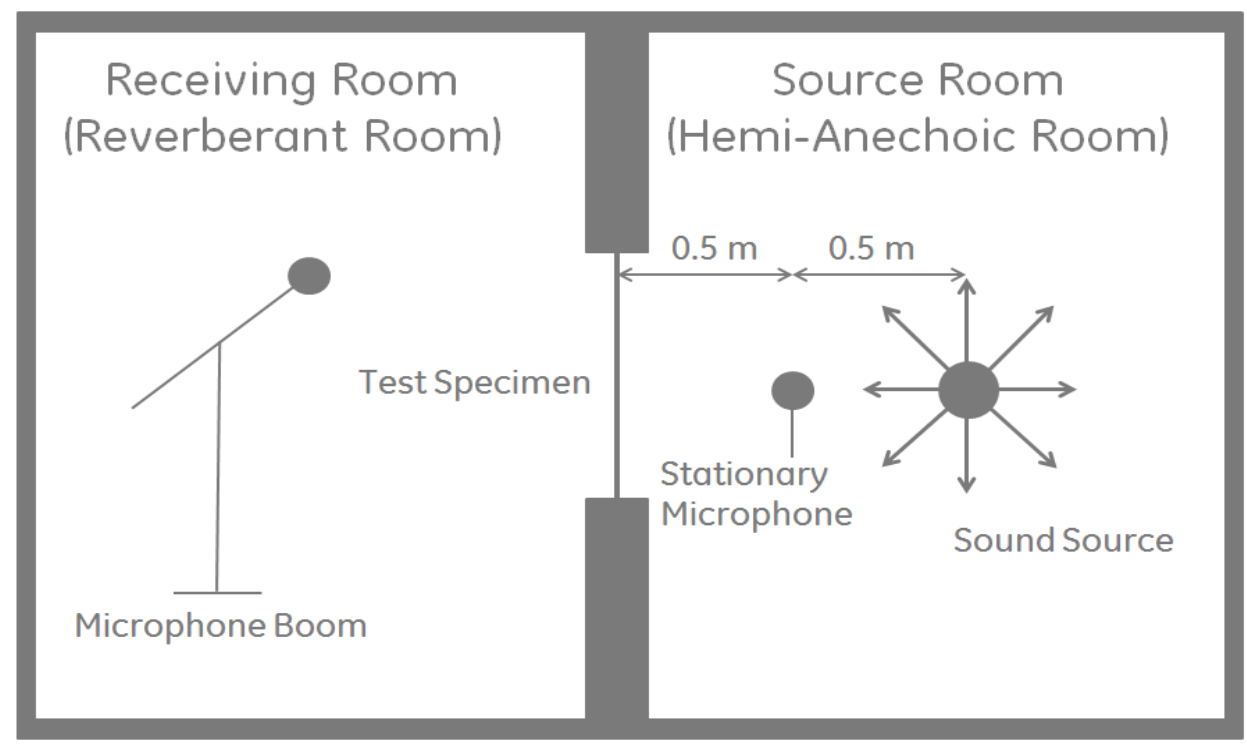

Figure 8. Top view of configurations for noise reduction testing.

The differences in test setup and available equipment require the redefinition of the sound transmission loss across the specimen. Transmission loss compares the difference in sound power in the two rooms, as shown in the background section. Since the testing conducted in this thesis resulted in sound pressure data in the source (hemi anechoic) and sound pressure data in the receiving room (reverberation), the terminology 
used to describe the difference in sound pressure across the test specimen is Noise Reduction (NR). It is given by

$$
N R=S P L_{S}-S P L_{R}
$$

where $\mathrm{SPL}_{S}$ is the sound pressure level $(\mathrm{dB})$ in the source room and $\mathrm{SPL}_{R}$ is the sound pressure level $(\mathrm{dB})$ in the receiving room. Sound pressure is converted to sound pressure level using the relationship

$$
S P L=10 \log _{10} \frac{p_{r m s}^{2}}{p_{\text {ref }}^{2}}
$$

where $\mathrm{p}_{\mathrm{rms}}$ is the sound pressure $(\mathrm{Pa})$ measured by the microphone and $\mathrm{p}_{\mathrm{ref}}$ is the reference pressure $(20 \mu \mathrm{Pa})$.

Note that noise reduction is not equal to transmission loss, but is directly related if the two rooms (receiving and source) are both reverberant. In the case of two reverberant rooms the transmission loss can be written as

$$
T L=N R+\log _{10} \frac{S_{w}}{S_{R} \alpha_{R}}
$$

where $S_{w}$ is the surface area of the specimen, $S_{R}$ is the area of all surfaces in the receiving room, and $\alpha_{R}$ is the room average absorption for the receiving room [18]. Since the specimen surface area is significantly smaller than the surface area of the receiving room and the average absorption of reverberant rooms is a positive value, the resulting value within the logarithm is between 0 and 1 . Therefore, it is expected that the value of TL will be less than that of NR. Since the difference between TL and NR is based on a 
constant, it is acceptable to compare the slopes and peak/valley frequencies in TL theory with NR experimental results while disregarding the amplitude shift between TL and NR.

Sound pressure is measured in the reverberant room using a microphone on a rotating boom, while the sound pressure is measured in the hemi-anechoic room using a directional microphone mounted directly between the source and the specimen $(0.5 \mathrm{~m}$ from the source, $0.5 \mathrm{~m}$ from the source plate). The source microphone is mounted such that it is facing the source, in a position that is centered on the specimen. The source is a loudspeaker (B\&K 4205) that produces a broadband sound (white noise) at approximately $100 \mathrm{~dB}$, and is placed one meter from the specimen. The filler wall is approximately 4 inches thick, and the specimen is mounted such that the frame is flush with the wall in the receiving room (same mounting as described in the modal analysis section). Figure 9, Figure 10 and Figure 11 show views of the specimen mounted in the filler wall (receiving and source room views) and a view of the sound source and source microphone. Each of the 4 configurations are tested using this test setup. 


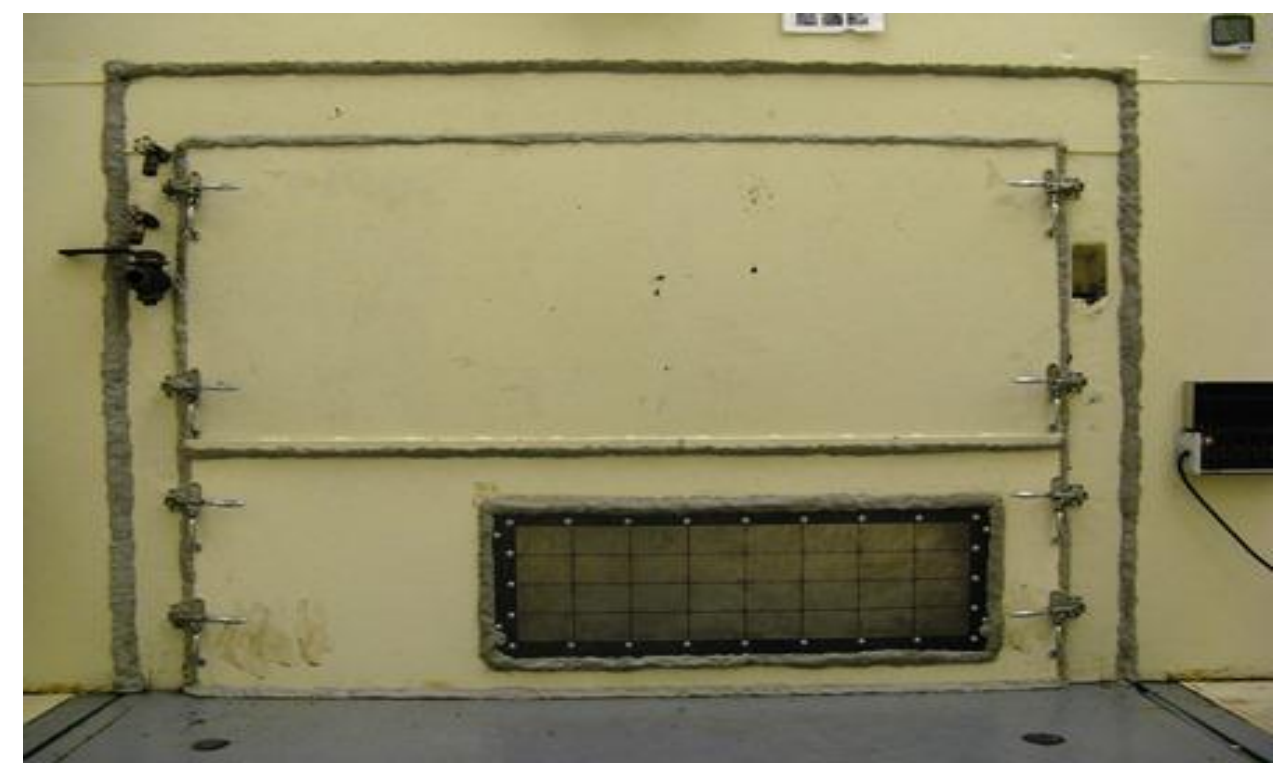

Figure 9. View of NR setup from receiving room.

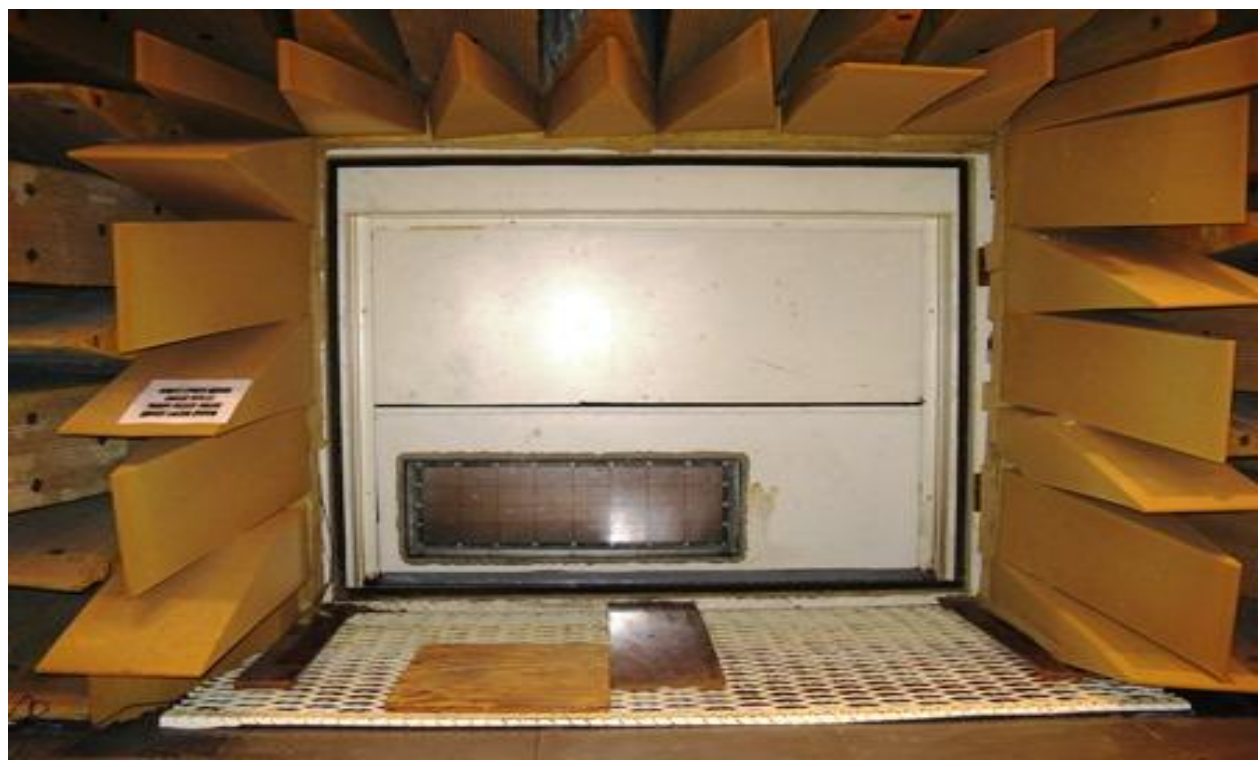

Figure 10. View of NR setup from the source room. 


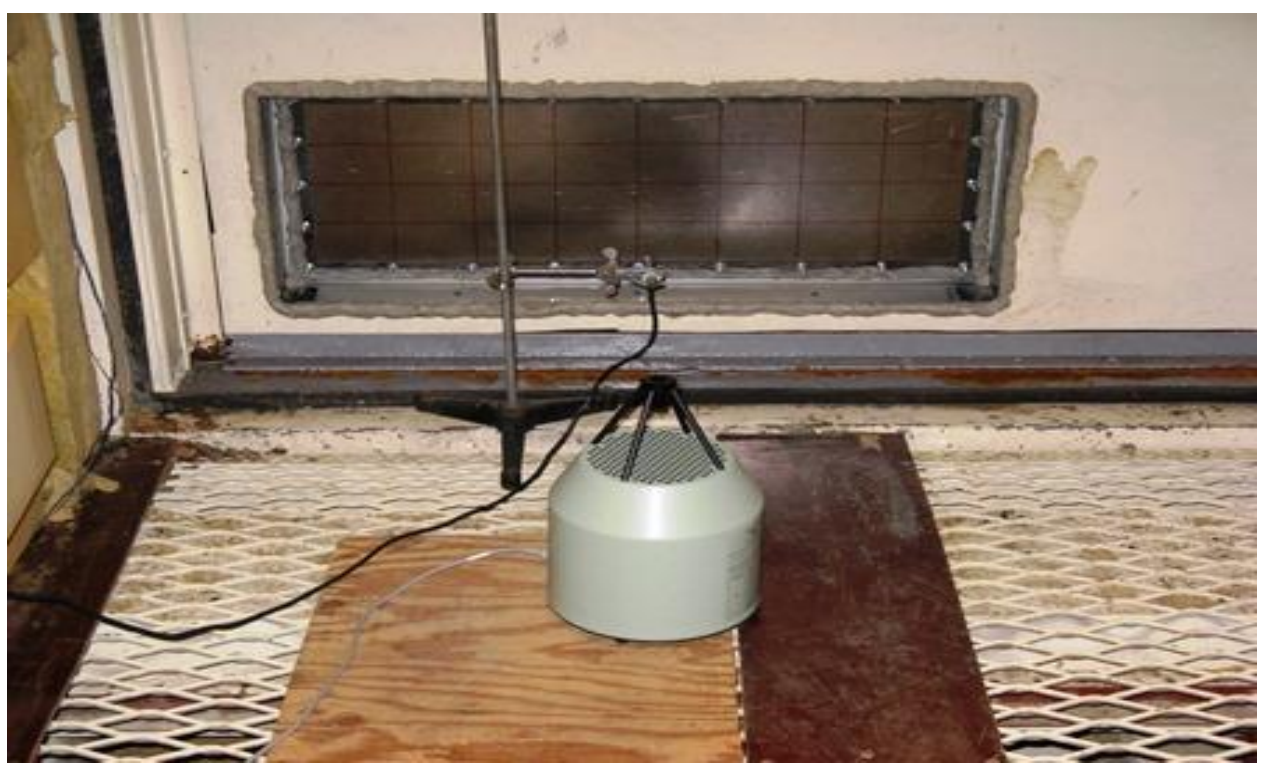

Figure 11. View of NR setup - sound source and source room microphone. 


\title{
IV. TRANSMISSION LOSS THEORY AND EXPERIMENTAL RESULTS
}

\author{
A. Single Wall Transmission Loss Theory \\ The theoretical transmission loss in these experiments is developed using some \\ assumptions that are necessary to simplify the theory [2]. The plates are assumed to be \\ uniform, unbounded, non-flexible and are mounted on a viscously damped suspension. \\ Additionally, the assumption is made that there are no flanking paths for sound to travel \\ around the specimen from the source room to the receiving room. The theoretical \\ transmission loss plot for single wall constructions is shown in Figure 12.
}




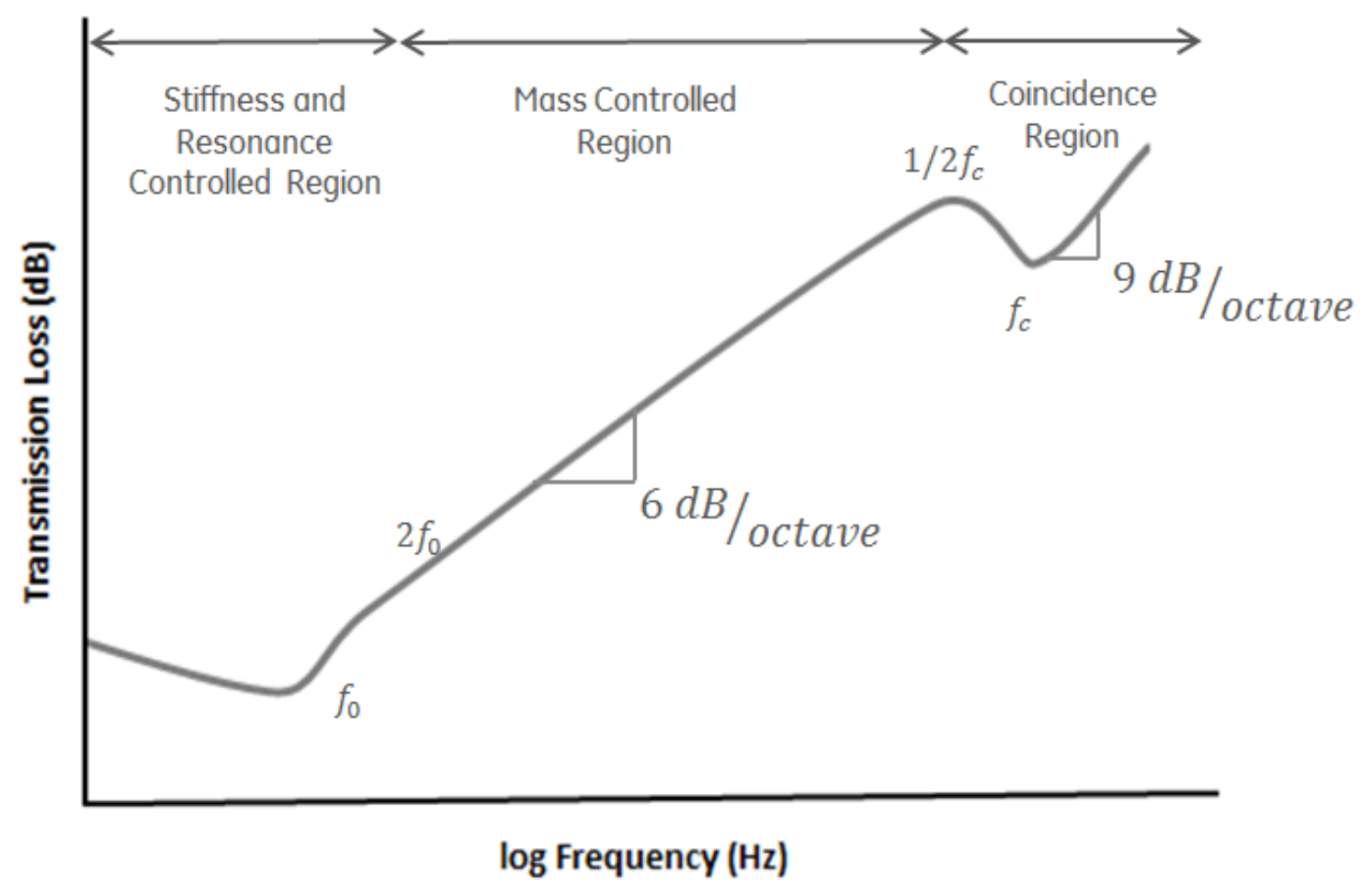

Figure 12. Theoretical transmission loss plot for single plate constructions.

The theoretical transmission loss curve of a flat plate has four main sections. The first section is called the stiffness controlled section. The stiffness controlled region is located at frequencies below that of the first resonant frequency $\left(f_{0}\right)$ of the panel. Two methods are used to determine the theoretical natural frequencies of the individual clamped specimen. The first method utilizes a table from a reference handbook [19] in which the natural frequencies of rectangular plates of various edge conditions are solved for using the Ritz method, and the second method utilized finite element modeling (FEM) carried out using ANSYS $®$ Workbench ${ }^{\mathrm{TM}}$. The relevant section of the table from reference [19] is shown below for reference. 


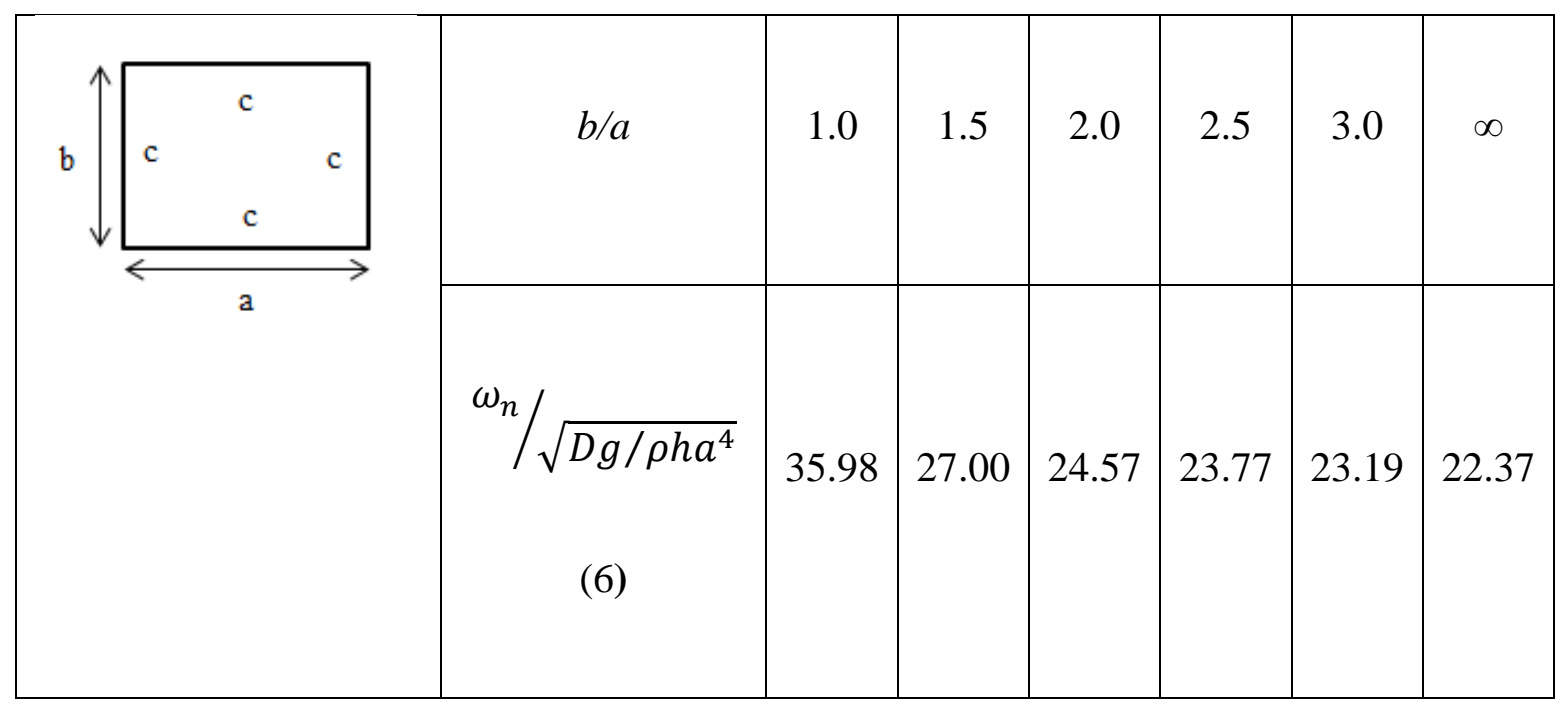

Table 1. Excerpt from shock and vibration handbook [19].

where $\omega_{\mathrm{n}}$ is the natural frequency $(\mathrm{rad} / \mathrm{sec}), g$ is the acceleration due to gravity $\left(\mathrm{m} / \mathrm{s}^{2}\right), \rho$ is the density $\left(\mathrm{N} / \mathrm{m}^{3}\right), h$ is the thickness of the plate (m), $a$ is the height of the plate (m) and $D$ is the flexural rigidity given by

$$
D=\frac{E h^{3}}{12\left(1-v^{2}\right)}
$$

where $E$ is Young's modulus ( $\mathrm{Pa}), h$ is the thickness of the plate (m), and $v$ is Poisson's ratio (approximated as 0.29). The values of the variables in Equations 6 and 7 are available in APPENDIX F.

With the specimen dimensions measuring $305 \mathrm{~mm}$ x $965 \mathrm{~mm}$, the aspect ratio of 965/305 (3.167) is outside the range of the reference table. For this reason, the calculation for natural frequency will be completed for both an aspect ratio of 3 and for an infinite aspect ratio. The results of these calculations, shown in Table 2, show that the 
use of an aspect ratio of 3 (rather than infinity) yields better correlation to the natural frequencies determined by finite element analysis (FEA).

\begin{tabular}{|c|c|c|}
\hline Method & $\begin{array}{c}\text { Specimen Thickness } \\
(\mathrm{mm})\end{array}$ & $\begin{array}{c}\text { First Natural Frequency } \\
(\mathrm{Hz})\end{array}$ \\
\hline Equation (6) (Aspect Ratio of 3) & $1.2 \mathrm{~mm}$ & 73.4 \\
\hline Equations (6) (Aspect Ratio of $\infty)$ & $1.2 \mathrm{~mm}$ & 73.3 \\
\hline FEM & $1.2 \mathrm{~mm}$ & 37.0 \\
\hline Equation (6) (Aspect Ratio of 3) & $0.6 \mathrm{~mm}$ & 35.7 \\
\hline Equation (6) (Aspect Ratio of $\infty$ ) & $0.6 \mathrm{~mm}$ & 36.8 \\
\hline FEM & $0.6 \mathrm{~mm}$ & \\
\hline
\end{tabular}

Table 2. Theoretical and numerical results for the first natural frequency of the rectangular plates.

Since $f_{0}$ for these plates are below $100 \mathrm{~Hz}$, outside the range of typical transmission loss ratings, there will be no further mention in this section regarding the theoretical transmission loss in the stiffness control region.

The second section of the theoretical transmission loss curve of a flat plate is called the resonance controlled section. This section begins at the first resonance frequency and continues until approximately two times the first resonance frequency. A 
survey of the literature shows that it is common for this section of the transmission loss curve to be relatively flat, experiencing little or no increase in transmission loss as frequency increases. Since this section is primarily below $100 \mathrm{~Hz}$ for the given specimen in these experiments, no further discussion of this section is offered here.

The third section of the transmission loss curve is called the mass controlled region. This region begins at a frequency slightly above $2 f_{0}$ and continues until half the critical frequency. The critical frequency $\left(f_{\mathrm{c}}\right)$, which occurs when the speed of the bending wave propagation is equal to the speed of the acoustic wave in the air, can be calculated using

$$
f_{c}=\frac{c^{2}}{2 \pi} \sqrt{\frac{m}{D}}
$$

where $c$ is the speed of sound $(\mathrm{m} / \mathrm{s}), m$ is the mass per unit area of the panel $\left(\mathrm{kg} / \mathrm{m}^{2}\right)$, and $D$ is the flexural rigidity $\left(\mathrm{kg}^{*} \mathrm{~m}^{2} / \mathrm{s}^{2}\right)$ [3]. The flexural rigidity is given by Equation (7). Using Equations (7) and (8), the critical frequency for the $1.2 \mathrm{~mm}$ and $0.6 \mathrm{~mm}$ thick plates are calculated as $19967 \mathrm{~Hz}$ and $10066 \mathrm{~Hz}$ respectively.

The theoretical transmission loss curve in the region roughly between $2 f_{0}$ and $1 / 2 f_{\mathrm{c}}$ follows mass law. There are multiple equations available to approximate mass law (varying based on the angle of incidence of the incident sound). Due to the laboratory setup during the transmission loss experiments in this study, the normal incidence mass law is used to predict the transmission loss in this region. The normal incidence mass law equation is 


$$
T L=20 \log _{10}(f m)-42 d B
$$

where $f$ is the frequency of the sound $(\mathrm{Hz})$ and $m$ is the mass per unit area of the flat plate $\left(\mathrm{kg} / \mathrm{m}^{2}\right)[1]$. This equation suggests that the slope of the transmission loss curve in the mass controlled region will be approximately $6 \mathrm{~dB}$ per octave, and that the transmission loss is directly correlated to the mass per unit area of the plate.

The fourth region of the transmission loss curve is called the coincidence controlled region. This region begins at approximately $1 / 2 f_{\mathrm{c}}$ and is characterized by a sharp decrease in transmission loss that reaches a minimum at the critical frequency. The section of the transmission loss curve above the critical frequency generally follows an increasing slope of $9 \mathrm{~dB}$ per octave [3]. Since the critical frequencies for the two plates used in these experiments are above the frequency range used for standard sound transmission ratings, there will be no further discussion regarding the region above the critical frequency in this thesis.

\section{B: Double Wall Transmission Loss Theory}

The theoretical transmission loss of a double plate wall with an air gap is more complicated than that of single plates. The same assumptions used for single plate transmission loss (uniform, unbounded, non-flexible) are used to simplify the theory. Also, the fluid in the cavity (air) is assumed to be bounded within the double wall structure such that it cannot leak out due to compression when the walls vibrate. The theoretical transmission loss plot for double wall structures is shown in Figure 13. 


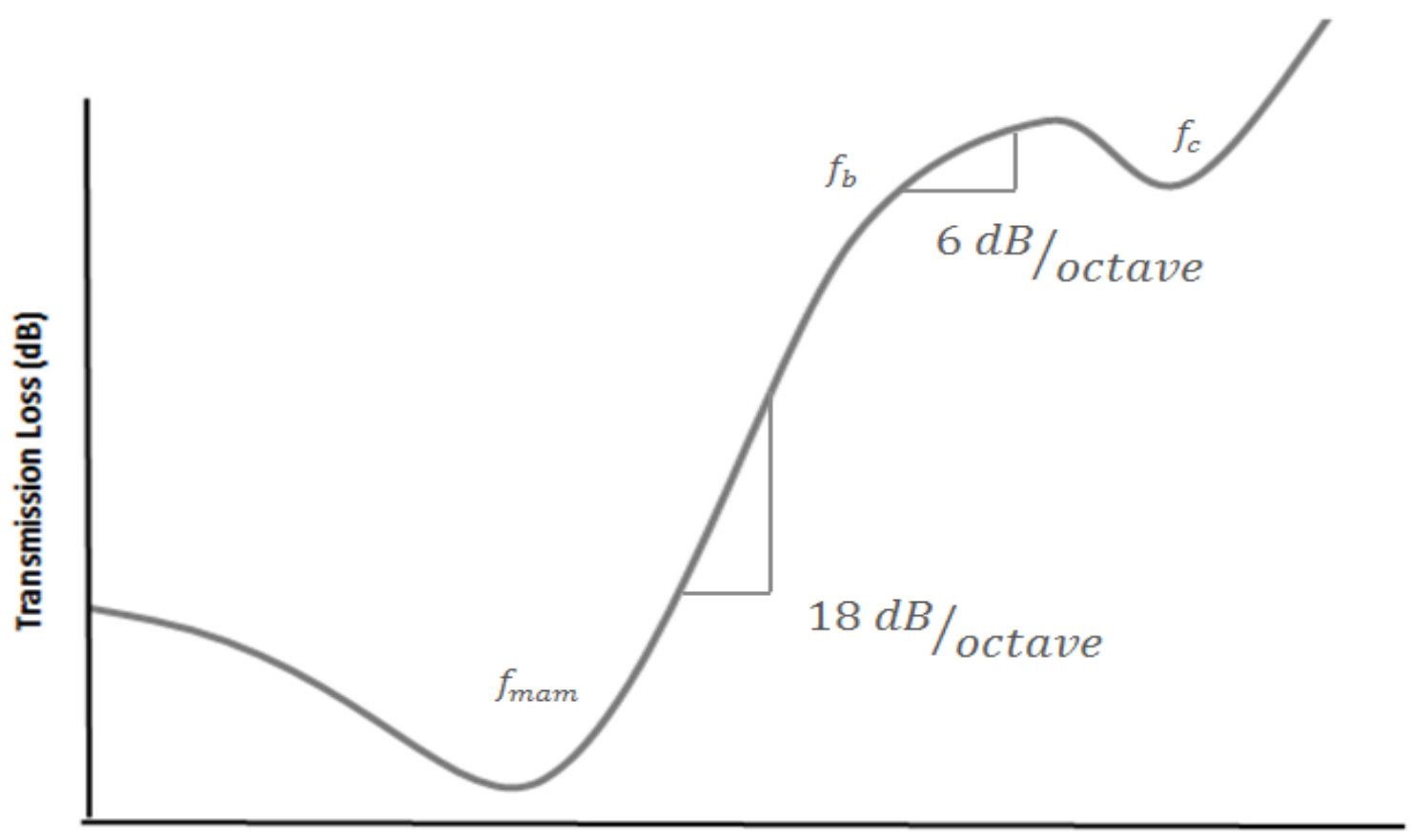

$\log$ Frequency $(\mathrm{Hz})$

Figure 13. Theoretical transmission loss plot for double plate configurations.

The theoretical transmission loss curve for double walls is characterized by four characteristics. The first is a frequency range below the mass-air-mass resonance frequency $\left(f_{\text {mam }}\right)$. In this range, the transmission loss performance follows a similar curve to that of a single plate of mass equal to that of sum of the mass of the two plates. The second characteristic of the theoretical transmission loss curve is the mass-air-mass resonant frequency. At this frequency the transmission loss is reduced due to the coupling of the two plates by the stiffness of the air gap. To derive the frequency at which this occurs, an analogous mass spring system is used, shown in Figure 14 [1]. 


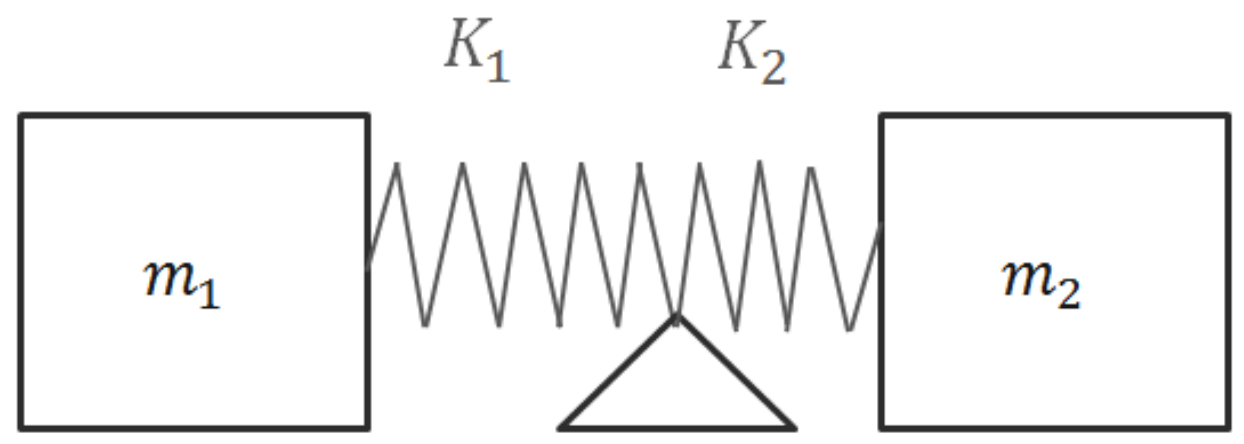

Figure 14. Mass spring system analogous to double wall mass-air-mass resonance.

The mass-air-mass resonant frequency occurs when the two plates have equal resonant frequencies, shown in Equation (10).

$$
f_{m a m}=\frac{\sqrt{K_{1} / m_{1}}}{2 \pi}=\frac{\sqrt{K_{2} / m_{2}}}{2 \pi}
$$

where the spring rates per unit area $\mathrm{K}_{1}$ and $\mathrm{K}_{2}(\mathrm{~N} / \mathrm{m}) / \mathrm{m}^{2}$ are in series between the two plates and $\mathrm{m}_{1}$ and $\mathrm{m}_{2}$ are the mass per unit area of the two plates. The spring rates per unit area are related by

$$
\frac{1}{K}=\frac{1}{K_{1}}+\frac{1}{K_{2}}
$$

Solving for $\mathrm{K}_{1}$ in Equation (11) and substituting into Equation (10) yields 


$$
f_{\text {mam }}=\frac{\sqrt{(K) \frac{\left(m_{1}+m_{2}\right)}{\left(m_{1} m_{2}\right)}}}{2 \pi}
$$

where $\mathrm{K}$ is spring rate of the air gap, given by

$$
K=\frac{\rho_{o} c^{2}}{d}
$$

where $\rho_{0}$ is the density of air, $c$ is the speed of sound in air $(343 \mathrm{~m} / \mathrm{s})$, d is the gap width (m) [2]. The theoretical mass-air-mass resonance frequency for the two experiment configurations in this thesis are offered in Table 3.

\begin{tabular}{|c|c|c|c|}
\hline $\begin{array}{c}\text { Mass per unit area } \\
\text { of Receiving Plate } \\
\left(\mathrm{kg} / \mathrm{m}^{2}\right)\end{array}$ & $\begin{array}{c}\text { Mass per unit area } \\
\text { of Source Plate } \\
\left(\mathrm{kg} / \mathrm{m}^{2}\right)\end{array}$ & $\begin{array}{c}\text { Air Gap Distance } \\
(\mathrm{mm})\end{array}$ & $\begin{array}{c}\text { Mass-Air-Mass } \\
\text { Resonant Frequency }\end{array}$ \\
\hline 4.70 & 9.32 & 1.9 & $775.7 \mathrm{~Hz}$ \\
\hline 4.70 & 9.32 & 3.8 & $548.5 \mathrm{~Hz}$ \\
\hline
\end{tabular}

Table 3. Mass-air-mass resonant frequencies of experimental configurations.

The third characteristic of the transmission loss curve displays increasing transmission loss from the mass-air-mass resonance valley until half of the higher critical frequency of the individual plates [3]. The increase in this section is divided into two sections of differing slopes. They are approximated as $18 \mathrm{~dB}$ per octave for an uncoupled wall at the lower frequencies within the section and $6 \mathrm{~dB}$ per octave in higher frequencies within the section. The frequency at which the transition from 18 to $6 \mathrm{~dB}$ per octave 
occurs is called the bridge frequency [4]. The bridge frequency calculation varies depending on the construction of the wall, with there being four commonly available equations for common construction types. These include equations for walls containing rigid point connections, rigid line connections, flexible point connections and flexible line connections. For this research where studs were not used, the calculation is completed for rigid point connections due to the lack of studs. The equation is given as

$$
f_{b}=f_{\operatorname{mam}}\left(\frac{\pi^{3} S}{8 \lambda_{c}^{2} n}\left(\frac{m_{1}}{m_{1}+m_{2}}\right)^{2}\right)^{1 / 4}
$$

where $S$ is the plate area $\left(0.294 \mathrm{~m}^{2}\right), \lambda c$ is the wavelength at the critical frequency, and $\mathrm{n}$ is the number of point connections [4]. After completing the calculation for a critical frequency of $19967 \mathrm{~Hz}$ and for 28 point connections, the estimated bridge frequency should be at approximately $1533 \mathrm{~Hz}$ for the $1.9 \mathrm{~mm}$ gap and $2168 \mathrm{~Hz}$ for the $3.8 \mathrm{~mm}$ gap.

The final characteristic of the theoretical transmission loss curve is the second valley that occurs at the highest critical frequency, $f_{c}$, for the two plates in the assembly [2]. At this frequency the transmission loss amplitude is approximately that of a single plate with mass equal to that of the sum of the two plates. 


\section{Single Wall Experimental Noise Reduction}

Measured third octave band NR curves for the two single plates are shown in Figure 15 along with the curves predicted by theory (Equation (9))

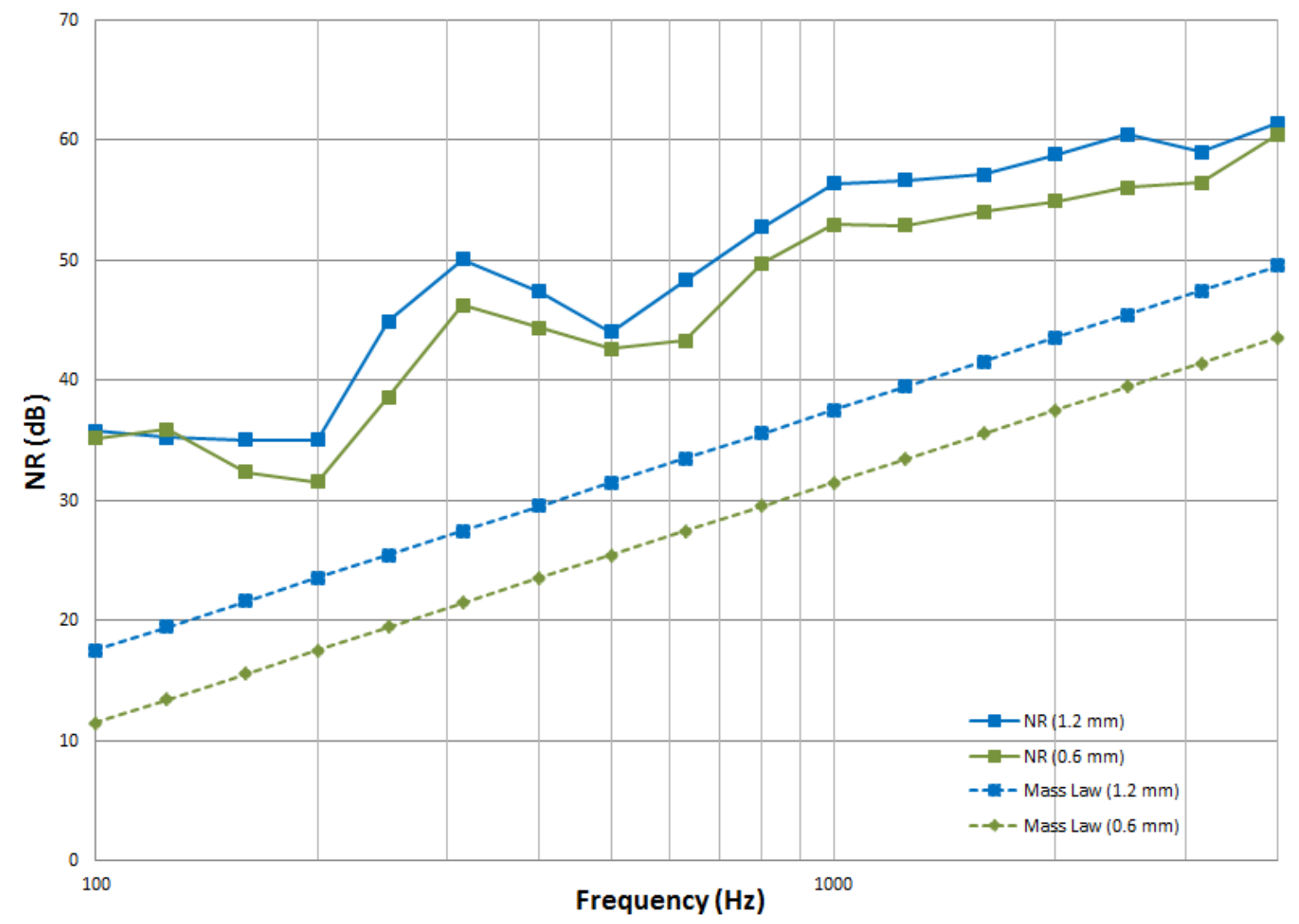

Figure 15. Measured NR and predicted TL for the two single plates.

From Figure 15, several observations can be made. First, the theoretical normal incidence mass law TL curves are less than the measured NR curves for both plate thicknesses. Due to the difference between TL and NR, which is discussed in the Design of Experiment section where TL and NR are correlated using Equation (5), this is expected. Second, the slope of the NR curve for each configuration generally matches the slope of the normal mass law TL curve (approximately $6 \mathrm{~dB}$ per octave). Third, the 
higher NR for the plate with higher mass per unit area is consistent with that predicted by theory. In addition, the normal incidence mass law TL theory predicts that doubling the mass per unit area (in this case doubling the thickness) should result in approximately a 6 $\mathrm{dB}$ increase in TL. However, results from this study show that the increase in NR is closer to $3 \mathrm{~dB}$ with the doubling of the thickness of these steel plates. This agrees with reference [5], which shows a TL increase of approximately 3-4 dB after doubling the thickness of glass.

Next, observe that the first section of the measured NR curve for both plate thicknesses is relatively constant (below $200 \mathrm{~Hz}$ ), rather than following the $6 \mathrm{~dB} / \mathrm{octave}$ slope predicted from the TL mass law theory. The constant NR curve in the low frequency region is similar to that found in references [5-6] and has been attributed to the difficulty in eliminating flanking paths for low frequency sound.

As presented earlier, the first natural frequencies are approximately $35 \mathrm{~Hz}$ for the $0.6 \mathrm{~mm}$ plate and $75 \mathrm{~Hz}$ for the $1.2 \mathrm{~mm}$ plate. Additionally, the critical frequencies, $f_{\mathrm{c}}$, for the two plates are approximately $7 \mathrm{kHz}$ and $10 \mathrm{kHz}$ for the $0.6 \mathrm{~mm}$ and $1.2 \mathrm{~mm}$ plates respectively. According to TL theory for single plate walls, it is expected that the NR curve between two times the first natural frequency and below the critical frequency would follow mass law. However, experimental results shown in Figure 15 reveal an uncharacteristic peak in NR for both single plate configurations in the $315 \mathrm{~Hz}$ third octave band. Investigation of this unexpected behavior is presented later in section E. 


\section{D: Double Wall Experimental Noise Reduction}

As explained previously, double wall configurations are typically characterized by four sections. The first section (located below mass-air-mass resonance) typically displays behavior much like that of a single plate of mass equal to the mass of the two plates combined. When the combined mass per unit area of the two plates are accounted for in the normal incidence mass law equation (Equation (9))), the result is approximately $3.5 \mathrm{~dB}$ higher in transmission loss when compared to the result of the equation when the $1.2 \mathrm{~mm}$ plate is considered alone. This behavior is confirmed in these results (Figure 16), as the two double plate configurations displayed approximately 3-4 $\mathrm{dB}$ increase in NR when compared to the single plate configurations between 100 and $200 \mathrm{~Hz}$. This compares favorably to the results outlined by in the literature [6]. 


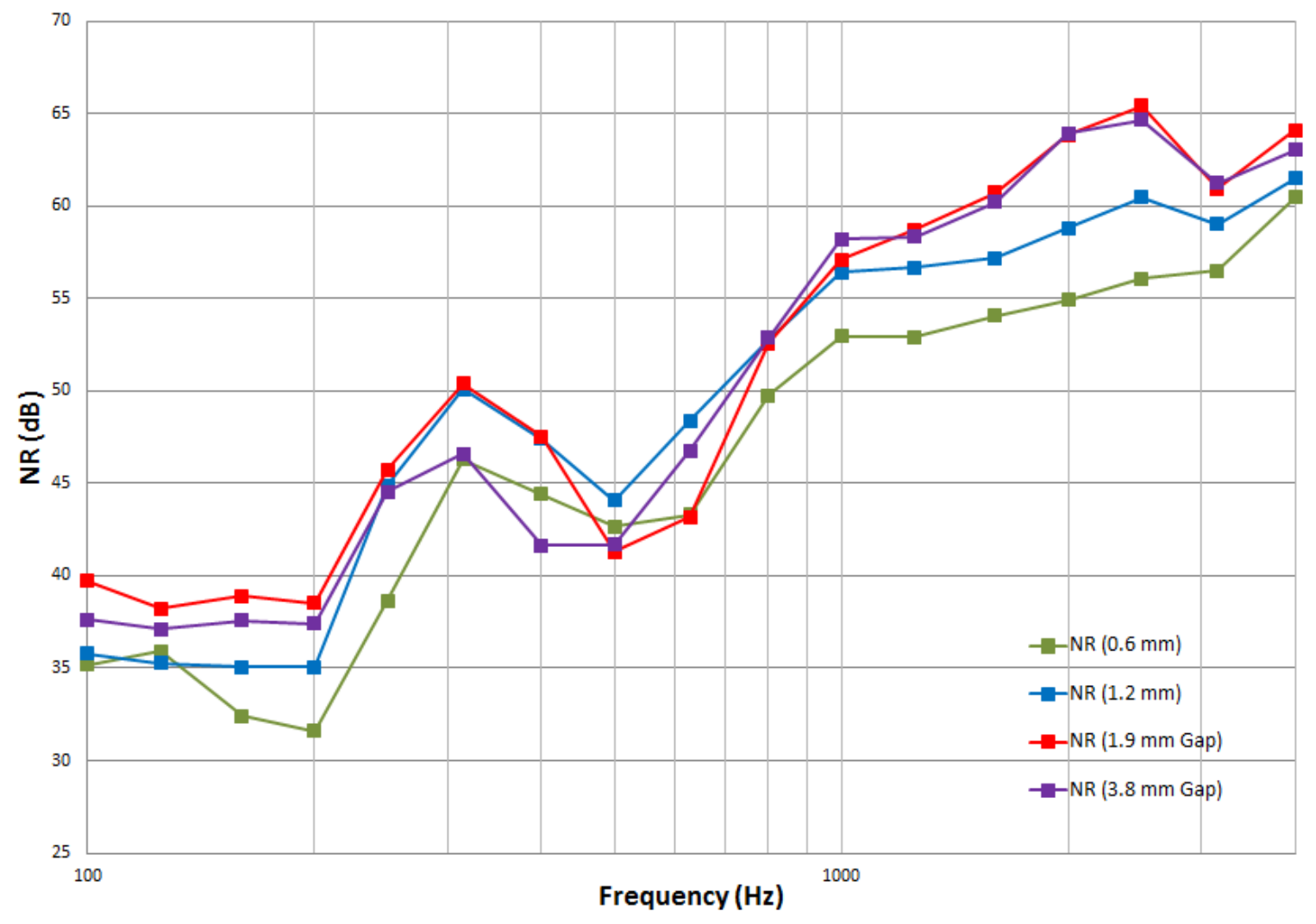

Figure 16. NR curves for all 4 test configurations.

As previously stated, the low frequency NR (below $200 \mathrm{~Hz}$ ) is expected, with generally higher NR than the single plate NR, due to the increase in mass. Another characteristic observed from experiment and predicted by theory is the NR valley due to the mass-air-mass resonance, which shifts to lower frequency with increase in gap thickness (Figure 17). 


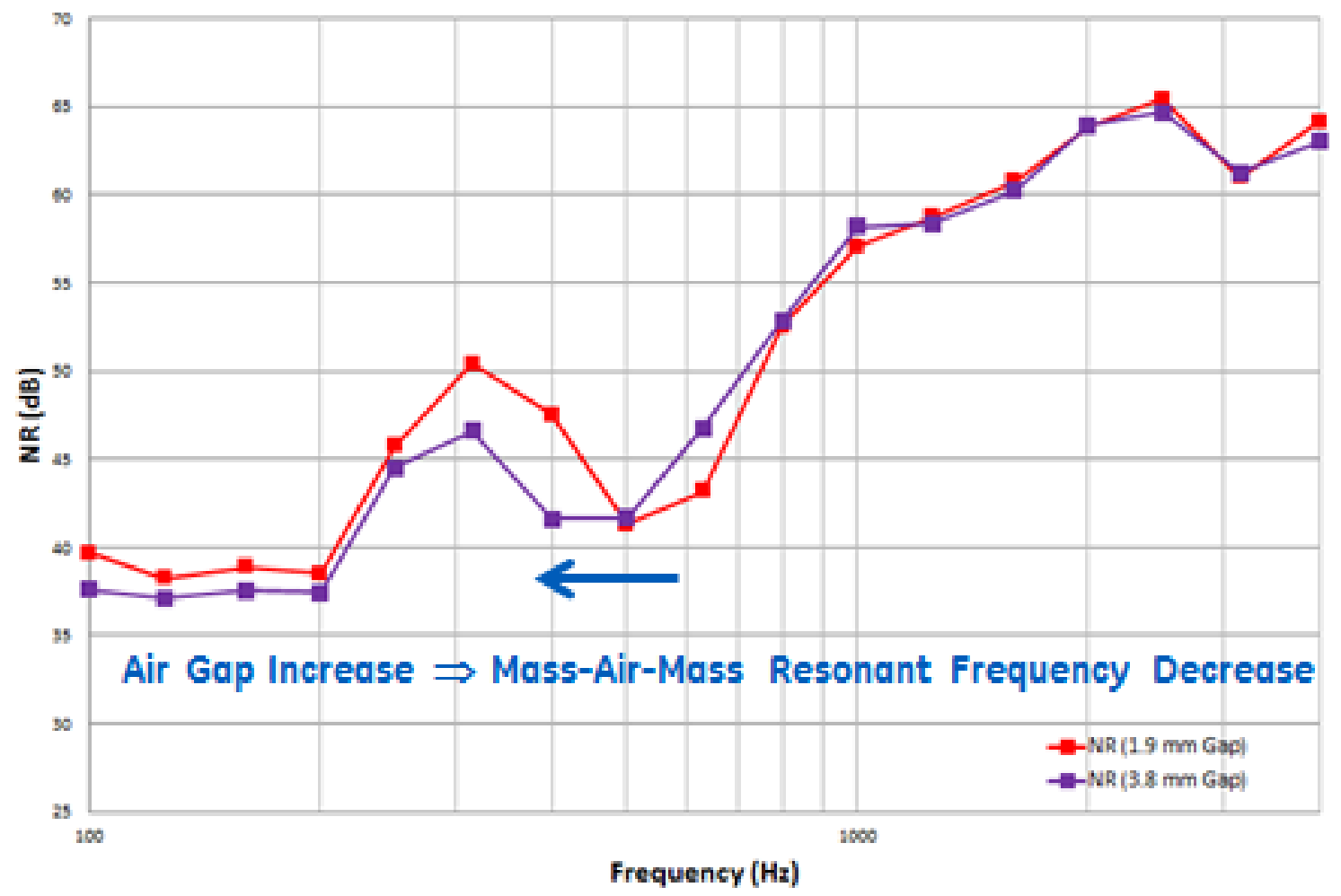

Figure 17. Double wall NR shows that an air gap increase corresponds to mass-air-mass resonant frequency decrease.

Another expected behavior of the double wall NR plots is that the critical frequency is independent of the air gap, occurring in the $3150 \mathrm{~Hz}$ third octave band for both air gaps (Figure 18). 


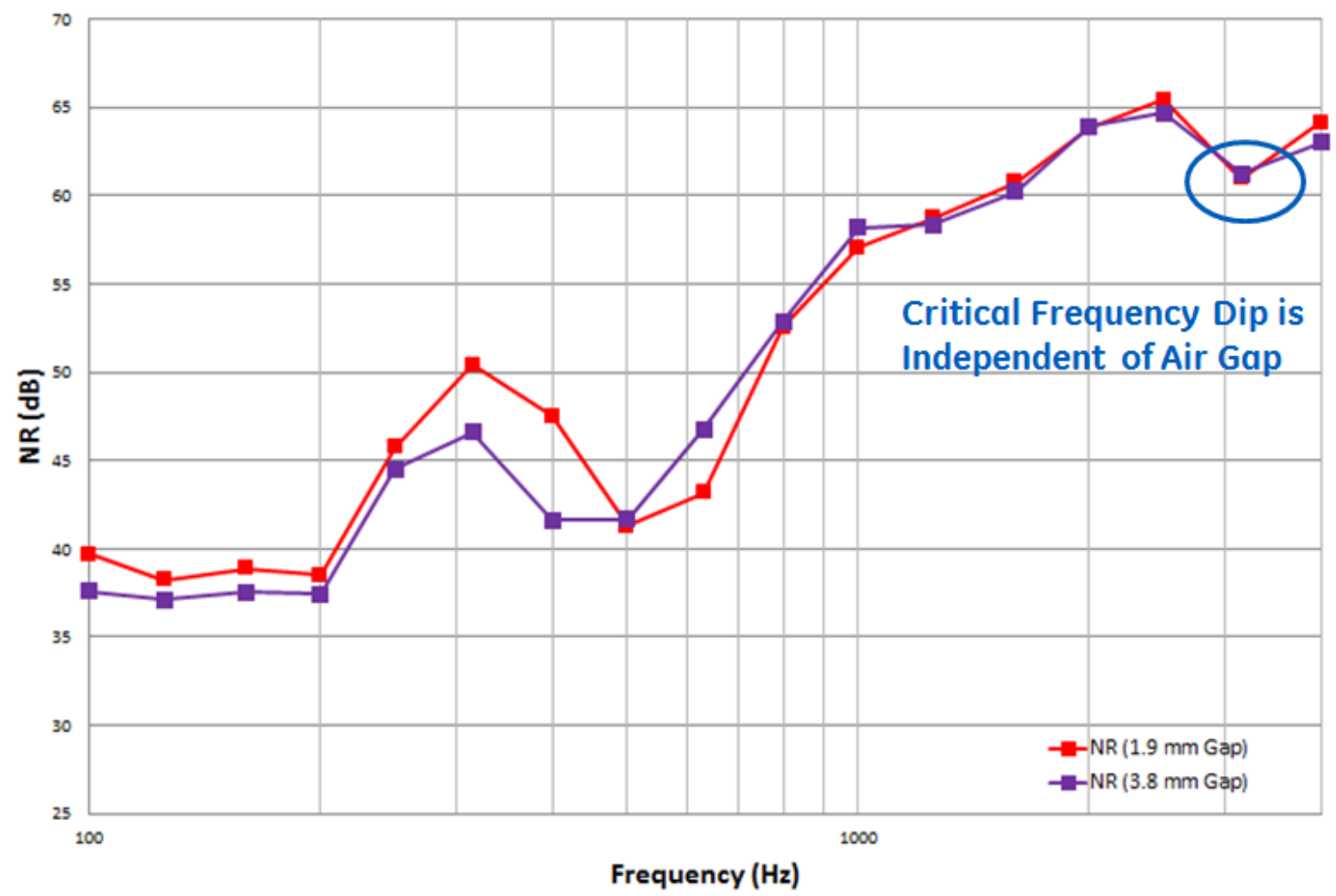

Figure 18. Double wall NR critical frequency is independent of the air gap.

Lastly, the predicted $18 \mathrm{~dB} /$ octave slope between the mass-air-mass resonance frequency $f_{\text {mam }}$ and the bridge frequency $f_{b}$, and the predicted $6 \mathrm{~dB} /$ octave slope between the bridge frequency and the critical frequency $f_{\mathrm{c}}$ are confirmed by the results as illustrated in Figure 19. 


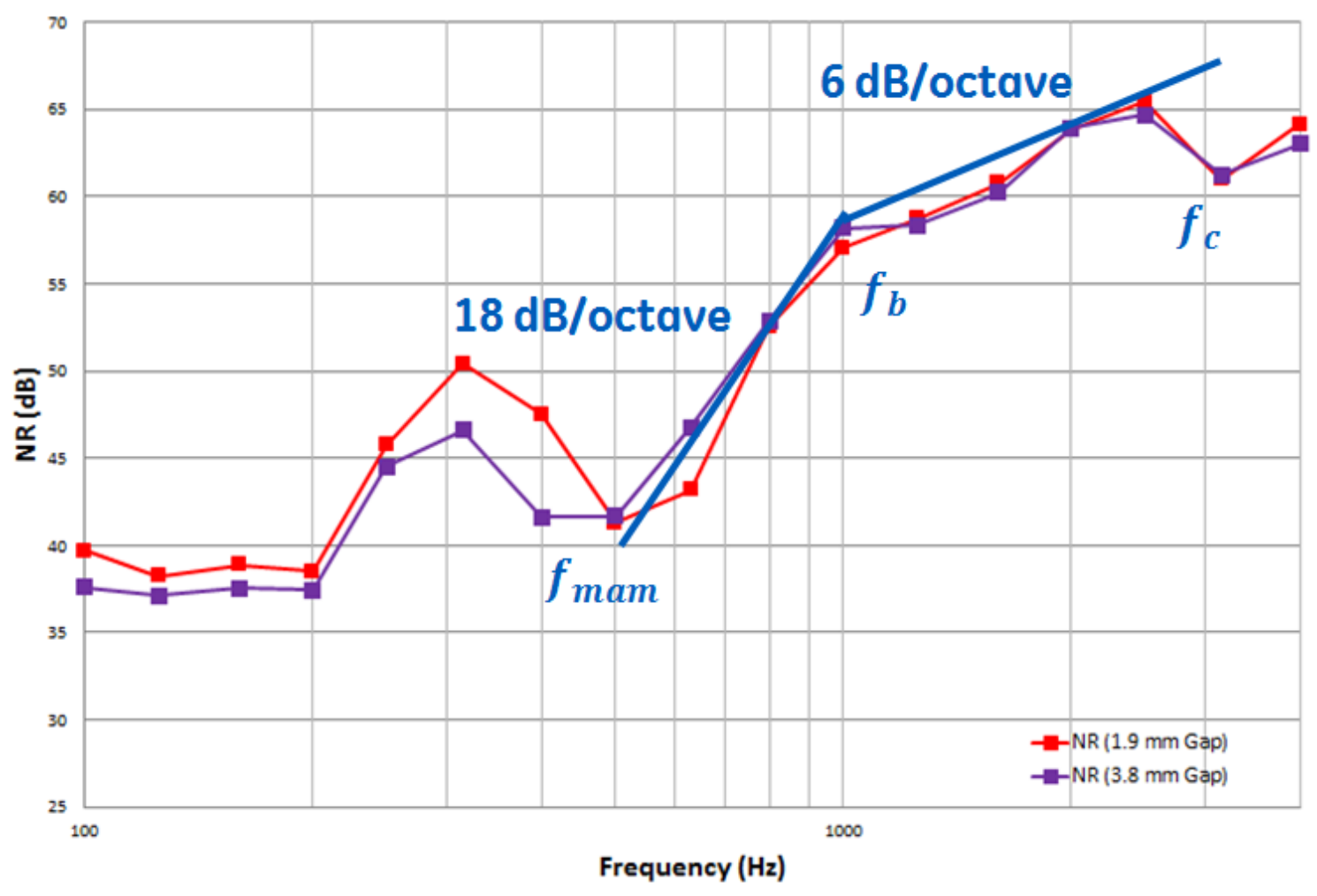

Figure 19. Double wall NR and predicted slopes.

E. Discrepancies Between Theory and Experiment Explained Through Structural

\section{Dynamics}

\section{Mass-Air-Mass Resonant Frequency}

The NR results show that there is a discrepancy between the predicted mass-airmass resonance NR valley and the location of the valley in the NR experiment. Figure 20 shows the NR of the two double plate configurations and indicates the frequencies at which the theory (Equation (12)) predicts the mass-air-mass frequency to occur. 


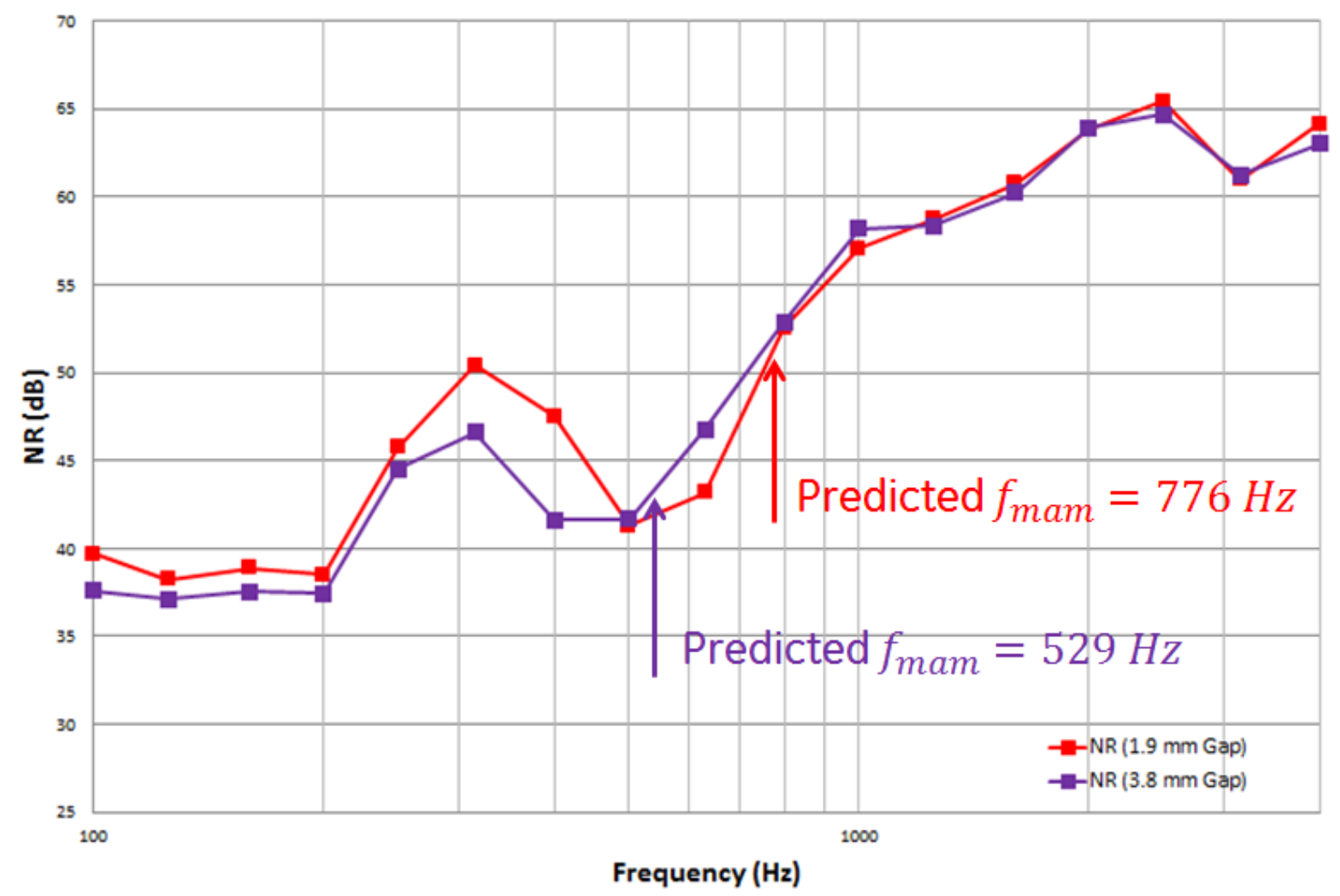

Figure 20. Mass-air-mass frequency predicted by Equation 12.

The location of the NR valley is not predicted with high accuracy using Equation 12, particularly for the $1.9 \mathrm{~mm}$ air gap. The mass-air-mass resonant frequency prediction (Equation (12)) is based on the theory that there is reduction in TL when the two plates experience a natural frequency at the same frequency. Contrary to the theory presented in which the two plates are rigid masses, in the experiment it is expected that the two flexible plates will display mode shapes. To investigate the cause of the discrepancy between the calculated mass-air-mass resonance and the experimental NR valley, experimental modal analysis is conducted on both air gap constructions, specifically to investigate if the shapes of the plate motion, or the synchronicity of the plates, can be used to predict better the mass-air-mass resonance. 
Despite the complicated mode shapes in the range of the mass-air-mass resonance (400-600 Hz), the modal analysis did prove to be of interest. First, the $1.9 \mathrm{~mm}$ air gap configuration contained a mode shape at $434 \mathrm{~Hz}$ in which the two plates vibrate in phase with each other and the two plates display the same deformation shape (see Figure 21).

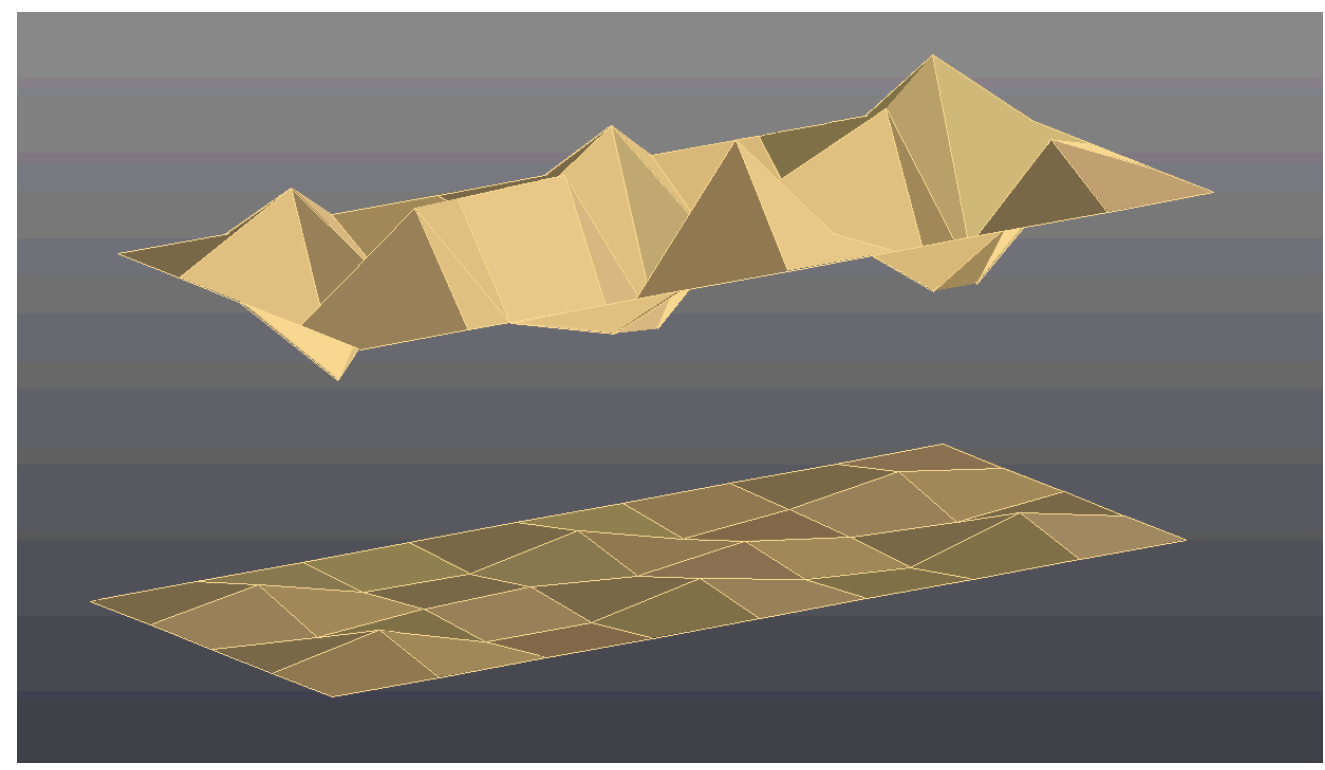

Figure 21. Mode shape of double plate configuration with $1.9 \mathrm{~mm}$ air gap at $434 \mathrm{~Hz}$.

Notice that the peaks and valleys in the top plate (receiving plate) match the peaks and valleys of the bottom plate (source plate). Figure 22 displays the $1.9 \mathrm{~mm}$ gap configuration NR curve with indicators for the calculated mass-air-mass resonant frequency and for the $434 \mathrm{~Hz}$ mode with synchronous plate motion. Notice that the location of the NR valley occurs at a frequency closer to $434 \mathrm{~Hz}$ than to the predicted frequency determined by theory (Equation (12)). 


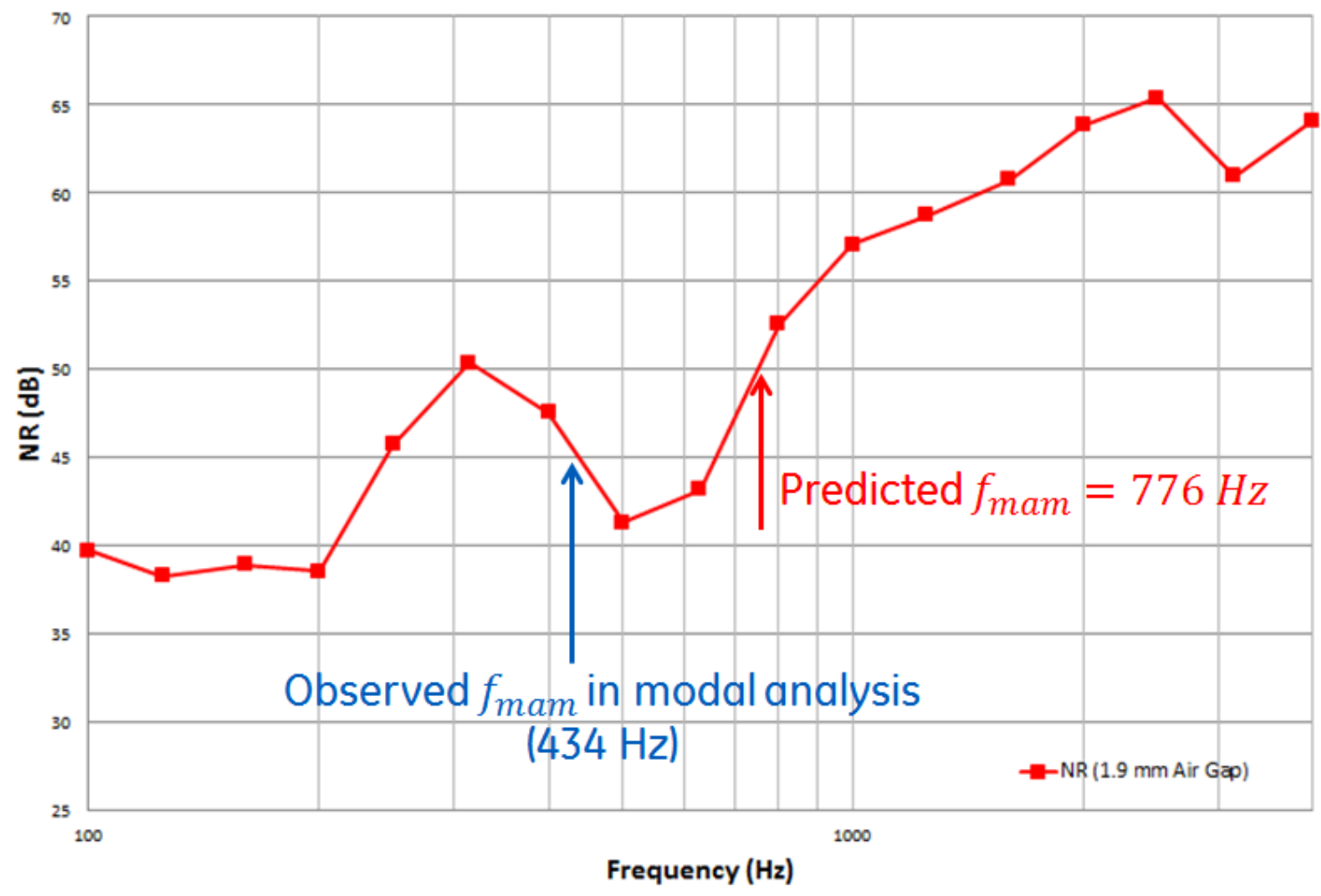

Figure 22. Predicted mass-air-mass frequency and frequency of observed synchronous plate motion in modal analysis for the $1.9 \mathrm{~mm}$ air gap.

For the $3.8 \mathrm{~mm}$ gap configuration, the first instance of a mode with a synchronous plate motion mode shape is at $402 \mathrm{~Hz}$ (Figure 23). This is followed by a second instance at $449 \mathrm{~Hz}$ (Figure 24). 


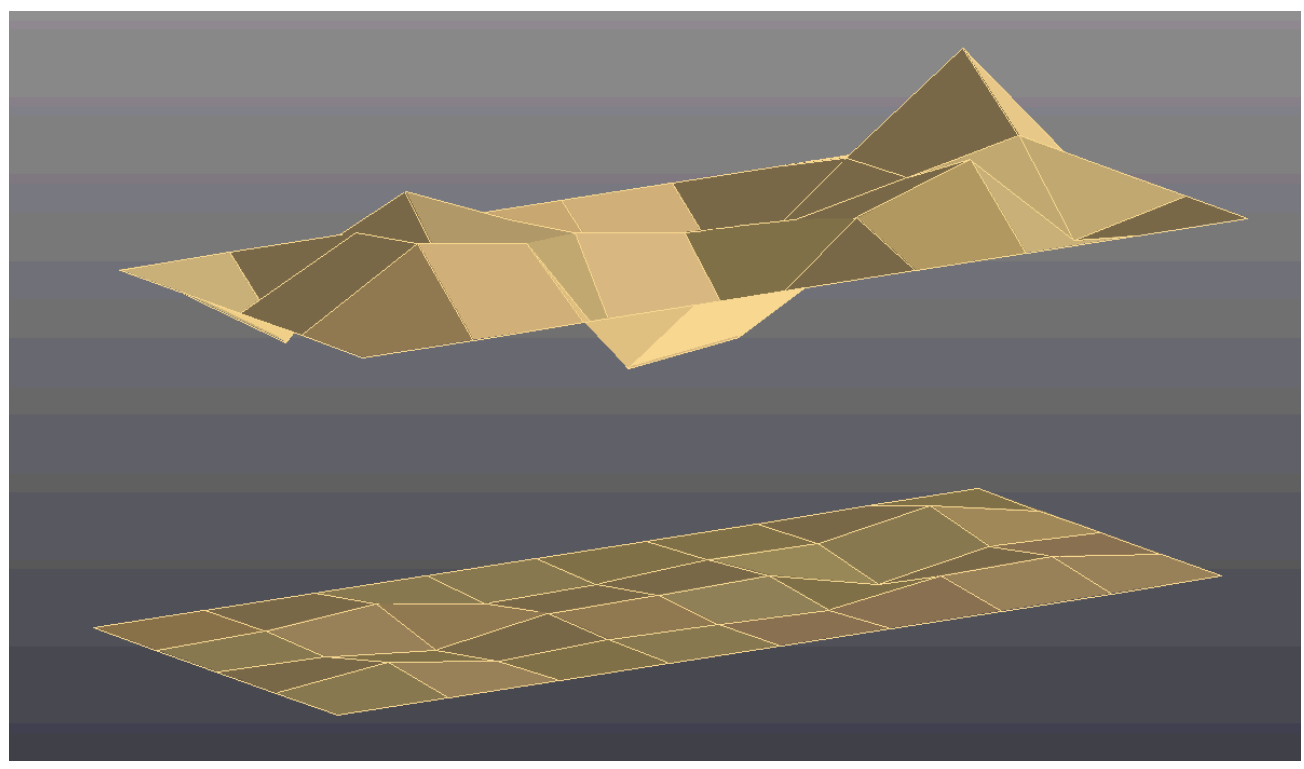

Figure 23. Mode shape of double plates with $3.8 \mathrm{~mm}$ air gap at $402 \mathrm{~Hz}$.

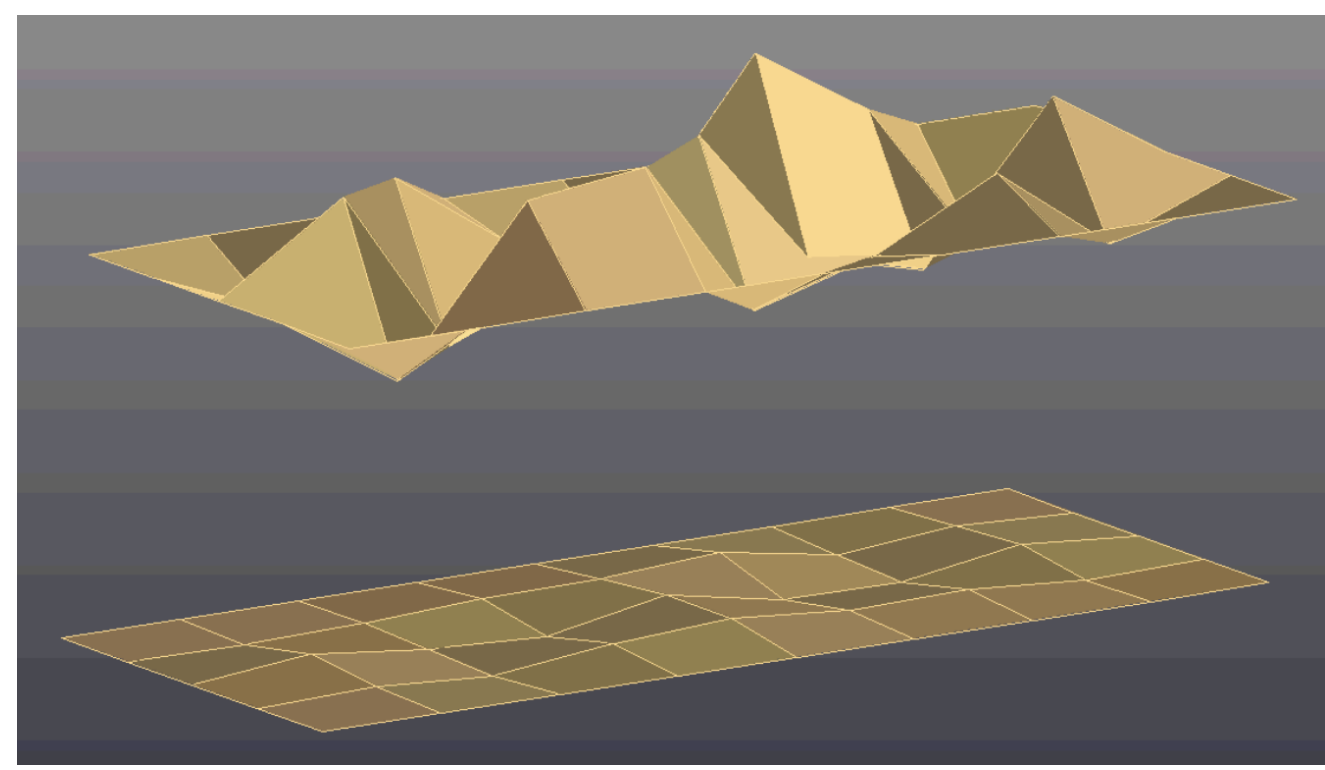

Figure 24. Mode shape of the double plates with 3.8 air gap at $449 \mathrm{~Hz}$.

Figure 25 shows the NR curve for the $3.8 \mathrm{~mm}$ gap configuration with an indicator for the theoretically predicted mass-air-mass resonant frequency and indicators showing the frequencies of the modes with synchronous mode shape motion. As shown, the 
modes more closely match the NR valley compared to the frequency predicted by theory (Equation (12)).

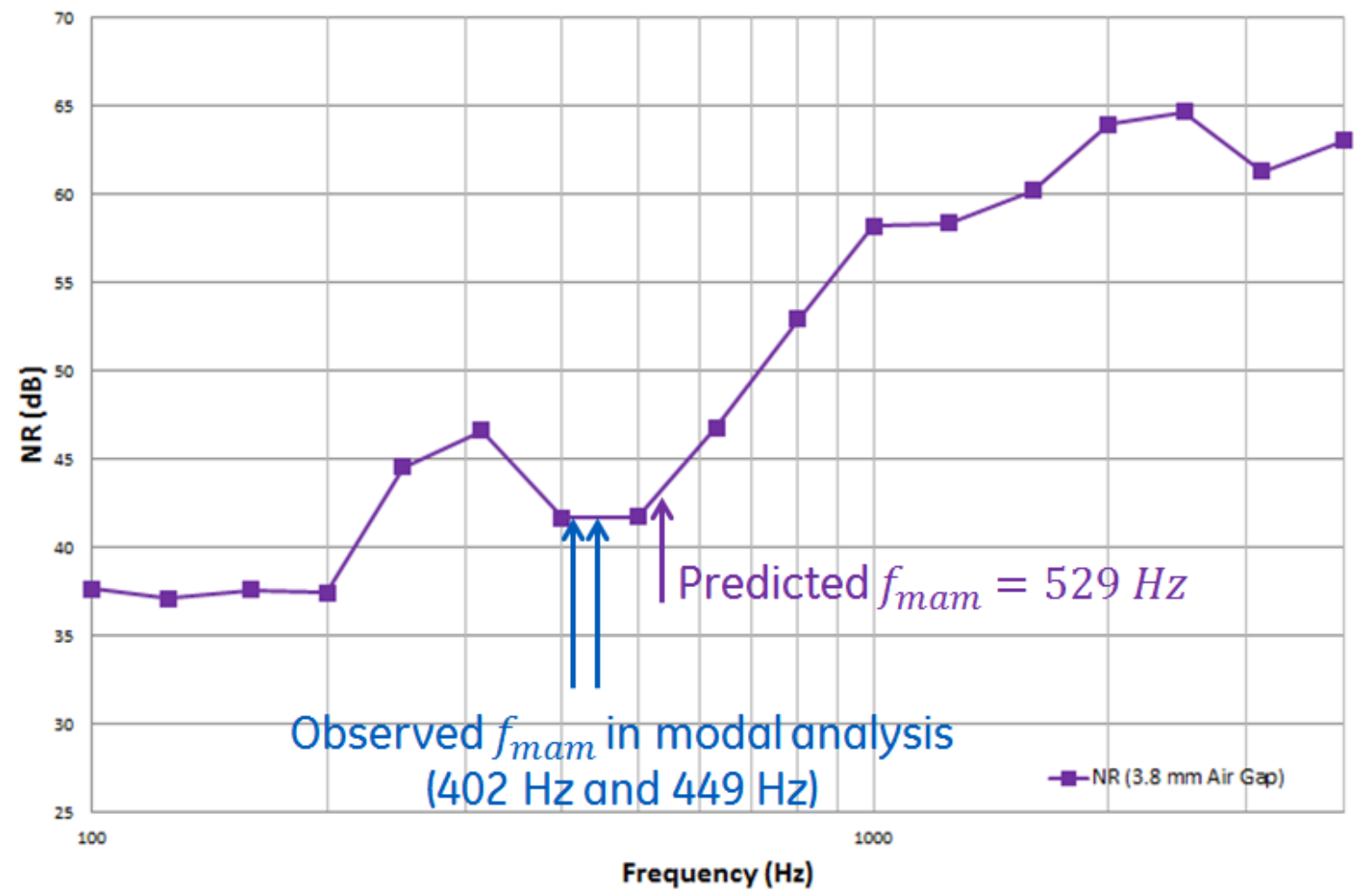

Figure 25. Predicted mass-air-mass frequency and frequency of observed synchronous plate motion in modal analysis for $3.8 \mathrm{~mm}$ air gap.

Since mode shape plate-to-plate synchronicity appears to have some relevance on the frequency of the NR valley, it is necessary to understand the synchronicity between the motion of the two plates for all the modes in the bandwidth of interest $(100-1000 \mathrm{~Hz})$. However, due to the presence of a large number of modes (30 and 33 for the $1.9 \mathrm{~mm}$ and $3.8 \mathrm{~mm}$ air gap configurations, respectively), visual inspection of the all of these mode shapes is both tedious and potentially inaccurate. This is especially true of the higher frequency modes with a large number of nodal lines. Therefore, the Modal Assurance 
Criterion (MAC) [20] is utilized to provide an objective tool to determine the modes that exhibit synchronous motion similar to those highlighted above.

MAC is a normalized function that related the degree of consistency between two modal vectors,

$$
M A C=\frac{\left(\Psi_{S}\right)^{H}\left(\Psi_{r}\right)\left(\Psi_{r}\right)^{H}\left(\Psi_{S}\right)}{\left(\Psi_{S}\right)^{H}\left(\Psi_{S}\right)\left(\Psi_{r}\right)^{H}\left(\Psi_{r}\right)}
$$

where $\Psi_{\mathrm{s}}$ and $\Psi_{\mathrm{r}}$ are the modal vectors for two different modes. If these modal vectors are identical, $\mathrm{MAC}=1$; if no consistency exists between the two vectors, $\mathrm{MAC}=0$. To utilize this tool for the purpose of determining the synchronicity between the source and receiving plates for a single mode, the modal vector for each mode is divided into two separate vectors, one containing the relative response of the source plate and another containing the response of the receiving plate. Since the MAC calculation must be completed for each mode shape, a MATLAB ${ }^{\circledR}$ program was written to complete the calculation for each mode shape and configuration. The program code used to complete the MAC calculation is offered in APPENDIX $\mathrm{H}$.

MAC values of the mode shapes for the $1.9 \mathrm{~mm}$ air gap double plate configuration are shown in Figure 26 along with the NR curve for this double wall construction. 


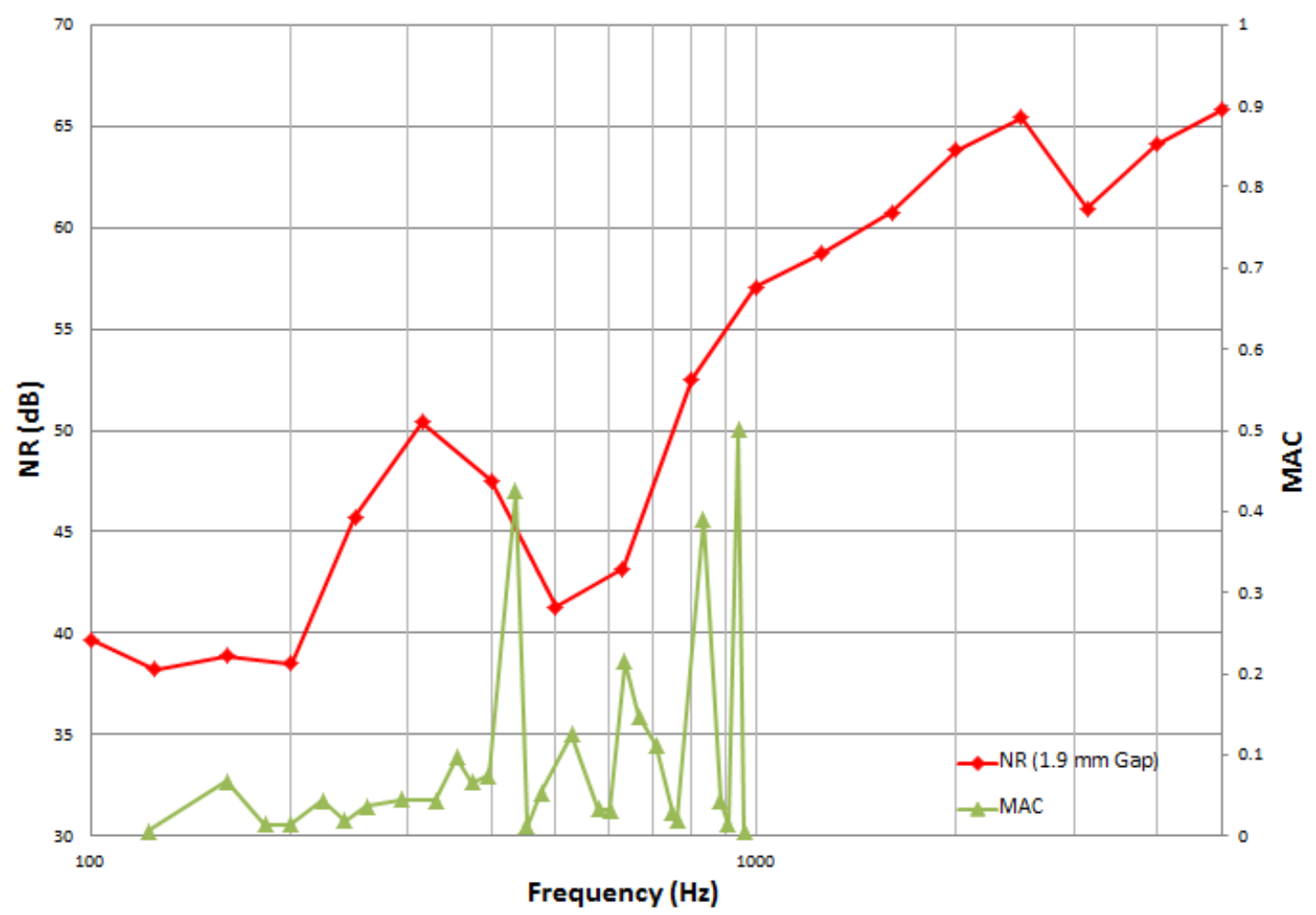

Figure 26. NR and MAC values for the $1.9 \mathrm{~mm}$ air gap double plate configuration.

First, the MAC value for the predicted mass-air-mass resonance $(776 \mathrm{~Hz})$ is actually a local minimum, not a maximum as would be expected. However, the MAC value corresponding to the mode shape at $434 \mathrm{~Hz}$ (circled in Figure 27), which displays plate synchronous motion, is 0.425 . This value is relatively large compared with MAC values below this frequency. It is also in the frequency range near the mass-air-mass NR valley. 


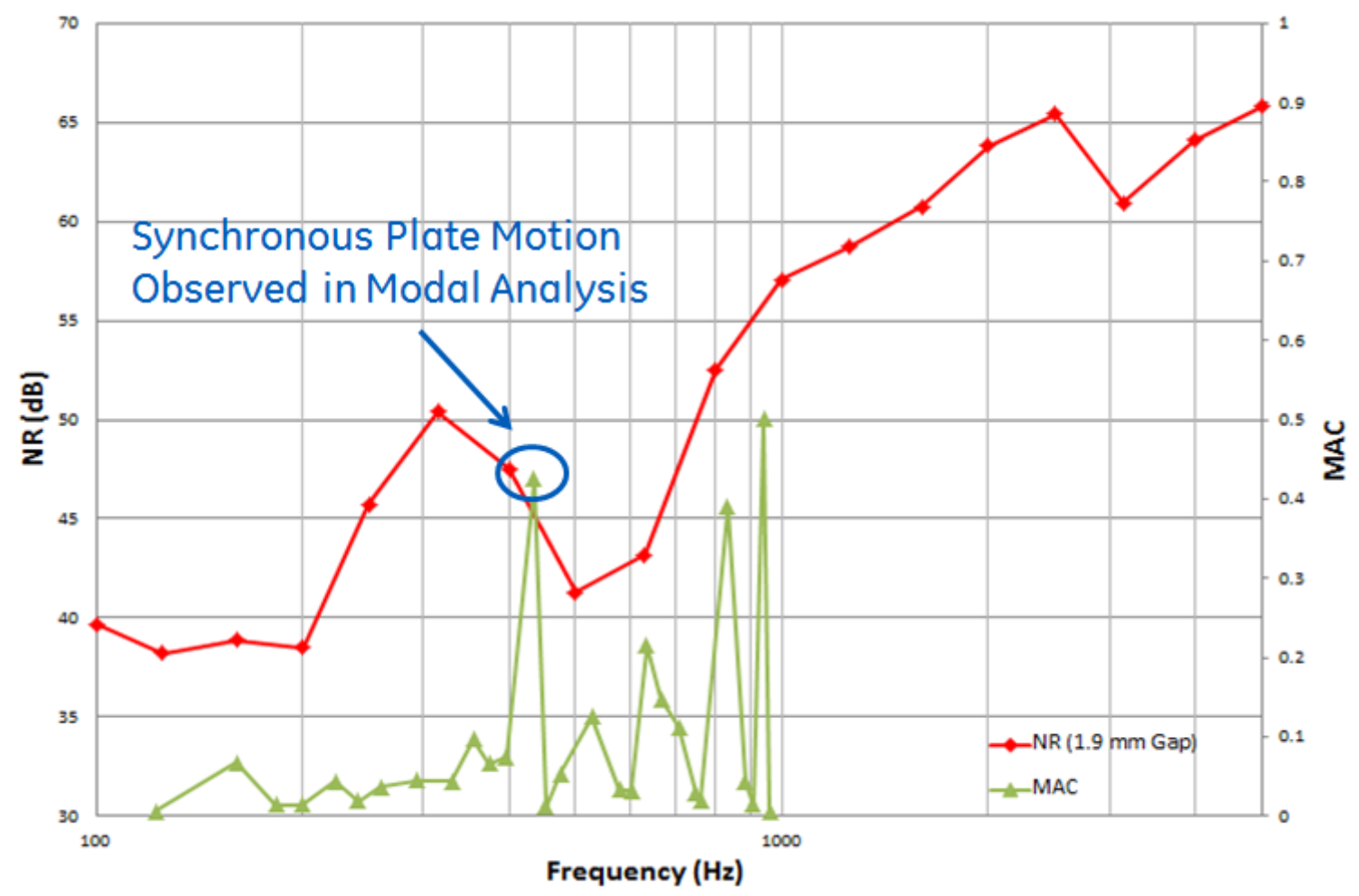

Figure 27. MAC value for observed mass-air-mass resonance in modal analysis, indicated by synchronous plate to plate vibration.

The peak in MAC at $434 \mathrm{~Hz}$ is not the only peak in MAC between 100 and 1000 Hz. There also exists peaks in MAC at $528 \mathrm{~Hz}, 634 \mathrm{~Hz}, 834 \mathrm{~Hz}$ and $941 \mathrm{~Hz}$.

Observations of the mode shapes offer some insight regarding the high values of MAC. First, the mode shapes at $528 \mathrm{~Hz}, 634 \mathrm{~Hz}$, and $941 \mathrm{~Hz}$ display behavior that includes similar plate deformation shapes between the source and the receiving plates, but the motions are out of phase. The mode shape at $834 \mathrm{~Hz}$ is the second instance of synchronous in-phase plate motion. Although none of the MAC peaks occur exactly at the NR valley, there is a concentration of mode shapes with higher MAC at frequencies near the mass-air-mass NR valley. 
To further investigate the usage of MAC in predicting the mass-air-mass resonance, the same study was completed for the $3.8 \mathrm{~mm}$ air gap configuration. The results of MAC and NR plotted vs frequency are shown below.

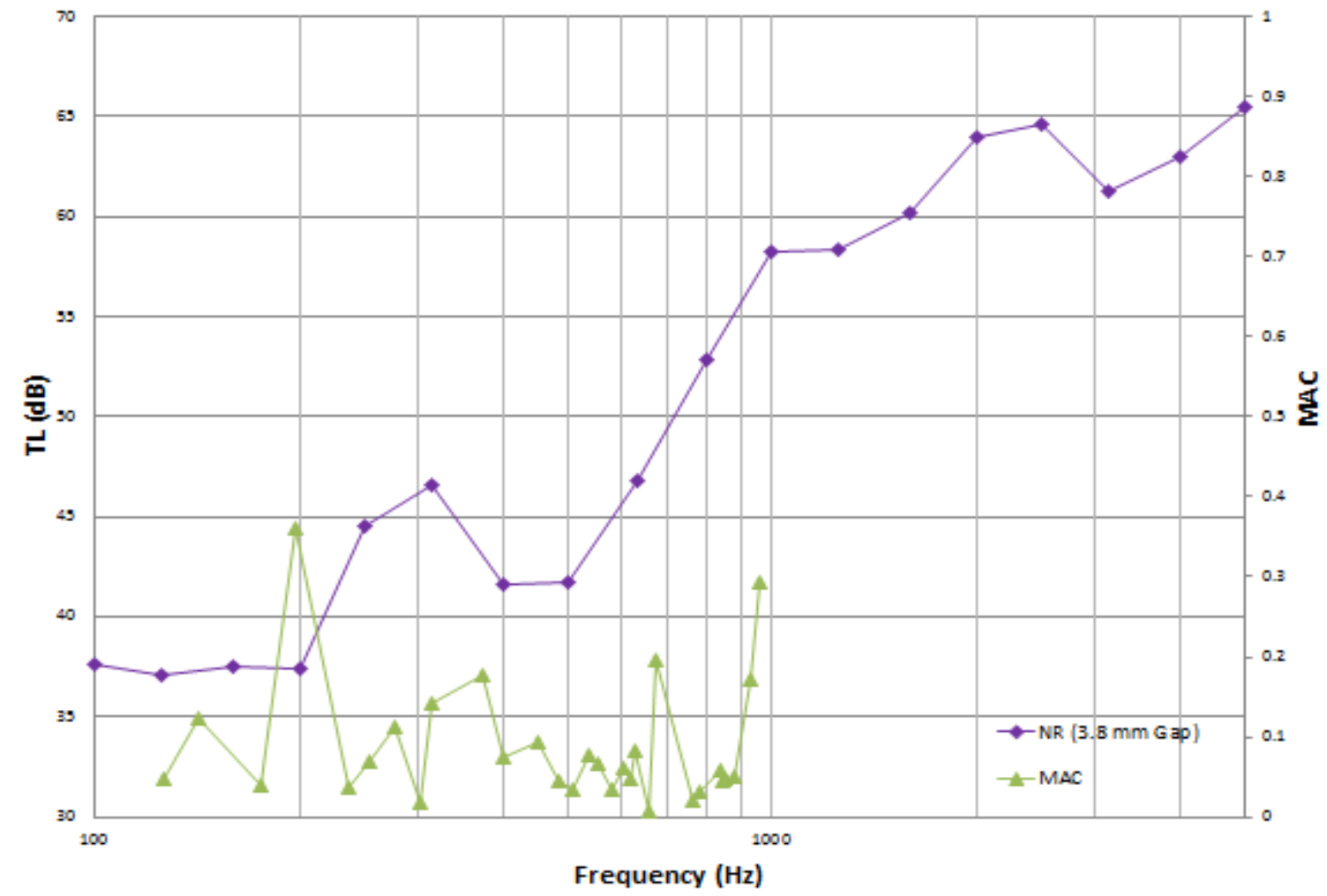

Figure 28. NR and MAC for the $3.8 \mathrm{~mm}$ air gap double plate configuration.

Similar to the MAC for the $1.9 \mathrm{~mm}$ air gap previously analyzed, the MAC value for the predicted mass-air-mass resonance $(529 \mathrm{~Hz})$ is actually a local MAC minimum, not the maximum that would be expected. Another similarity to the $1.9 \mathrm{~mm}$ air gap is that the MAC values are not as close to unity as would be expected for mass-air-mass resonance. In fact, the maximum MAC values for the $3.8 \mathrm{~mm}$ air gap construction are even lower than for the $1.9 \mathrm{~mm}$ air gap. It is theorized that this can be attributed to the 
reduction in coupling between the two plates due to the larger air gap. However, there does exist a local maximum at one of the frequencies previously identified through observation as the mass-air-mass resonance, the mode shape of the $449 \mathrm{~Hz}$ mode. It appears from the observation of the MAC values that the $449 \mathrm{~Hz}$ mode shape (indicated in Figure 29) included more synchronicity than that of the $402 \mathrm{~Hz}$ mode shape. After visual inspection of the mode shapes, this is confirmed.

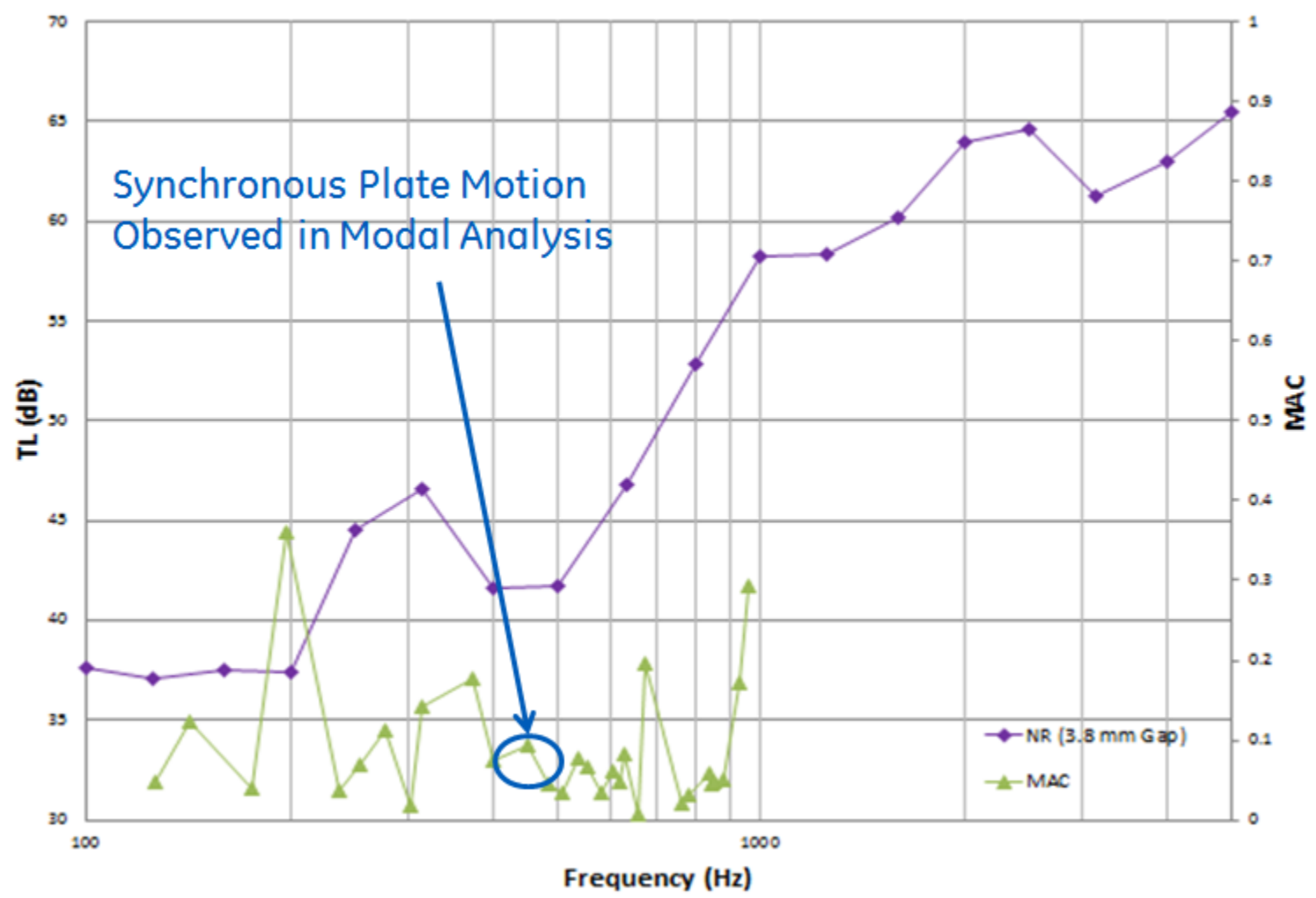

Figure 29. MAC value for observed mass-air-mass resonance in modal analysis, indicated by synchronous plate to plate vibration.

Unlike Figure 26 (1.9 mm air gap), there does not appear to be a high concentration of modes with high MAC value near the mass-air-mass NR valley. 
Complete tables of the MAC values for the $1.9 \mathrm{~mm}$ and $3.8 \mathrm{~mm}$ air gap configurations are offered in APPENDIX I and APPENDIX J respectively.

\section{Bridge Frequency}

Another discrepancy between available TL theory and the experimental NR results is the location of the bridge frequency. The predicted values for the bridge frequency (Equation (14)) are shown in Figure 30 below.

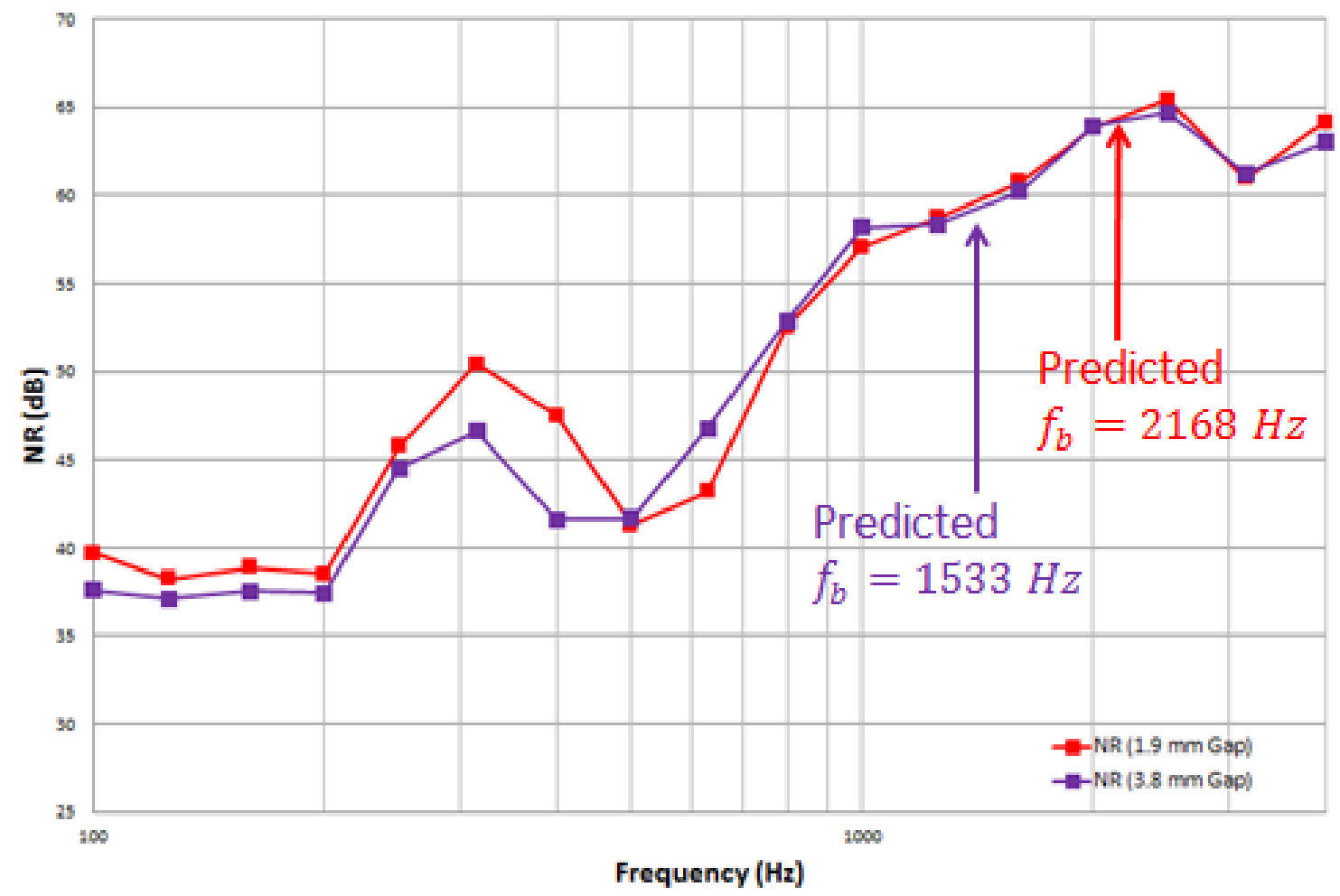

Figure 30. Predicted bridge frequency for $1.9 \mathrm{~mm}$ and $3.8 \mathrm{~mm}$ air gap configurations. 
The bridge frequency for both double plate configurations is over predicted by Equation (14). To investigate this discrepancy, accelerometers were placed on the center each plate (location 23) during the NR experiments. Below, the NR plot for the $1.9 \mathrm{~mm}$ air gap is shown in combination with the narrow band acceleration data plotted on a secondary axis. Included are labels for the observed mass-air-mass resonance, observed bridge frequency, and calculated bridge frequency.

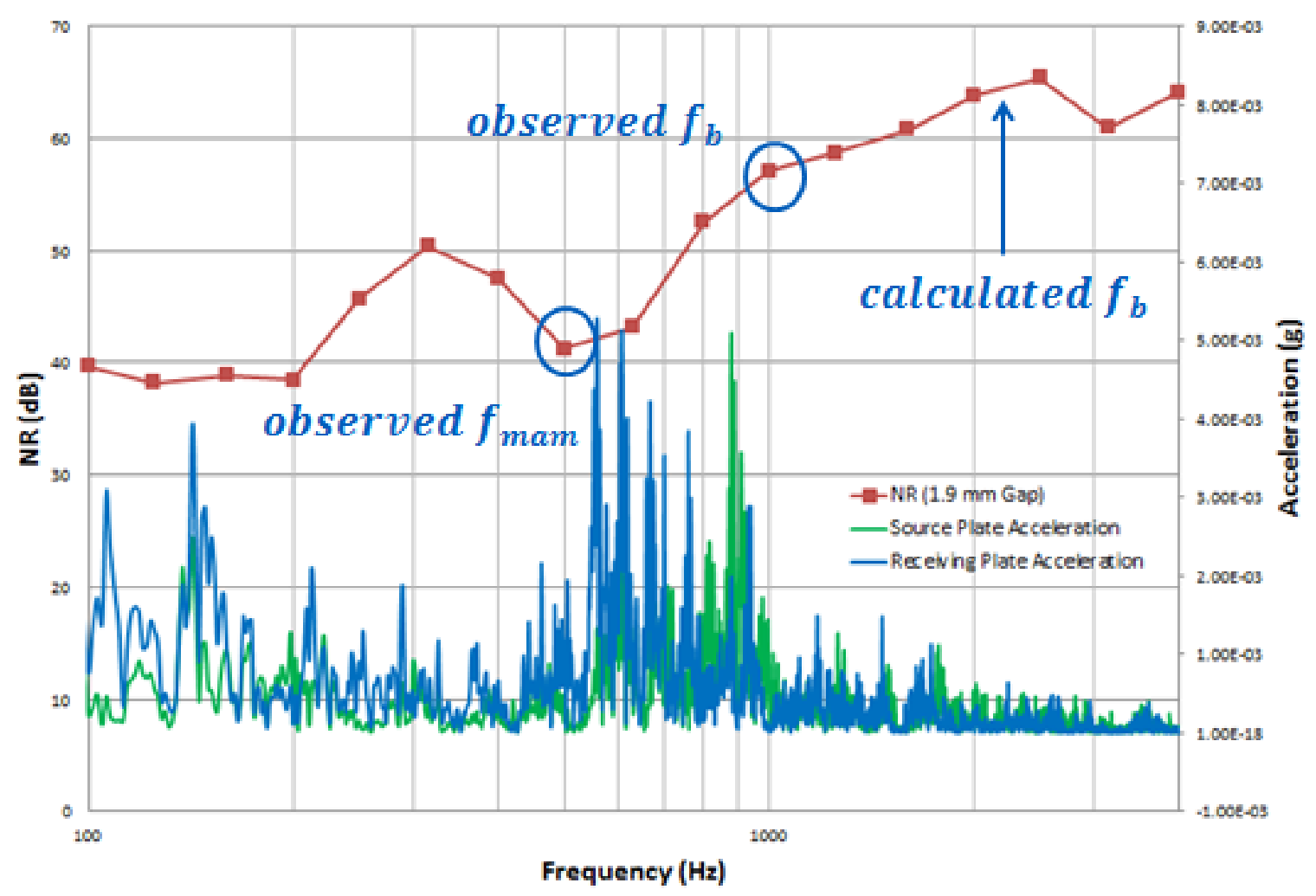

Figure 31. NR and plate acceleration of double plates with $1.9 \mathrm{~mm}$ air gap.

The plate vibration amplitude for both plates is amplified between the mass-airmass resonance and the bridge frequency. This would indicate that a cause for the steep increase in $\mathrm{NR}$ (18 $\mathrm{dB}$ per octave slope) is the increase of mechanical work done by the 
two plates. There also exists a frequency range in which there is a change in which plate experiences more acceleration. Specifically, the receiving plate acceleration decreases and the source plate acceleration increases. The source plate becomes the plate with more acceleration very close to the experimental bridge frequency. The slope change from 18 to $6 \mathrm{~dB}$ per octave (at the bridge frequency) occurs at a frequency in which the acceleration of both plates decreases and becomes relatively equal to one another in amplitude.

Next, the NR plot for the larger air gap $(3.8 \mathrm{~mm})$ is observed. Again, the plot includes the narrow band acceleration due to sound excitation plots of both the receiving plate and the source plate, and indicators for the mass-air-mass resonance valley, observed bridge frequency, and the calculated bridge frequency. 


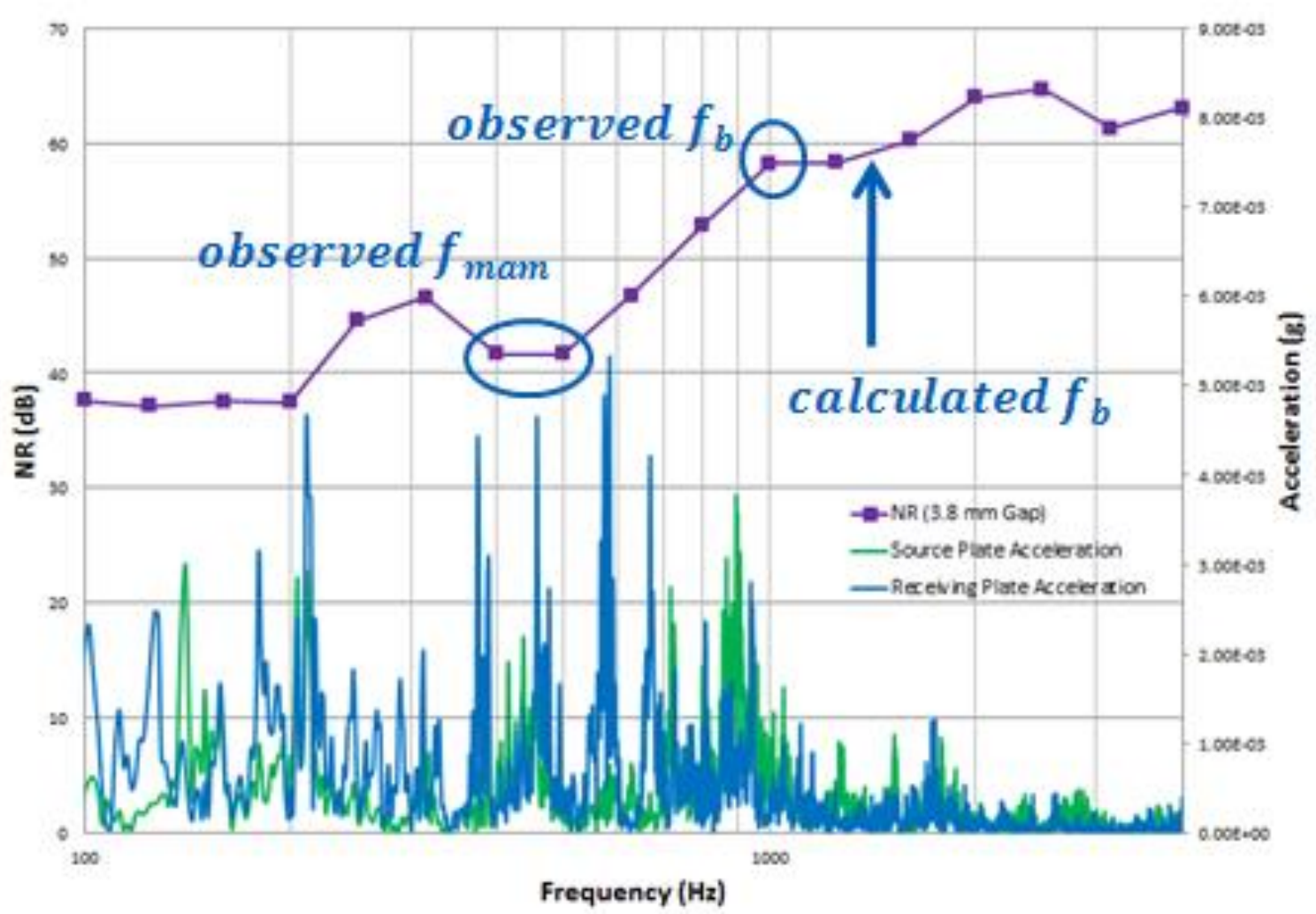

Figure 32. NR and plate acceleration of double plates with $3.8 \mathrm{~mm}$ air gap.

Figure 32 shows striking similarities to the graph for the $1.9 \mathrm{~mm}$ air gap (Figure 31). The bridge frequency occurs in both configurations when the acceleration of both plates reduces in amplitude and are of similar amplitude to one another. Using theory for single wall TL, $6 \mathrm{~dB}$ per octave is indicative of mass law. To display the mass dependence displayed by the double plate configurations between the bridge frequency and the critical frequency Figure 33 is offered below. 


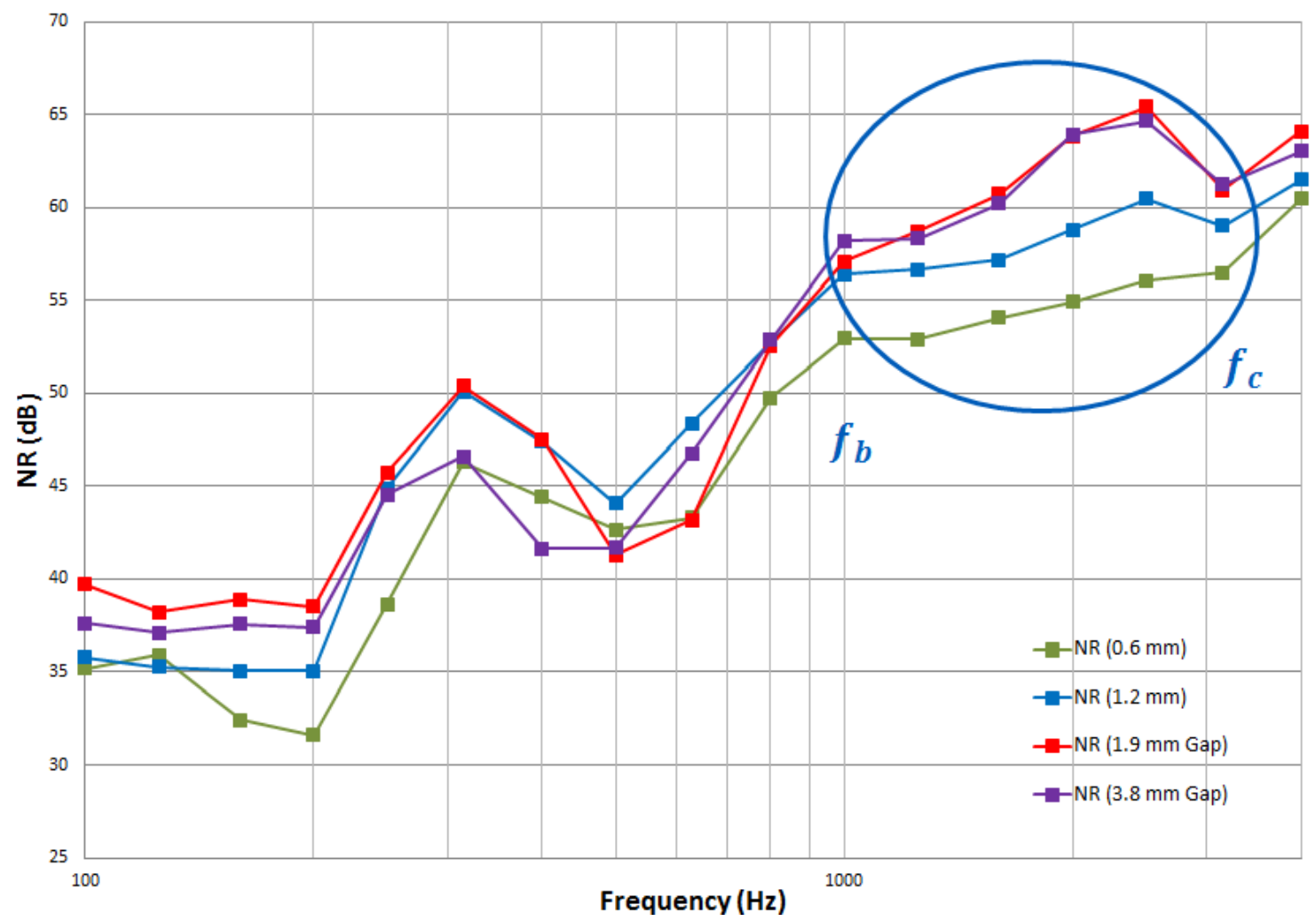

Figure 33. Mass dependent NR between bridge frequency and critical frequency for the double plate configurations.

Figure 33 shows that the two double wall configurations have similar NR plots in the region between the bridge frequency $f_{b}$ and the critical frequency $f_{c}$. This would indicate that the air gap is not a major contributor to NR in this region. Solving the mass law equation for a plate of thickness equal to the sum of the two plates yields a TL increase of $3.5 \mathrm{~dB}$ compared to that of the $1.2 \mathrm{~mm}$ single plate. This agrees relatively well with the experimental results shown in Figure 33 as the NR of both double wall configurations is $3-5 \mathrm{~dB}$ higher than the NR for the $1.2 \mathrm{~mm}$ plate for frequencies between $1600 \mathrm{~Hz}$ and $2500 \mathrm{~Hz}$. However, at the lower frequencies within this region $(1000 \mathrm{~Hz}$ to 
$1250 \mathrm{~Hz}$ ), the difference between the double wall NR and the $1.2 \mathrm{~mm}$ single wall construction is not as large as expected.

It should be noted that there some frequency bands in which the larger air gap is favorable for NR and other frequencies at which the smaller air gap is more favorable. It is described in the literature [5] that the air gap thickness is not a major factor in TL below the mass-air-mass resonant frequency. However, Quirt [5] does describe a trend of steady increase in TL with increase in air gap thickness at frequencies above the massair-mas resonance. This increase in TL due to air gap thickness increase was not observed in these results when the air gap was doubled. Predictions developed by London [9] indicate an increase of $6 \mathrm{STC}$ for the doubling of the gap spacing. Less aggressive gains in TL were observed by Quirt [5], which show a trend of 3 STC increase for the doubling of the air gap. Quirt [5] attributes the difference between his results and London's to the lack of absorptive materials in the air cavity in his testing of glass windows. Unfortunately, due to the differences in gap thickness (testing in this thesis utilize smaller gaps) and material selection (steel vs. glass), there are no conclusions that can be drawn as to the cause of the lack of NR increase with the doubling of the air gap.

\section{Uncharacteristic NR Peak at $315 \mathrm{~Hz}$}

As stated in the section C (Single Wall Experimental Noise Reduction), there is an unexpected peak in NR at $315 \mathrm{~Hz}$ for the single plates. To investigate this discrepancy, acceleration data measured during the NR experiments for each plate and

corresponding frame (measured slightly above location 41, in the top center of the frame) 
is considered. The plate and frame acceleration due to sound excitation is shown in Figure 34 for the $0.6 \mathrm{~mm}$ plate configuration in combination with the NR results for the same configuration.

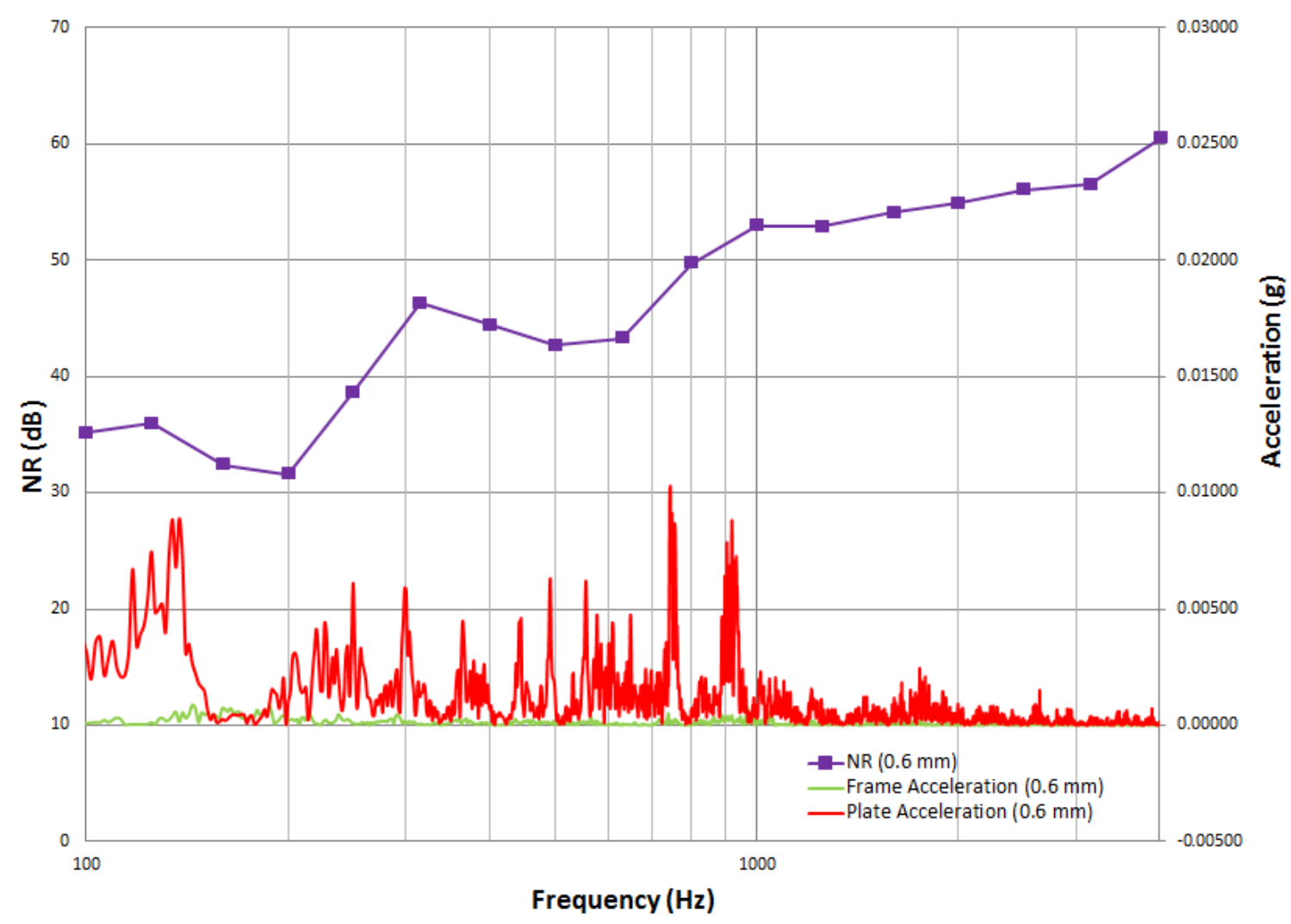

Figure 34. NR and acceleration of $0.6 \mathrm{~mm}$ single plate and frame.

The plate experiences significantly more vibration amplitude than the frame, as expected since the frame is mounted to the filler wall. The second observation is that there appears to be reduced plate acceleration in the region near the peak at $315 \mathrm{~Hz}$, compared to the levels of acceleration in frequency bands below $200 \mathrm{~Hz}$ and above 500 $\mathrm{Hz}$. 
Similar observations are made after viewing the narrow band acceleration data for the frame and plate for the $1.2 \mathrm{~mm}$ single plate configurations (Figure 35).

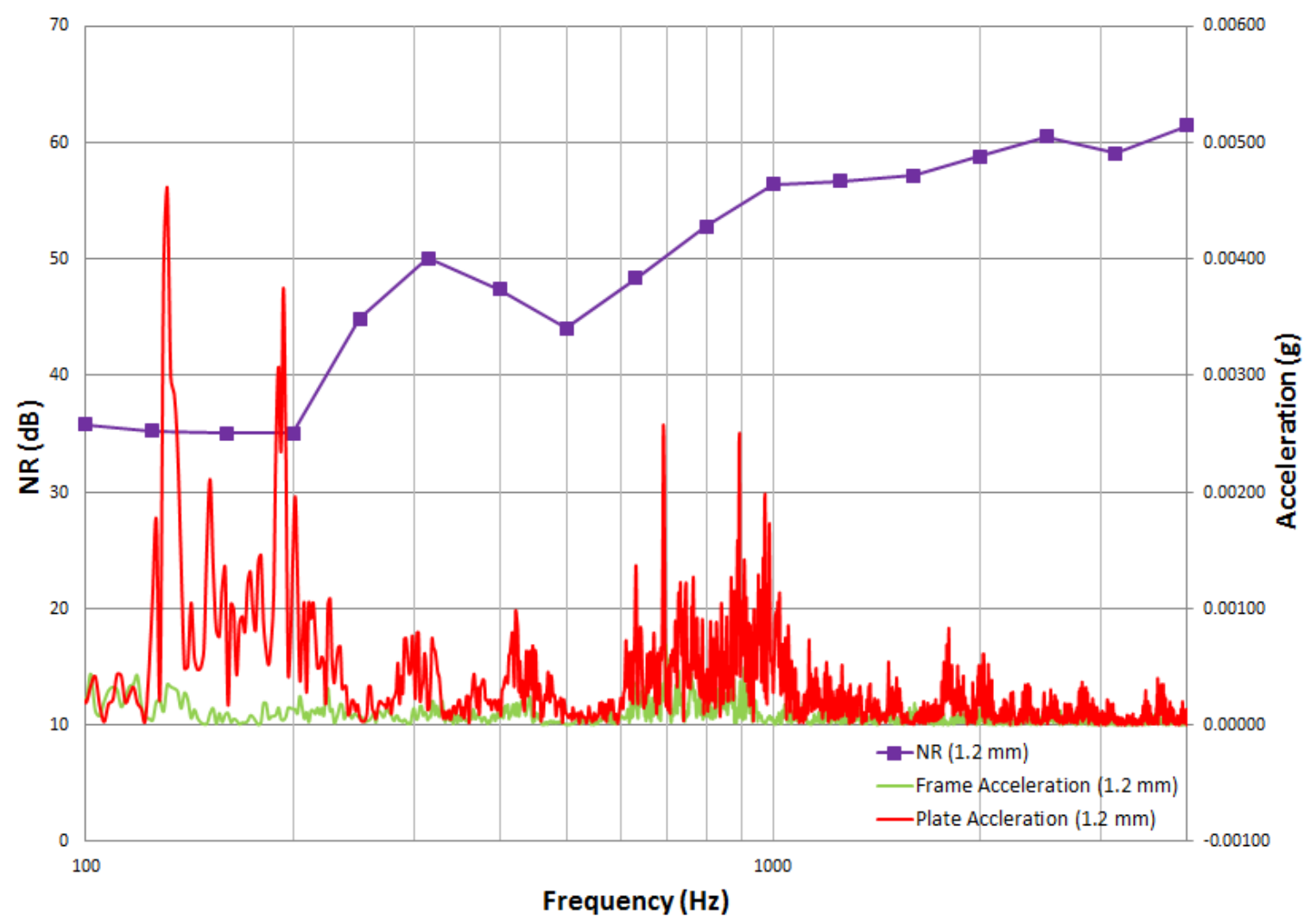

Figure 35. NR and acceleration of $1.2 \mathrm{~mm}$ single plate and frame.

Note that similar to the $0.6 \mathrm{~mm}$ single plate, the acceleration of the frame is less than the acceleration of the plate and the plate acceleration is reduced in the region of the unexpected NR peak at $315 \mathrm{~Hz}$. Interestingly, there is also a peak in NR at $315 \mathrm{~Hz}$ in both double wall NR curves. From Figure 31 (1.9 mm air gap NR and plate vibration) and Figure 32 (3.8 $\mathrm{mm}$ air gap NR and plate vibration), similar reduced plate vibration is evident near the NR peak at $315 \mathrm{~Hz}$. Since the NR peak occurred in all four 
configurations at $315 \mathrm{~Hz}$, and the acceleration data showed a high concentration of increased plate excitation near that frequency, it can be assumed that the NR peak is due to the test setup that remained constant along all test. Two such test conditions that remained consistent between all four tests are the use of the same filler wall and the same frame (dimensions, bolt pattern and mounting). 


\section{CONCLUSION}

Noise reduction testing was completed for two steel plate constructions and for two constructions using the same two plates from the single plate tests with varying air gap thickness. Results compared favorably with theory from previous literature. The NR of the single plate constructions generally followed the normal incidence mass law slope in the mass law region, and confirmed that an increase in mass per unit area results in an increase in NR. The double wall NR plots confirmed existing theory that the air gap thickness influences the frequency of the mass-air-mass resonance where a valley in NR curve exists. Specifically, the NR valley decreased in frequency as the air gap thickness increased. Also, the NR curves of the double wall constructions displayed a clear bridge frequency in which the slope of the NR curves changes from $18 \mathrm{~dB}$ per octave to $6 \mathrm{~dB}$ per octave, as discussed in the literature. Despite the similarities between available theory and the experimental results, discrepancies were discovered. The mass-air-mass resonant frequency was over predicted by the equation offered in the literature. The better predictor for the NR valley near the mass-air-mass frequency was the frequency at which the two plates display synchronous plate vibration as revealed by experimental modal analysis. Furthermore, Modal Assurance Criterion (MAC) was used to investigate the degree of synchronicity between the source and receiving plates and there is a concentration of high MAC values near the mass-air-mass NR valley for the $1.9 \mathrm{~mm}$ air gap. An additional discrepancy between existing theory and the experimental results is 
the over prediction of the bridge frequency for both air gap configurations. The bridge frequency was over predicted for the $1.9 \mathrm{~mm}$ gap by approximately $1200 \mathrm{~Hz}$ and by approximately $500 \mathrm{~Hz}$ for the $3.8 \mathrm{~mm}$ gap. The bridge frequency was better predicted by examining the acceleration plots of the two plates while excited by sound during NR experiments, where it was observed that the two plates display significantly reduced vibration amplitudes at frequencies above the observed bridge frequency. Lastly, there was an unexpected NR peak at $315 \mathrm{~Hz}$ for all four constructions. After investigation of the plate acceleration of the four constructions, it is apparent that there is increased excitation in the frequency region near the NR peak at $315 \mathrm{~Hz}$ for all four constructions. This leads to the conclusion that the test setup was responsible for the unexpected peak at $315 \mathrm{~Hz}$. 


\section{RECOMMENDATIONS}

Further study should be conducted understand the correlation between the massair-mass resonant frequency NR valley and synchronous plate motion in experimental modal analysis. Increased understanding may be accomplished by performing these experiments on construction type materials (plywood, gypsum and glass) and air gaps from $2 \mathrm{~mm}$ to $100 \mathrm{~mm}$. This would allow the experimental modal analysis and accompanying NR to be more easily compared to existing theory. Similar study could be conducted regarding the correlation between the bridge frequency and plate acceleration. 


\section{REFERENCES}

[1] C. E. Wilson, Noise Control: Measurement, Analysis, and Control of Sound and Vibration, Malabar, Florida: Krieger Publishing Company, 1989.

[2] F. Fahy and P. Gardonio, Sound and Structural Vibration: Radiation, Transmission and Response, 2nd ed., New Delhi: Elsevier, 2007.

[3] C. Hansen, Noise Control: From Concept to Application, London: Taylor \& Francis Group, 2005.

[4] V. Hongisto, M. Lindgren and R. Helenuis, "Sound Insulation of Double Walls An Experimental Parametric Study," Acta Acustica United with Acustica, vol. 2002, pp. 904-923, 2002.

[5] J. D. Quirt, "Sound Transmission Through Windows I. Single and Double Glazing," Journal of the Acoustical Society of America, vol. 72, no. 3, pp. 834844, 1982.

[6] J. D. Quirt, "Sound Transmission Through Windows II. Double and Triple Glazing," Journal of the Acoustical Society of America, vol. 74, no. 2, pp. 534$542,1983$.

[7] E. C. Sewell, "Two-Dimensional Solution for Transmission of Reverberant Sound Through a Double Partition," Journal of Sound and Vibration, vol. 12, no. 1, pp. 33-57, 1970.

[8] J. L. Davy, "Sound transmission of cavity walls due to structure borne transmission via point and line connections," Journal of the Acoustical Society of America, vol. 132, no. 2, pp. 814-821, 2012.

[9] A. London, "Transmission of Reverberant Sound Through Double Walls," Journal of Research on the National Bureau of Standards, vol. 44, 1950. 
[10] W. A. Utley and B. L. Fletcher, "The Effect of Edge Conditions on the Sound Insulation of Double Windows," Journal of Sound and Vibration, vol. 26, no. 1, pp. 63-72, 1973.

[11] American Society for Testing and Materials (ASTM), ASTM E90-09: Standard Test Method for Laboratory Measurement of Airborne Sound Transmission Loss of Building Partitions and Elements.

[12] T. Kihlman and A. C. Nilsson, "The Effects of Some Laboratory Designs and Mounting Conditions on Reduction Index Measurements," Journal of Sound and Vibration, vol. 24, no. 3, pp. 349-364, 1972.

[13] F. X. Xin and T. J. Lu, "Analytical and Experimental Investigation on Transmission Loss of Clamped Double Panels: Implication of Boundary Effects," Journal of the Acousitcal Society of America, vol. 125, no. 3, pp. 1507-1517, 2009.

[14] "Acoustic Performance," U.S. Green Building Council (USGBC), Leadership in Energy and Environmental Design (LEED), [Online]. Available: http://www.usgbc.org/credits/eq10.

[15] Soundproofing Company Inc: Noise Control for Real Life, "Soundproofing 101," [Online]. Available: http://www.soundproofingcompany.com/soundproofing101/. [Accessed 27 January 2014].

[16] E. C. Sewell, "Transmission of Reverberant Sound Through a Single-Leaf Partition Surrounded by and Infinite Rigid Baffle," Journal of Sound and Vibration, vol. 12, no. 1, pp. 21-32, 1970.

[17] A. Nilsson and T. Kihlman, "Influence of Boundary Conditions Upon the Reduction Index of a Wall Between Two Rectangular Rooms," in Seventh International Congress on Acoustics, Budapest, 1971.

[18] J. S. Lamancusa, "Transmission of Sound Through Structures," [Online]. Available: http://www.me.psu.edu/lamancusa/me458/9_trans.pdf. [Accessed 15 November 2014].

[19] C. M. Harris and A. G. Pierson, Harris' Shock and Vibration Handbook, McGrawHill, 2002.

[20] R. J. Allemang, "The Modal Assurance Criterion - Twenty Years of Use and Abuse," Journal of Sound and Vibration, vol. 37, no. 8, pp. 14-23, 2003. 
[21] American Society for Testing and Materials, ASTM E413-04: Classification for Rating Sound Insulation.

[22] American Society for Testing and. Materials, ASTM E1332-10a: Standard Classification for Rating Outdoor-Indoor Sound Attenuation.

[23] "Overview of mateirals for Low Carbon Steel," MatWeb - Material Property Data , [Online]. Available:

http://www.matweb.com/search/DataSheet.aspx?MatGUID=034970339dd14349a 8297d2c83134649\&ckck=1. [Accessed 4 November 2014]. 


\section{APPENDIX A: Calculation of Sound Power from Sound Pressure}

Laboratory configuration used for this testing utilized reference sound power source located on the floor of the reverberation (receiving) room. The equations below reflect the conversion of sound pressure to sound power for this testing.

$$
\frac{\mathrm{w}}{\mathrm{w}_{\mathrm{ref}}}=\frac{\mathrm{p}^{2}}{\mathrm{p}_{\mathrm{ref}}{ }^{2}} * \frac{2 \pi \mathrm{r}^{2}}{\rho v} * S
$$

where:

$$
\begin{aligned}
& \mathrm{w}=\text { sound power }(\text { Watts }) \\
& \mathrm{W}_{\text {ref }}=\text { reference sound power }(1 \times 10-12 \text { Watts }) \\
& \mathrm{p}=\text { sound pressure }(\mathrm{Pa}) \\
& \mathrm{p}_{\text {ref }}=\text { reference sound pressure }(20 \times 10-6 \mathrm{~Pa}) \\
& \mathrm{r}=\text { radius of hemisphere radiating } \\
& \mathrm{S}=\text { acoustic impedance of air }(400 P a * \mathrm{~S} / \mathrm{m})
\end{aligned}
$$


APPENDIX B: One Third Octave Band Ranges and Center Frequencies

\begin{tabular}{|c|c|c|}
\hline Lower Band Limit (Hz) & Center Frequency $(\mathrm{Hz})$ & Upper Band Limit (Hz) \\
\hline 89.1 & 100 & 112 \\
\hline 112 & 125 & 141 \\
\hline 141 & 160 & 178 \\
\hline 178 & 200 & 224 \\
\hline 224 & 250 & 282 \\
\hline 282 & 315 & 355 \\
\hline 355 & 400 & 447 \\
\hline 447 & 500 & 562 \\
\hline 562 & 630 & 708 \\
\hline 708 & 800 & 891 \\
\hline 891 & 1000 & 1122 \\
\hline 1122 & 1250 & 1413 \\
\hline 1413 & 1600 & 1778 \\
\hline 1778 & 2000 & 2239 \\
\hline 2239 & 2500 & 2818 \\
\hline 2818 & 3150 & 3548 \\
\hline 3548 & 4000 & 4467 \\
\hline 4467 & 5000 & 5623 \\
\hline
\end{tabular}

Table 4. One third octave band ranges and center frequencies 


\section{APPENDIX C: Method of Calculating STC [1]}

Sound transmission class (STC) is calculated by comparing transmission loss measured in the laboratory at each third octave band with the standard STC contour, following ASTM E413 (Classification for Rating Sound Insulation) [21]. The contour is composed of line segments of varying slope. The first segment is from $125 \mathrm{~Hz}$ to $400 \mathrm{~Hz}$ and has a slope of $3 \mathrm{~dB}$ per one third octave. The second segment is from $400 \mathrm{~Hz}$ to 1250 $\mathrm{Hz}$ and has a slope of $1 \mathrm{~dB}$ per one third octave. The final segment is from $1250 \mathrm{~Hz}$ to $4000 \mathrm{~Hz}$ and has a slope of $0 \mathrm{~dB}$ per one third octave. The TL at $500 \mathrm{~Hz}$ is equal to the STC value of the standard STC contour. A sample curve of STC 40 is shown below.

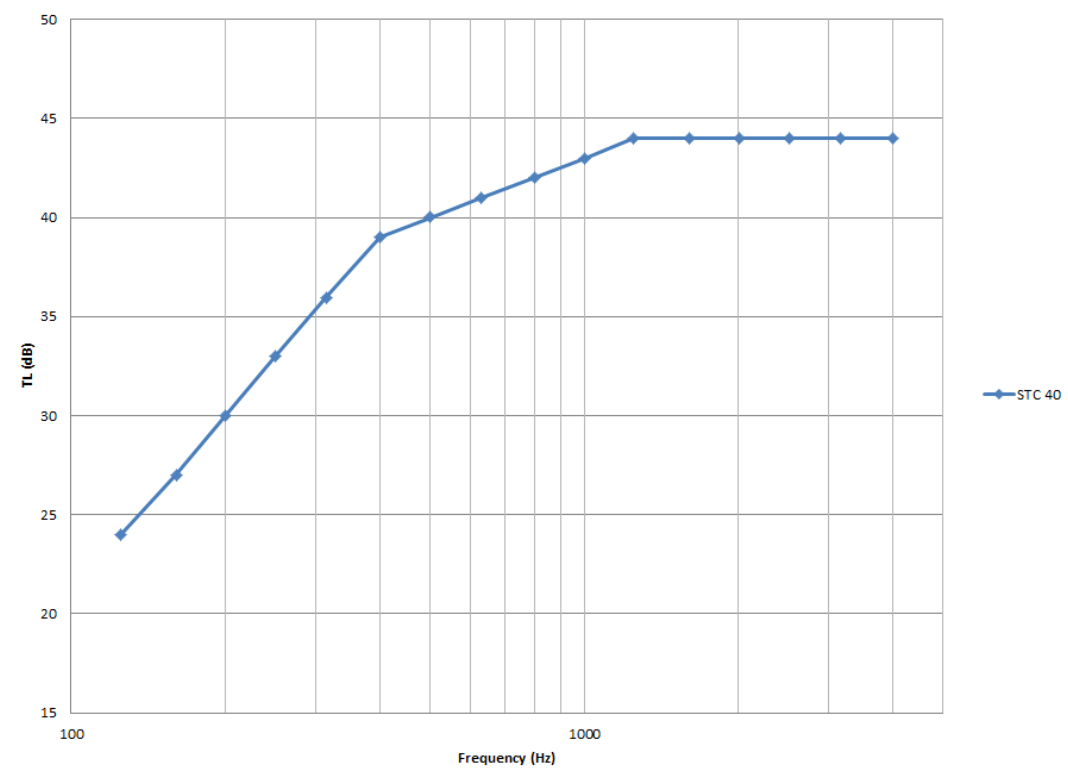

Figure 36. STC 40 contour.

The measured TL of the specimen is compared to the contour for a given STC, where any measured value that is below the contour is referred to as a deficiency. The deficiency is quantified as the $\mathrm{dB}$ difference between the contour and the measured value. 
For example, if the measure value at $500 \mathrm{~Hz}$ is $37 \mathrm{~dB}$, then there are 3 deficiencies at 500 Hz. To determine if the specimen meets an STC, the deficiencies across the entire frequency range $(125 \mathrm{~Hz}$ to $4000 \mathrm{~Hz})$ are added and the sum cannot exceed 32 for the given STC. Additionally, no single one third octave band can have a measured value more than $8 \mathrm{~dB}$ below the STC contour. The STC for the specimen is the highest STC in which both requirements are met. 


\section{APPENDIX D: Method of Calculating OITC [22]}

The method for determining the OITC requires transmission loss data from 80 to $4000 \mathrm{~Hz}$ and requires A-weighting. Below is a table that is used to determine OITC.

\begin{tabular}{|c|c|c|c|c|c|}
\hline Column 1 & Column 2 & Column 3 & Column 4 & Column 5 & Column 6 \\
\hline $\begin{array}{c}\text { Band Center } \\
(\mathrm{Hz})\end{array}$ & $\begin{array}{c}\text { Reference } \\
\text { Sound } \\
\text { Spectrum } \\
(\mathrm{dB})\end{array}$ & $\begin{array}{c}\text { A- } \\
\text { weighting } \\
\text { correction } \\
(\mathrm{dB})\end{array}$ & $\begin{array}{c}\text { Column 2 } \\
\text { Column 3 }\end{array}$ & $\begin{array}{c}\text { Transmission } \\
\text { Loss (dB) }\end{array}$ & $\begin{array}{c}\text { Column 4 - } \\
\text { Column 5 }\end{array}$ \\
\hline 80 & 103 & -22.5 & 80.5 & & \\
\hline 100 & 102 & -19.1 & 82.9 & & \\
\hline 125 & 101 & -16.1 & 84.9 & & \\
\hline 160 & 98 & -13.4 & 84.6 & & \\
\hline 200 & 97 & -10.9 & 86.1 & & \\
\hline 250 & 95 & -8.6 & 86.4 & & \\
\hline 315 & 94 & -6.6 & 87.4 & & \\
\hline 400 & 93 & -4.8 & 88.2 & & \\
\hline 500 & 93 & -3.2 & 89.8 & & \\
\hline 630 & 91 & -1.9 & 89.1 & & \\
\hline 900 & 90 & -0.8 & 89.2 & & \\
\hline 1000 & 89 & 0 & 89.0 & & \\
\hline 1250 & 89 & 0.6 & 89.6 & & \\
\hline 1600 & 88 & 1.0 & 89.0 & & \\
\hline 2000 & 88 & 1.2 & 89.2 & & \\
\hline 2500 & 87 & 1.3 & 88.3 & & \\
\hline 3150 & 85 & 1.2 & 86.2 & & \\
\hline 4000 & 84 & 1.0 & 85.0 & & \\
\hline
\end{tabular}

Table 5. Table for calculating OITC

After entering the transmission loss values in the table (column 5) and completing the calculation for each one third octave band in column 6, the following calculation are made. 
Sum Column $\left.4(d B A)=10 \log \sum_{f} 10^{\left({ }^{\text {Column }} 4_{f} / 10\right.}\right)=100.13 d B$

Sum Column $\left.6(d B A)=10 \log \sum_{f} 10^{\left(\text {Column }_{f} / 10\right.}\right)$

$$
\text { OITC Rating }=100.13 \mathrm{~dB}-(\text { Sum Column } 6)
$$

The summation terms in Equation (17) and Equation (18) refer to $f$, the center frequency of each third octave band. The final result is the solution to Equation (19), which is a single number that can be used to evaluate the sound barrier quality, with higher OITC corresponding to better sound barrier performance. 
APPENDIX E: Drawings Used to Create the Test Specimen and Frame

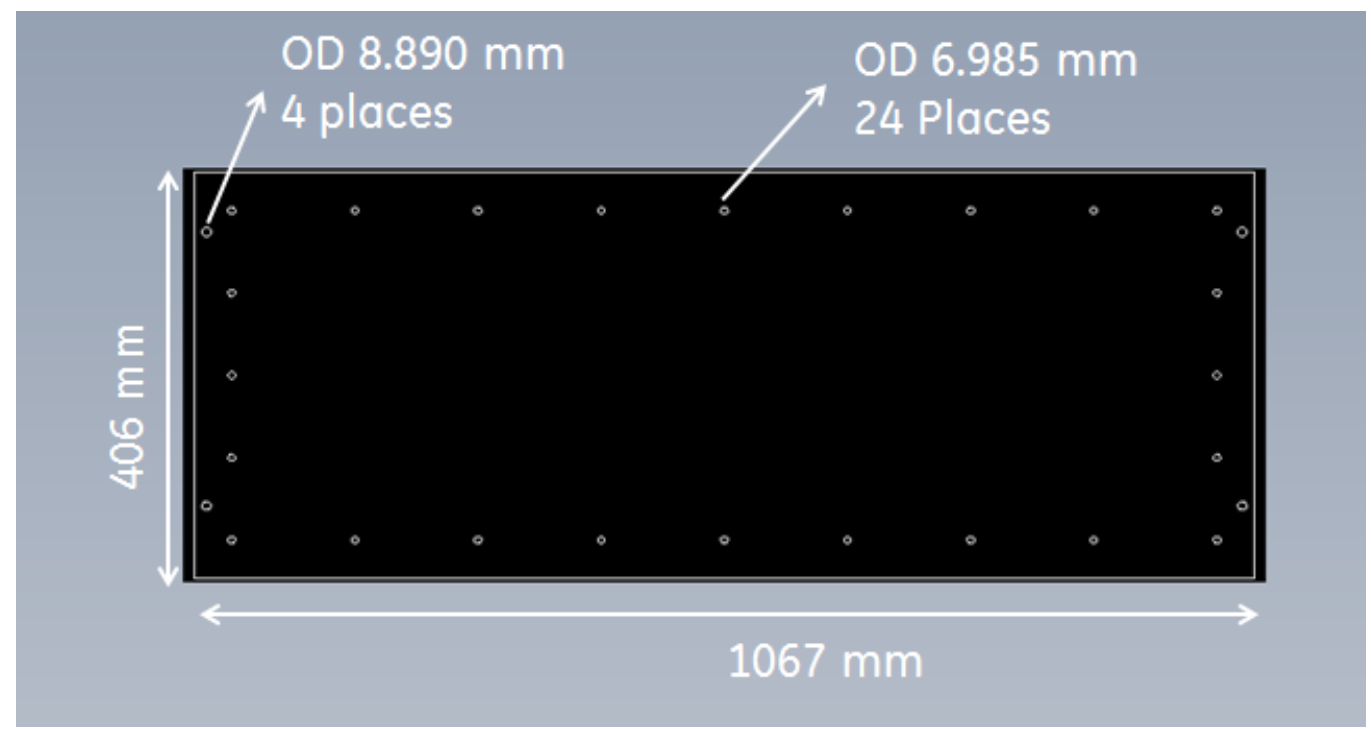

Figure 37. Drawing used to cut test specimen.

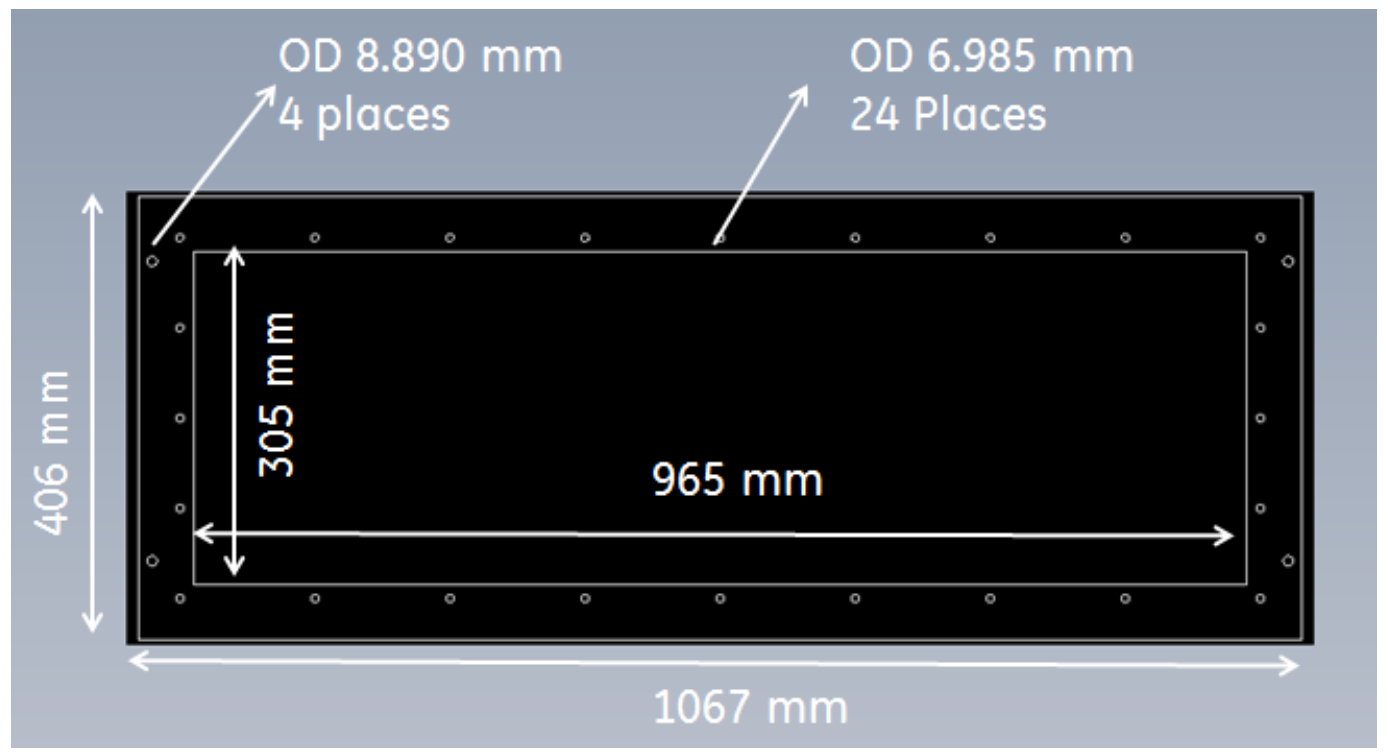

Figure 38. Drawing used to cut frame.

Note that the 24 holes measuring $6.985 \mathrm{~mm}$ in diameter are used for the bolts to clamp the test specimen together. The four $8.890 \mathrm{~mm}$ holes are used to mount the entire fixture to the filler wall. 
APPENDIX F: Values of the Constants for Equations 6 and 7

\begin{tabular}{|c|c|c|}
\hline Constant & Value & Units \\
\hline E, Young's Modulus [23] & 200 & $\mathrm{GPa}$ \\
\hline h, plate thickness & 0.6 or 1.2 & $\mathrm{~mm}$ \\
\hline v, Poisson's Ratio & 0.29 & $\mathrm{~m} / \mathrm{s}^{2}$ \\
\hline g, acceleration due to & 9.81 & $\mathrm{~N} / \mathrm{m}^{3}$ \\
\hline gravity & & $\mathrm{mm}$ \\
\hline$\rho$, density [23] & 76518 & \\
\hline a, plate height & 305 & \\
\hline
\end{tabular}

Table 6. Values of constants in Equations 6 and 7 
APPENDIX G: FEM Mode Shapes (First 4 Mode Shapes of Single Plates) and Experimental Modal Analysis (First 4 Mode Shapes of all Configurations)

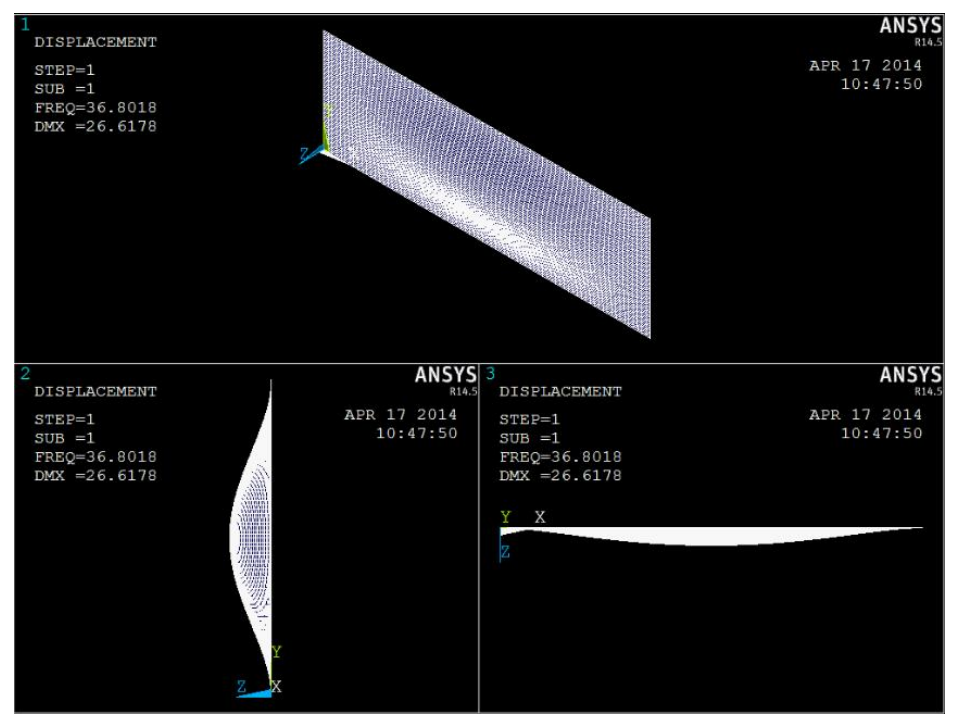

Figure 39. FEM first mode shape for $0.6 \mathrm{~mm}$ plate $(36.8 \mathrm{~Hz})$.

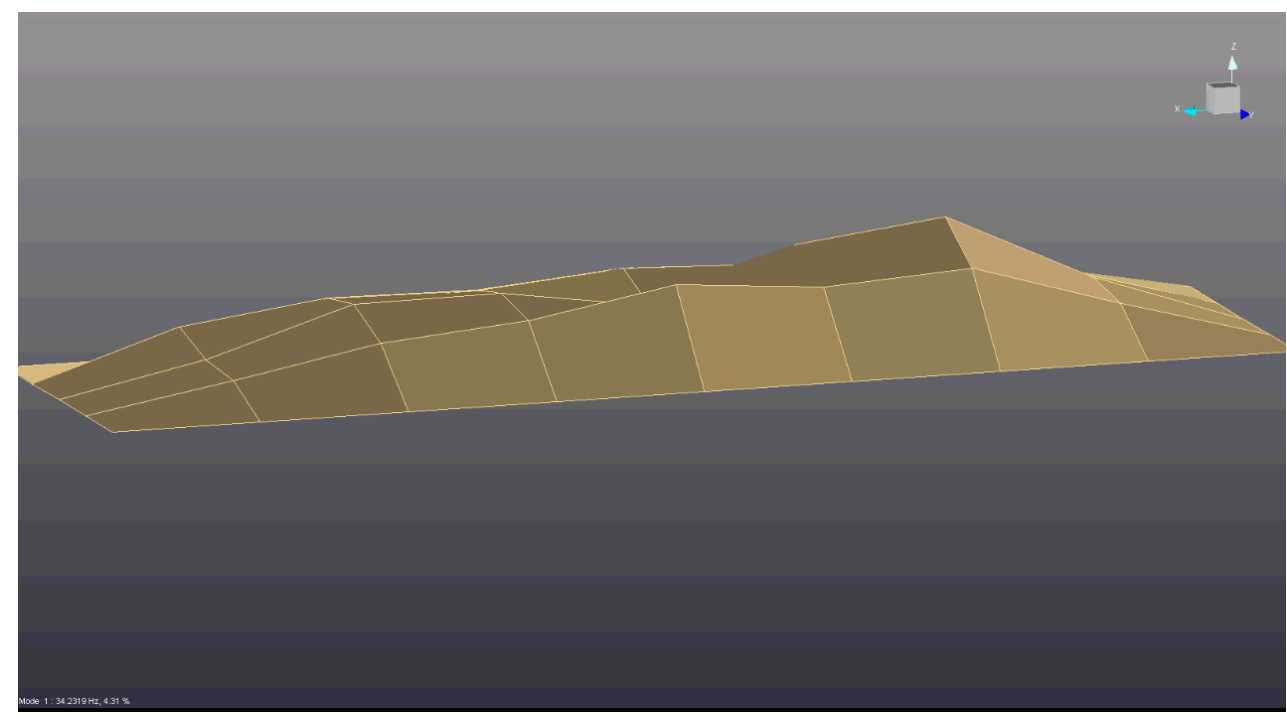

Figure 40. EMA first mode shape for $0.6 \mathrm{~mm}$ plate $(34.2 \mathrm{~Hz})$. 


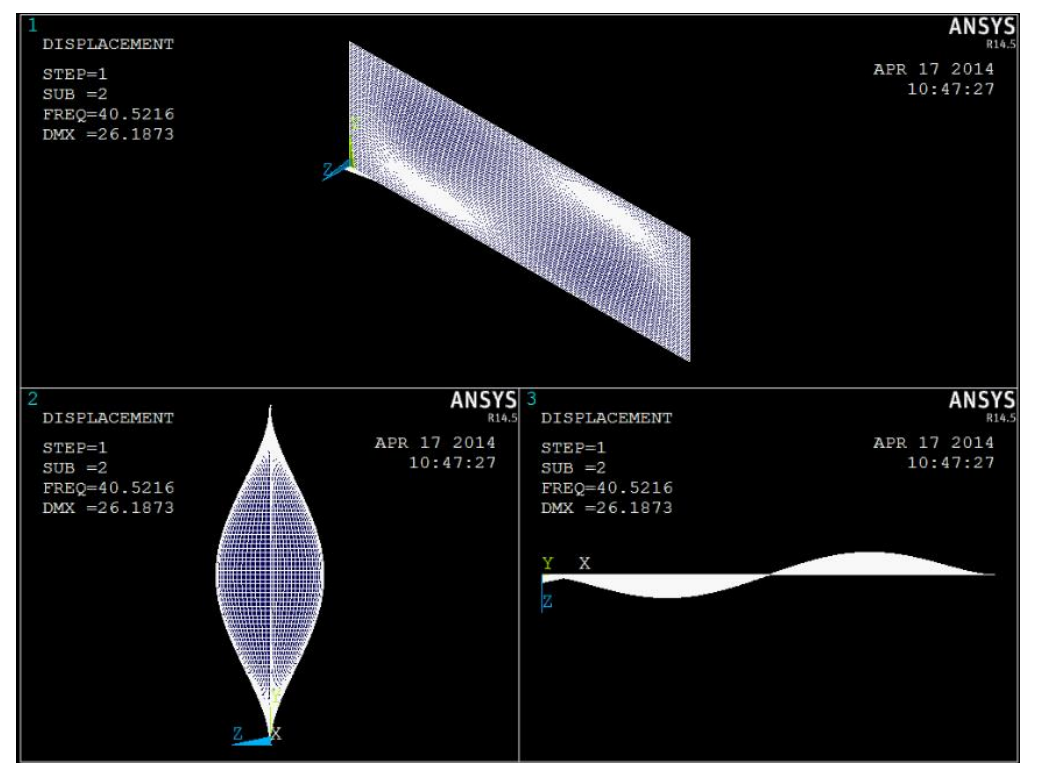

Figure 41. FEM second mode shape for $0.6 \mathrm{~mm}$ plate $(40.5 \mathrm{~Hz})$.

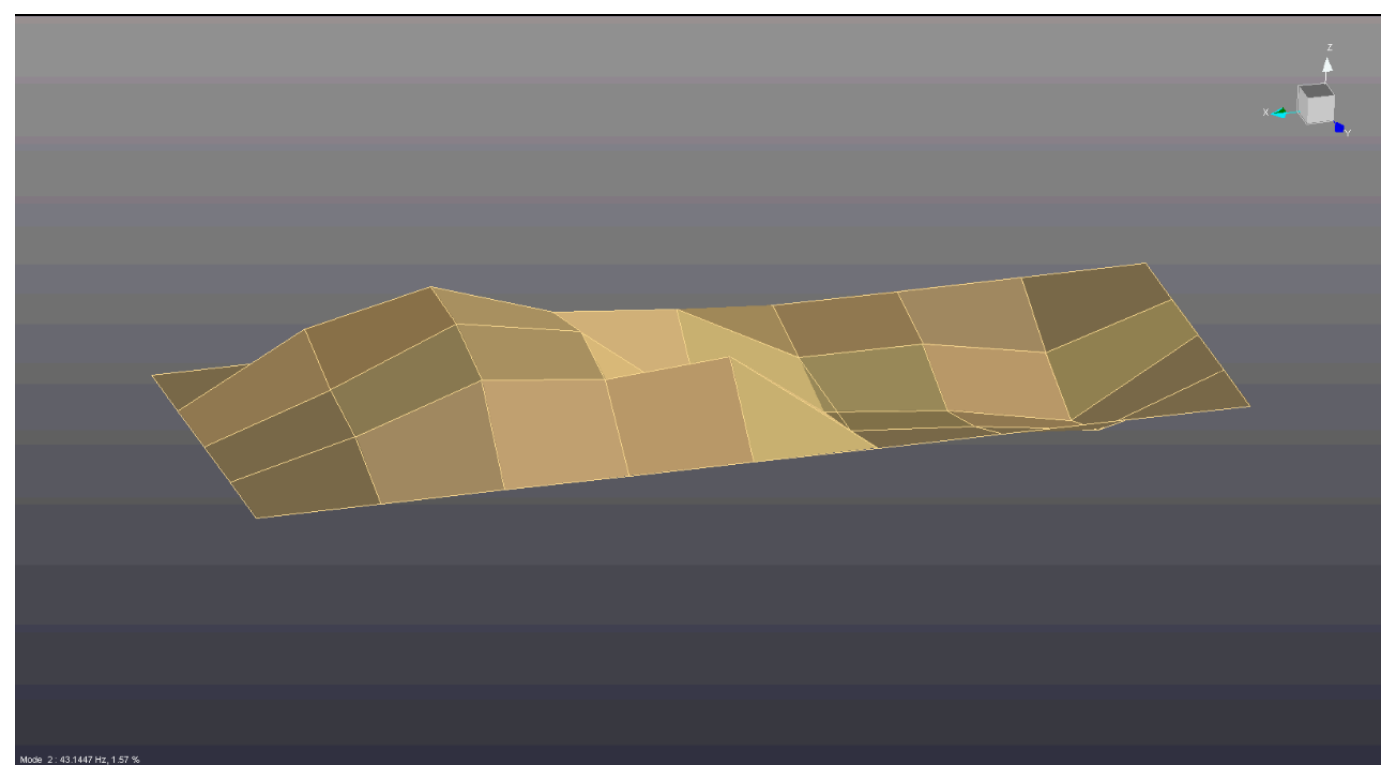

Figure 42. EMA second mode shape for $0.6 \mathrm{~mm}$ plate $(43.1 \mathrm{~Hz})$. 


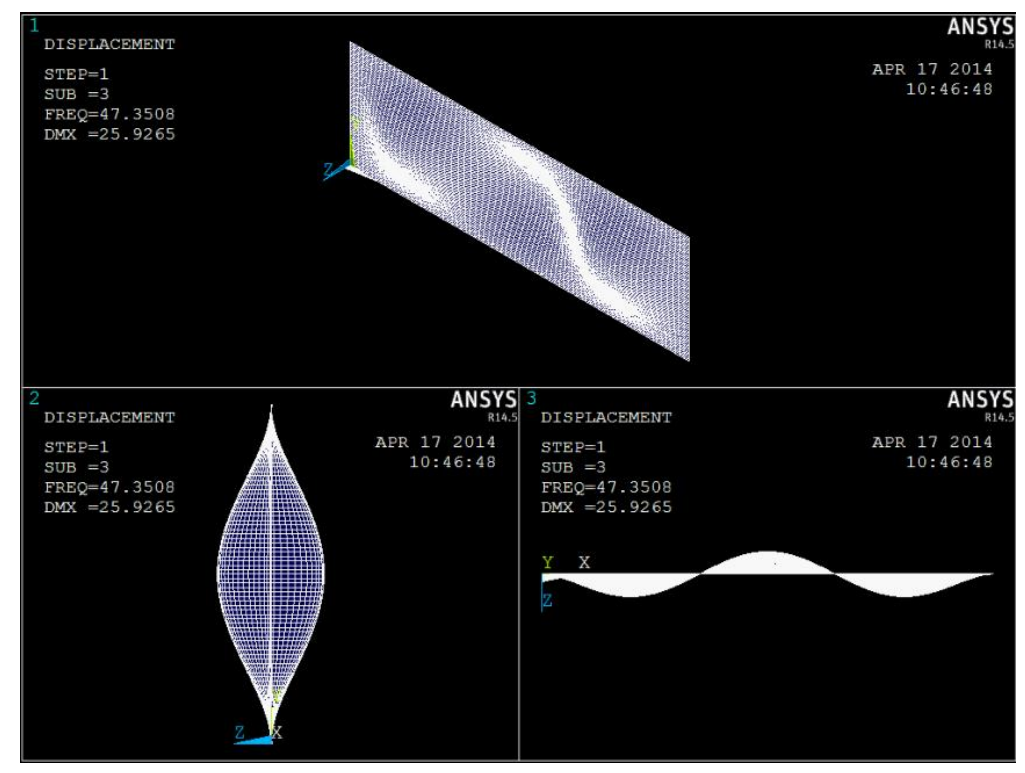

Figure 43. FEM third mode shape for $0.6 \mathrm{~mm}$ plate $(47.4 \mathrm{~Hz})$.

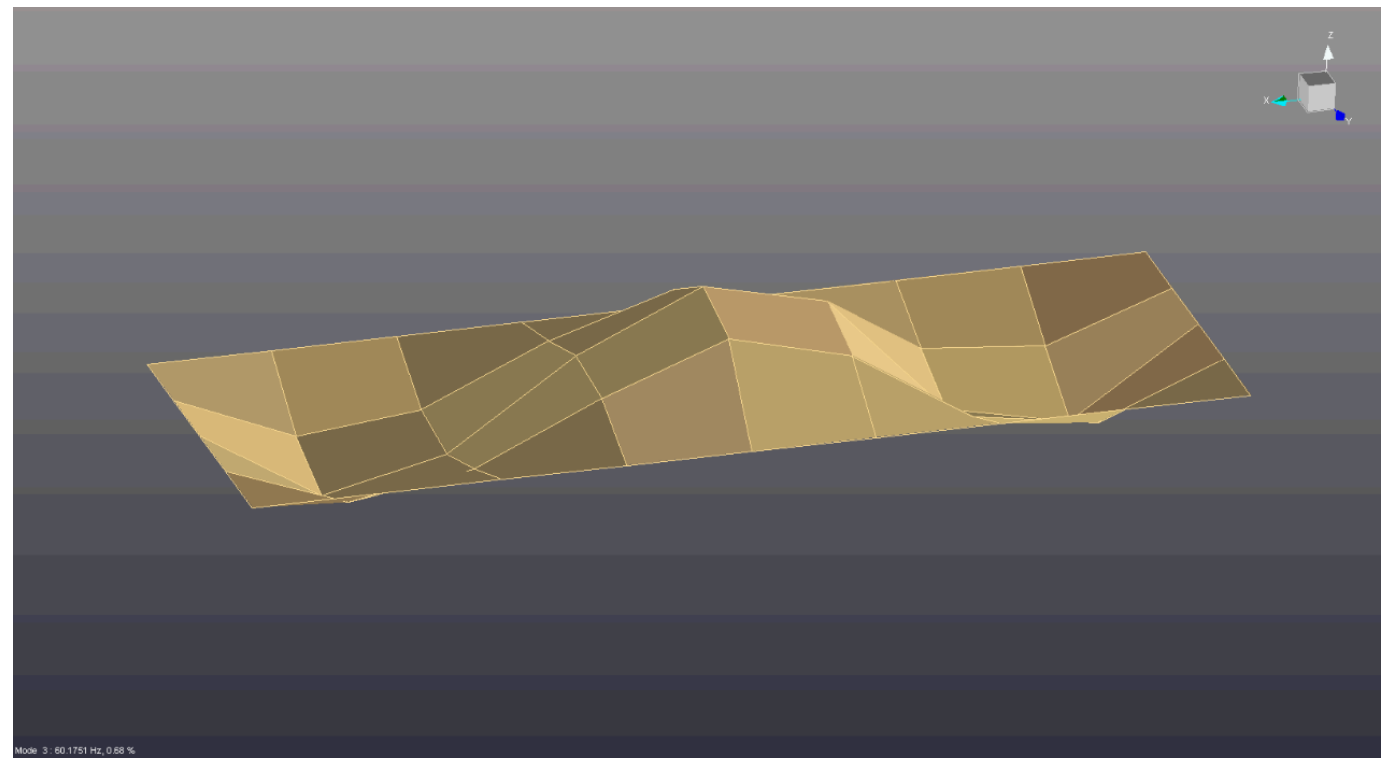

Figure 44. EMA third mode shape for $0.6 \mathrm{~mm}$ plate $(60.2 \mathrm{~Hz})$. 


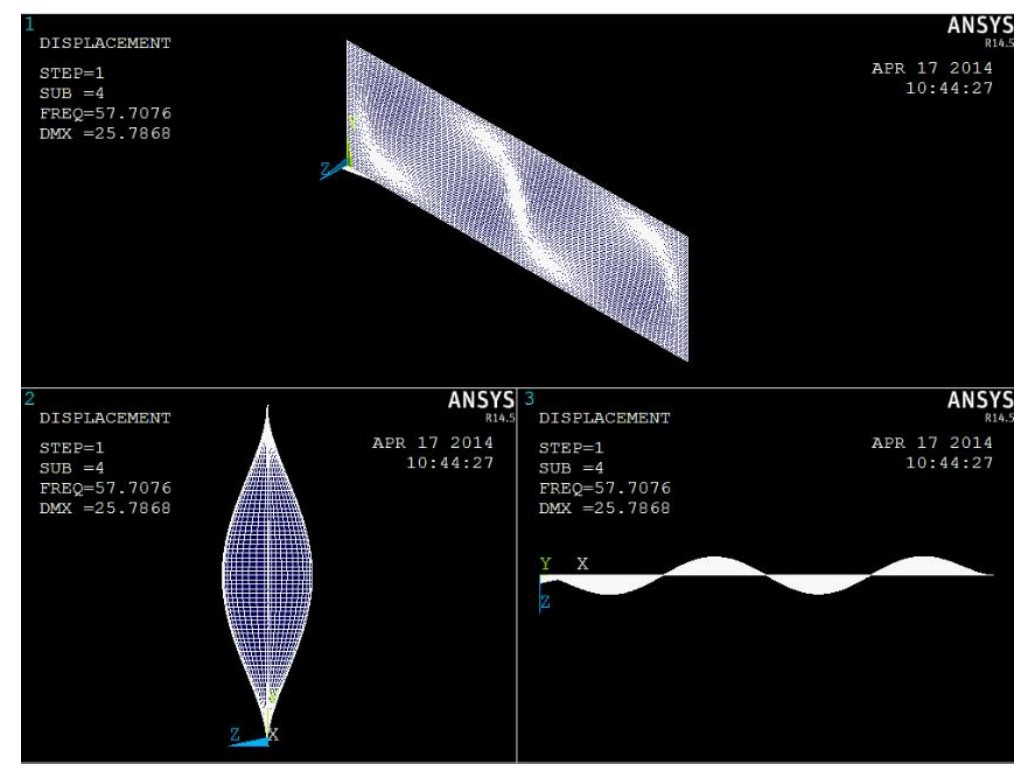

Figure 45 . FEM fourth mode shape for $0.6 \mathrm{~mm}$ plate $(57.7 \mathrm{~Hz})$.

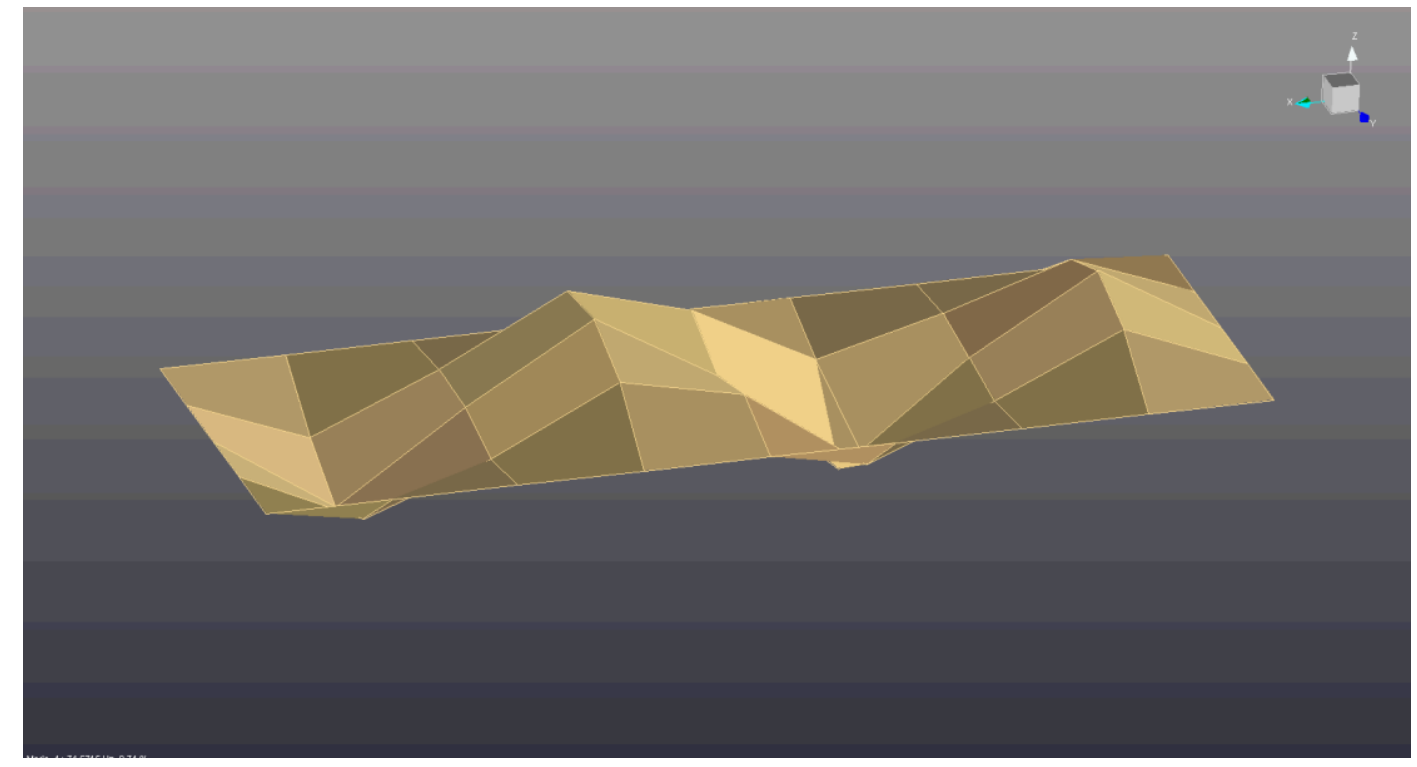

Figure 46. EMA fourth mode shape for $0.6 \mathrm{~mm}$ plate $(74.5 \mathrm{~Hz})$. 


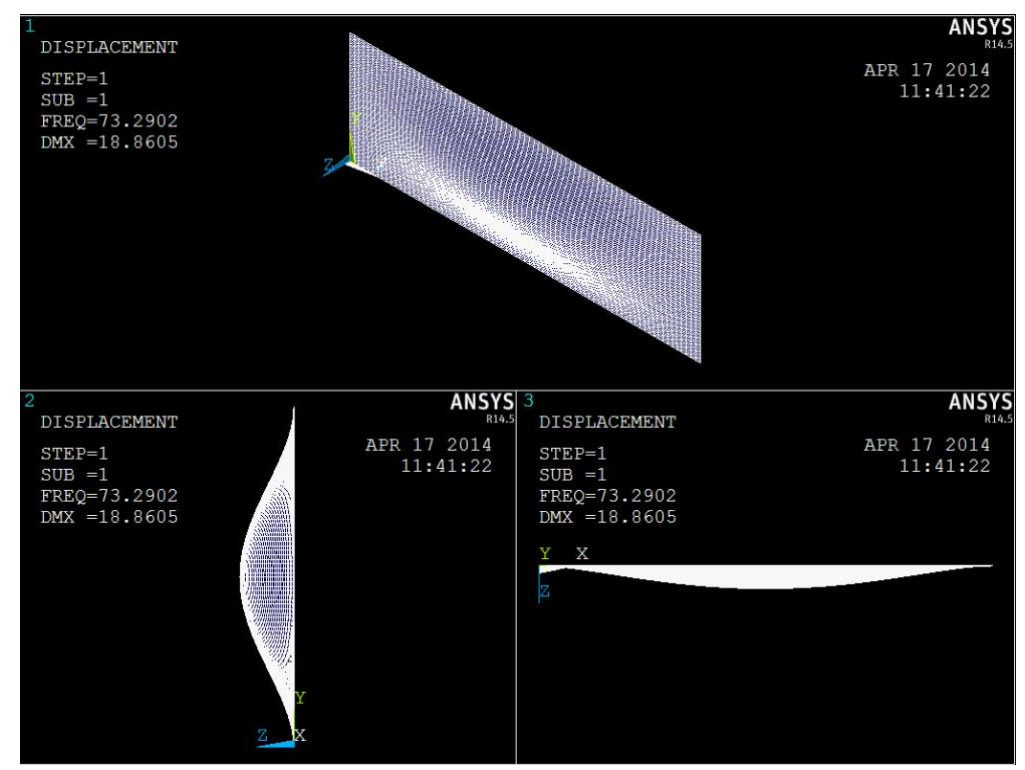

Figure 47. FEM first mode shape for $1.2 \mathrm{~mm}$ plate $(73.3 \mathrm{~Hz})$.

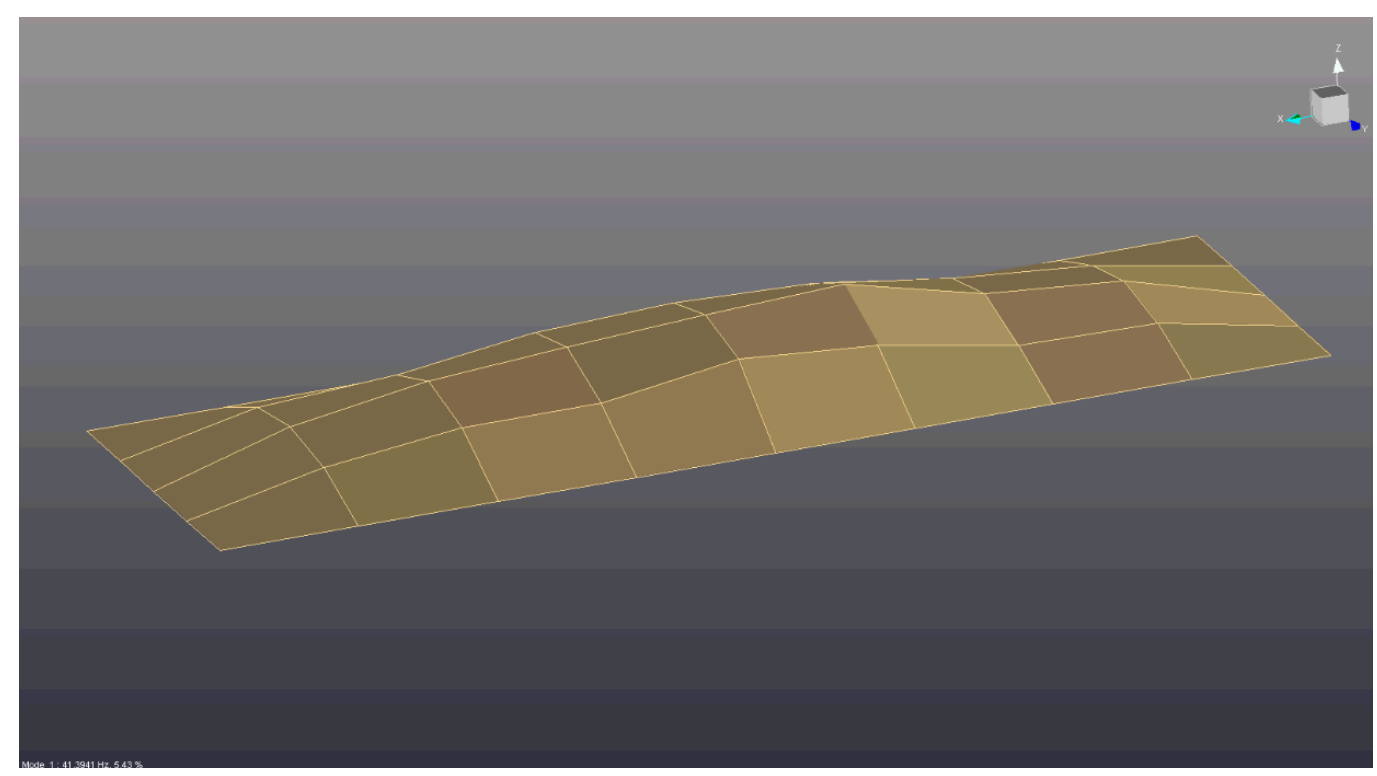

Figure 48. EMA first mode shape for $1.2 \mathrm{~mm}$ plate $(41.4 \mathrm{~Hz})$. 


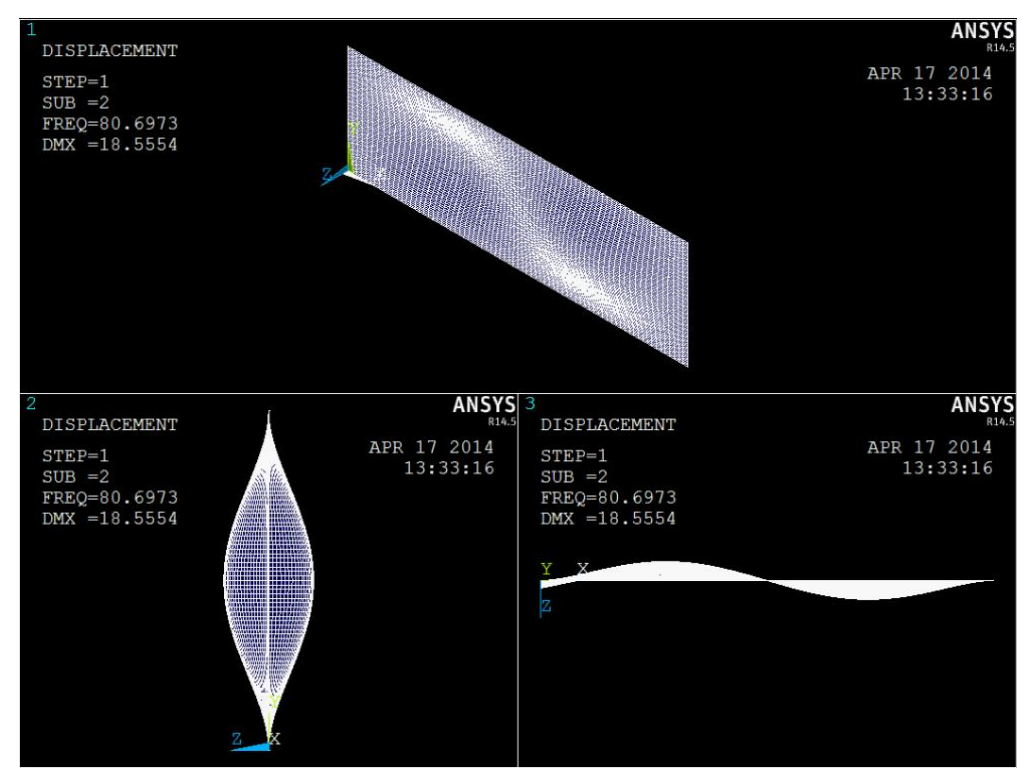

Figure 49. FEM second mode shape for $1.2 \mathrm{~mm}$ plate $(80.7 \mathrm{~Hz})$.

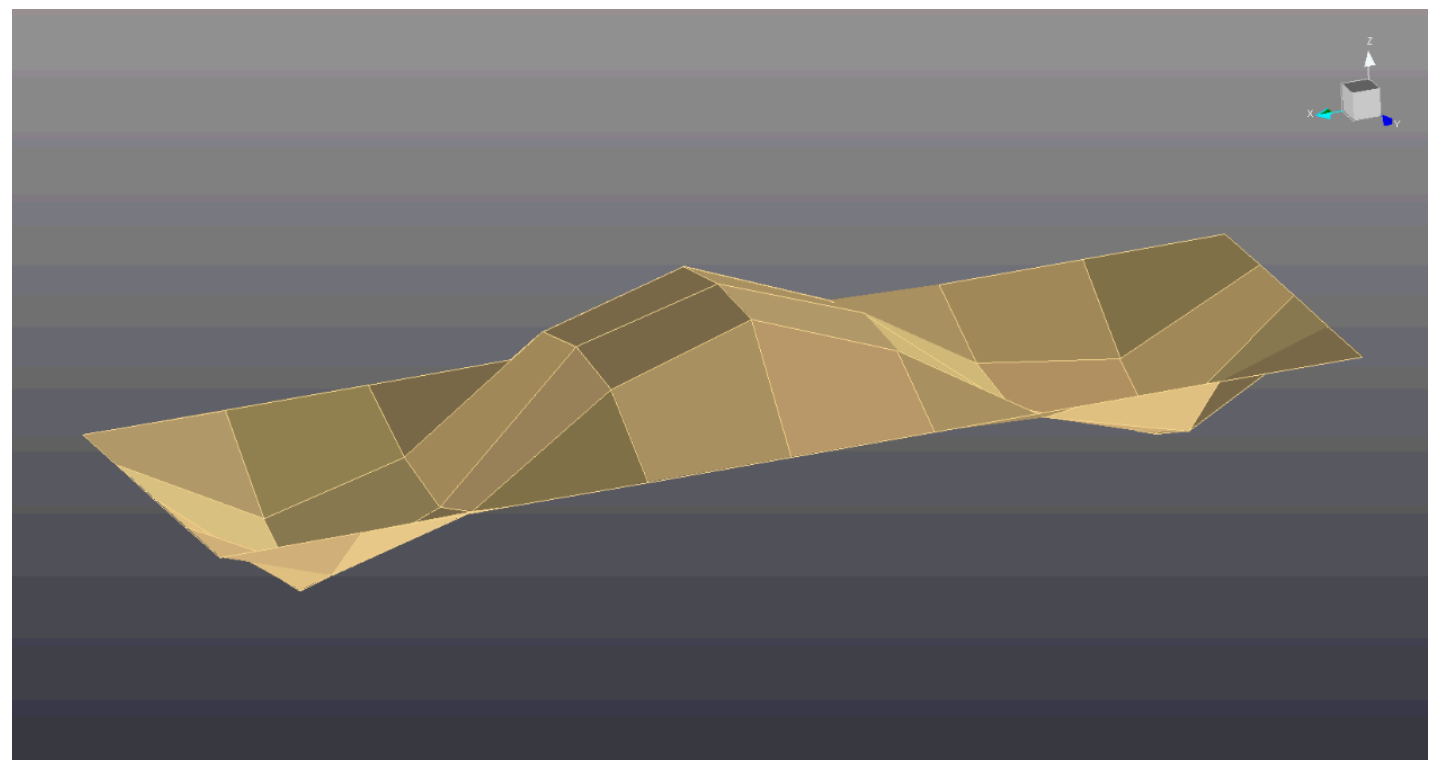

Figure 50. EMA second mode shape for $1.2 \mathrm{~mm}$ plate $(76.3 \mathrm{~Hz})$. 


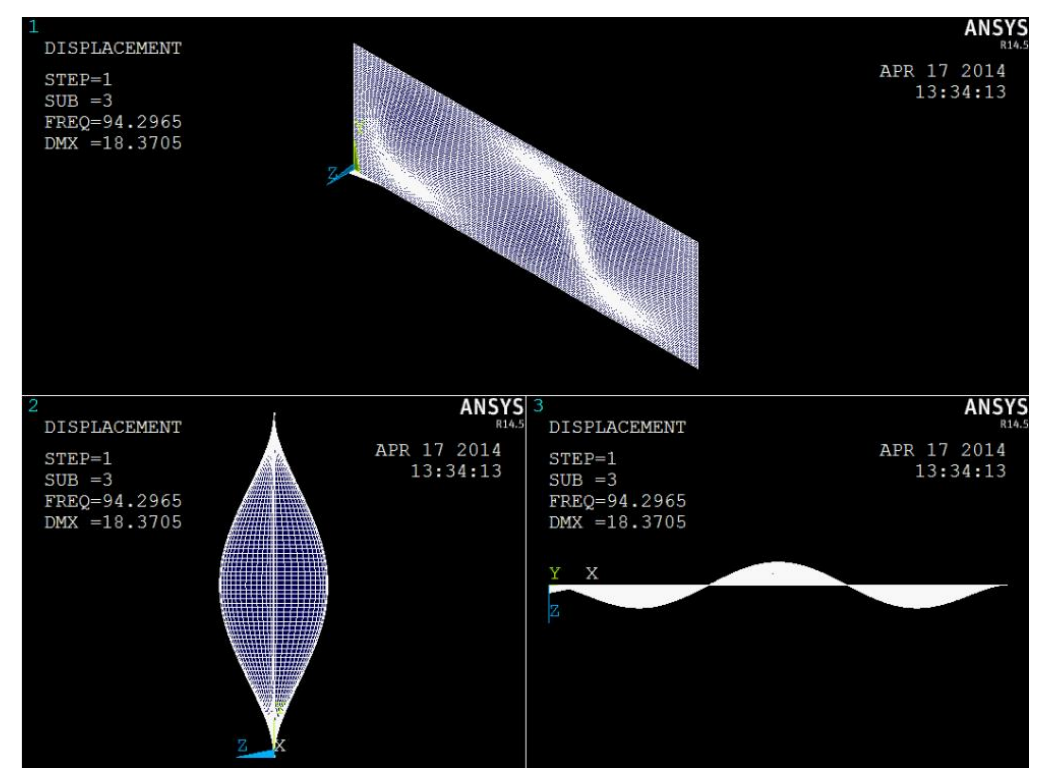

Figure 51: FEM third mode shape for $1.2 \mathrm{~mm}$ plate $(94.3 \mathrm{~Hz})$.

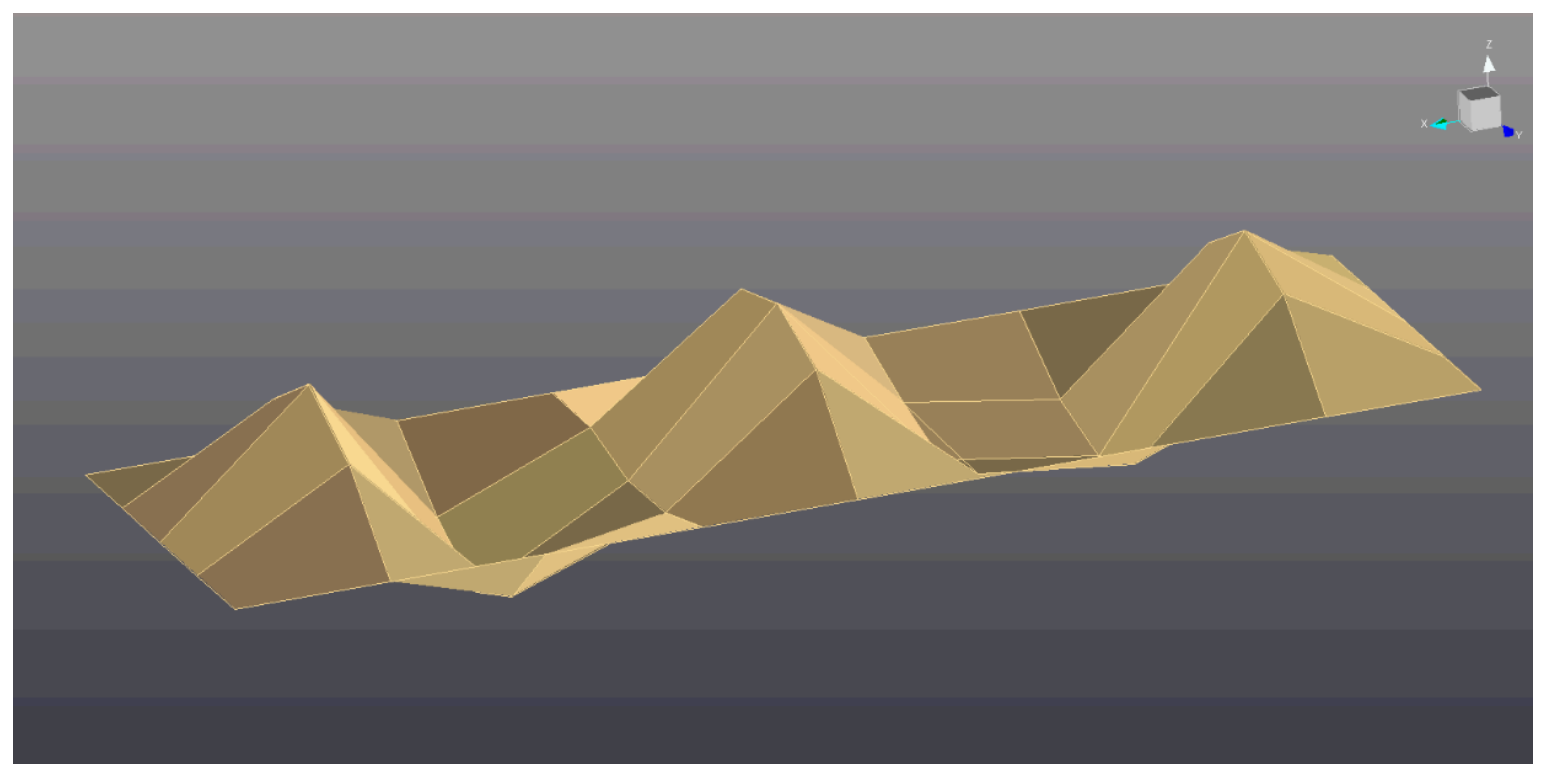

Figure 52. EMA third mode shape for $1.2 \mathrm{~mm}$ plate (130.2). 


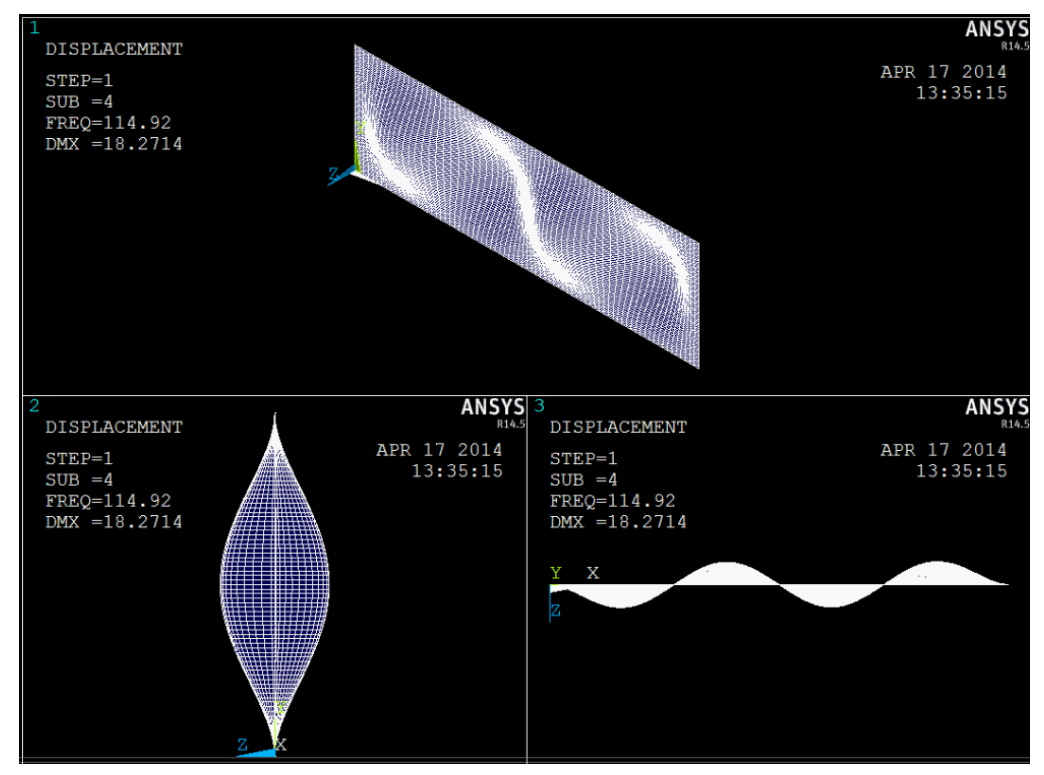

Figure 53. FEM fourth mode shape for $1.2 \mathrm{~mm}$ plate $(114.9 \mathrm{~Hz})$.

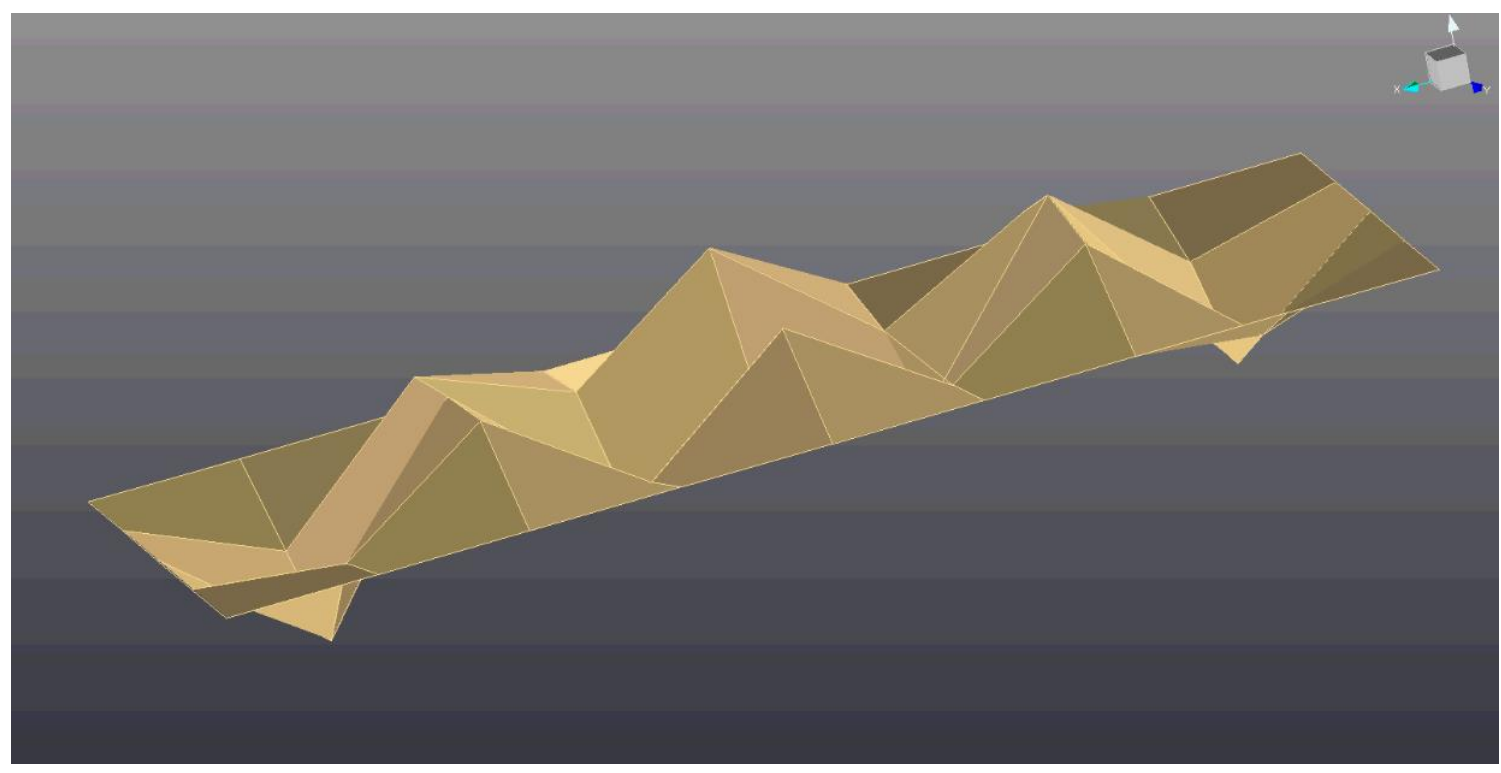

Figure 54. EMA fourth mode shape for $1.2 \mathrm{~mm}$ plate $(261.6 \mathrm{~Hz})$. 


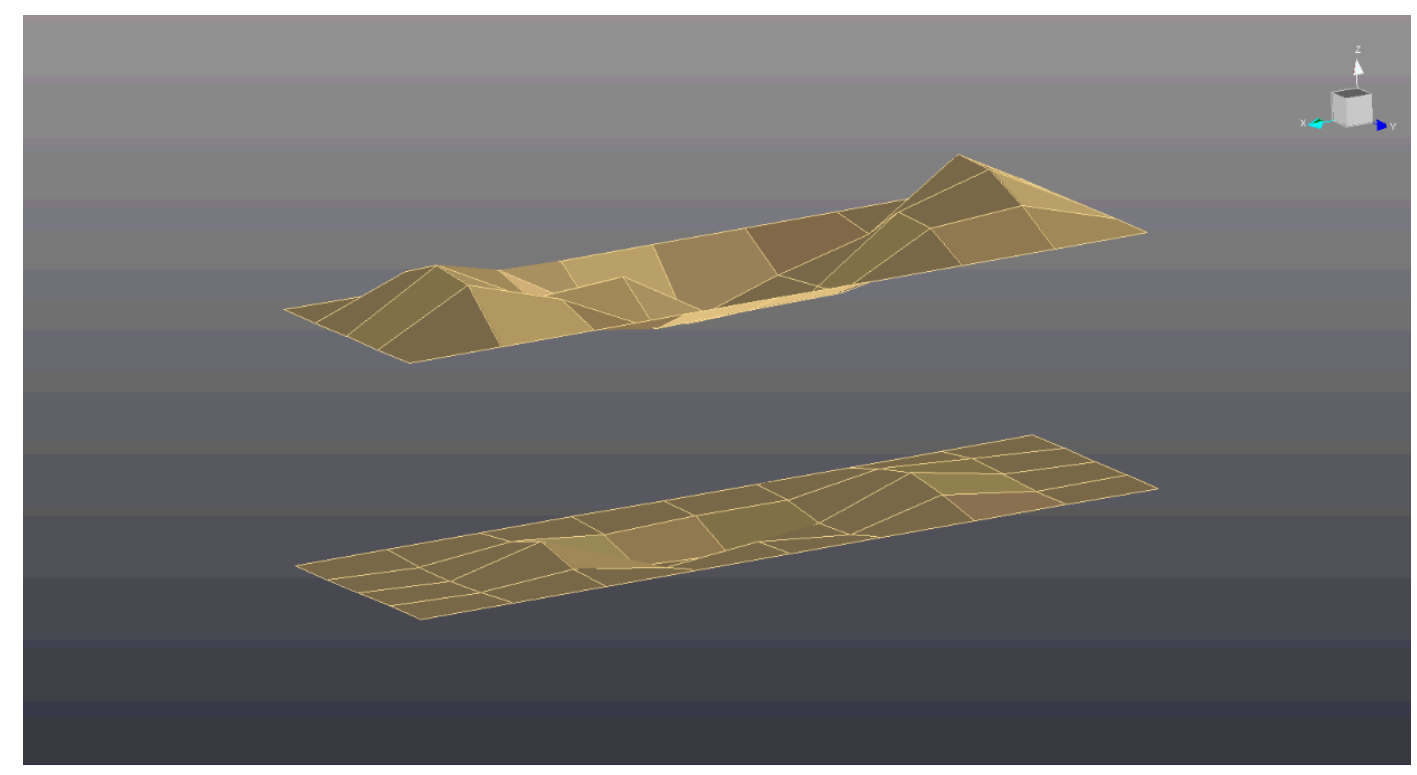

Figure 55. EMA first mode shape $1.9 \mathrm{~mm}$ air gap $(34.6 \mathrm{~Hz})$.

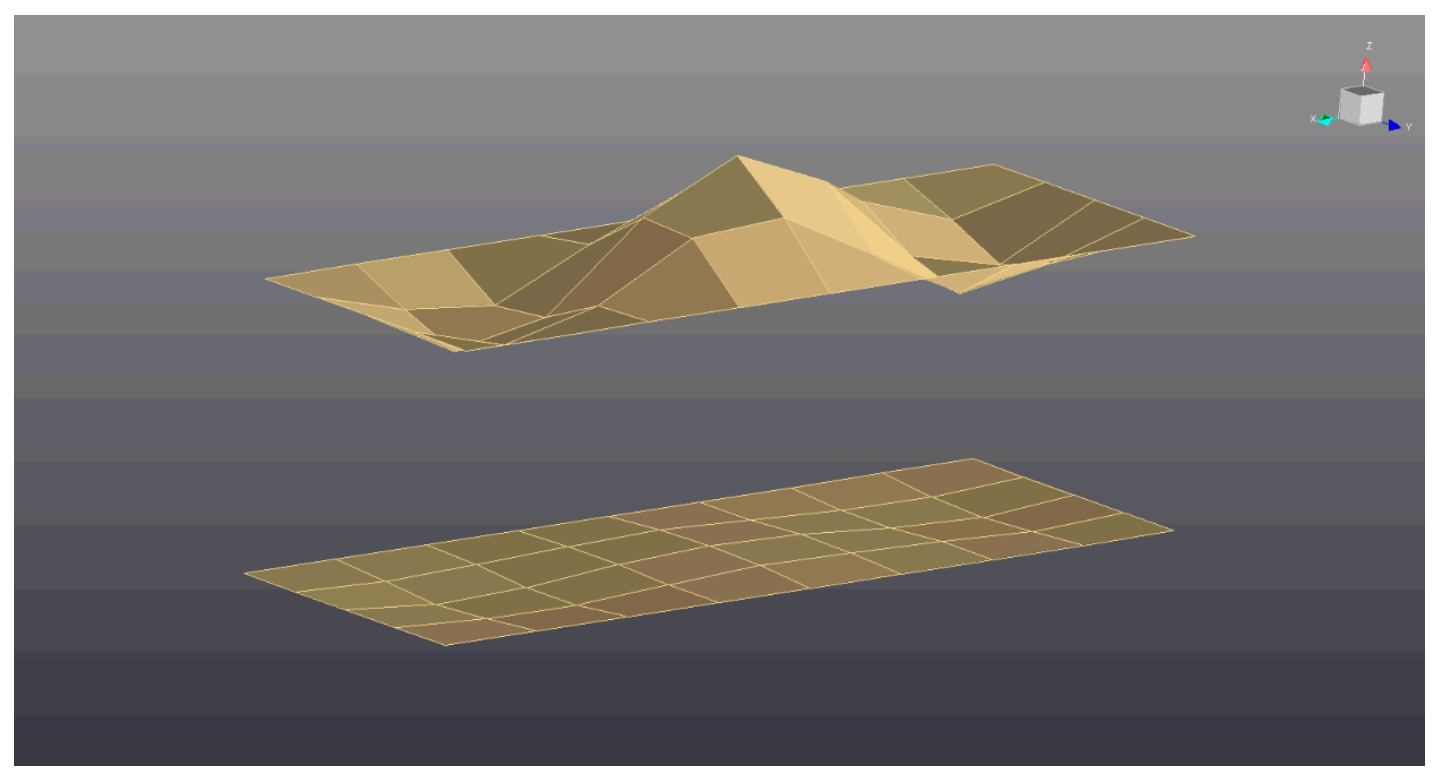

Figure 56. EMA first mode shape $3.8 \mathrm{~mm}$ air gap $(40.0 \mathrm{~Hz})$. 


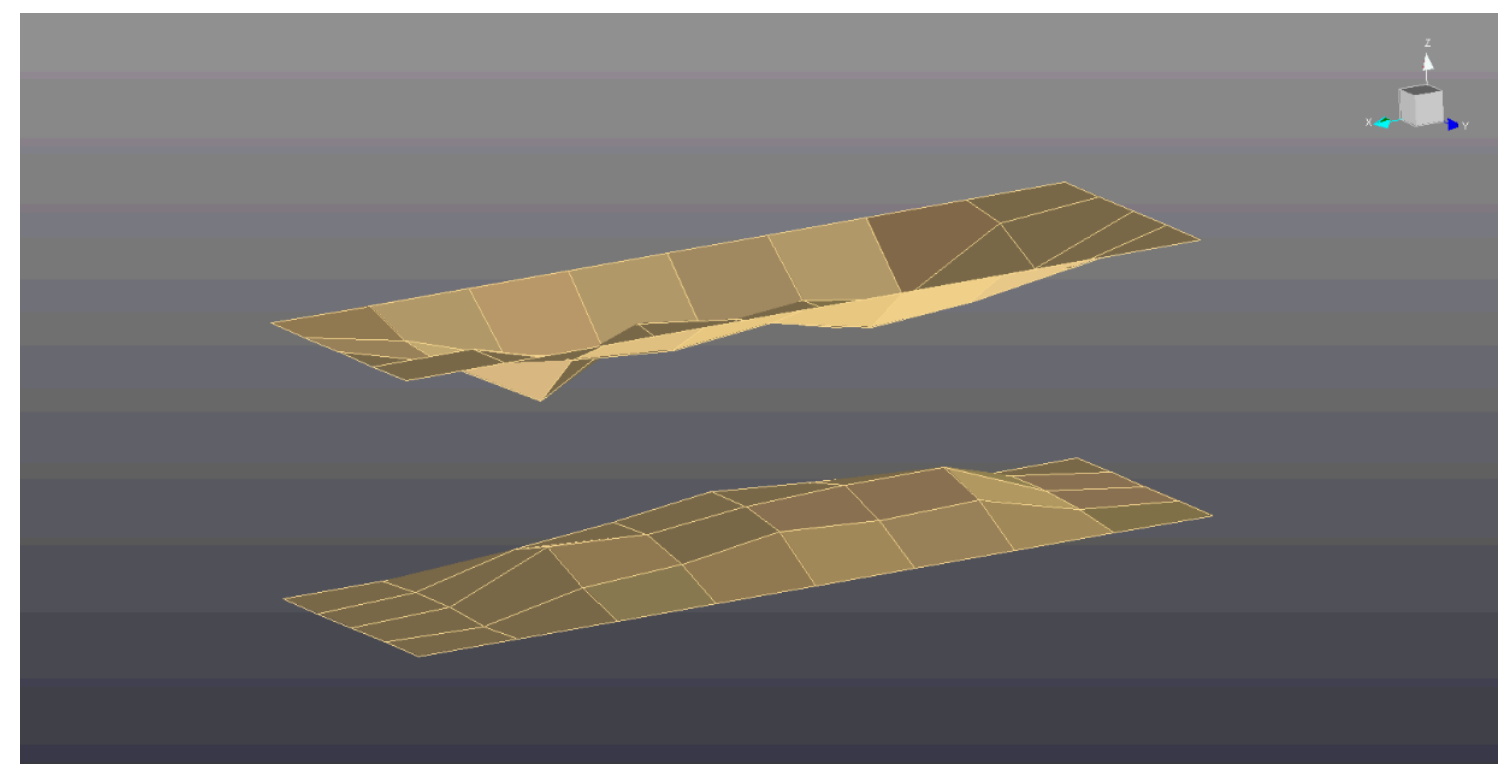

Figure 57. EMA second mode shape of $1.9 \mathrm{~mm}$ air gap $(50.8 \mathrm{~Hz})$.

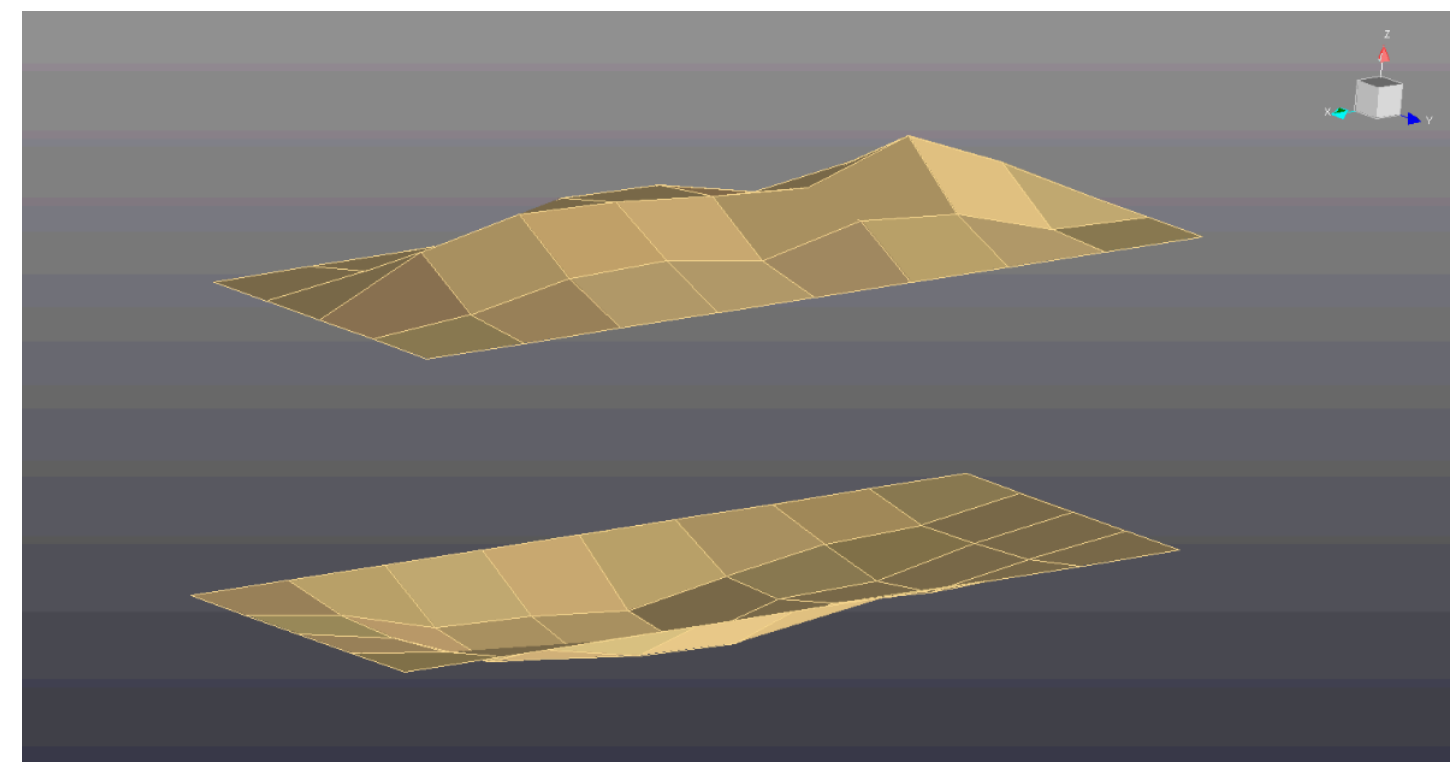

Figure 58. EMA second mode shape of $3.8 \mathrm{~mm}$ air gap $(58.2 \mathrm{~Hz})$. 


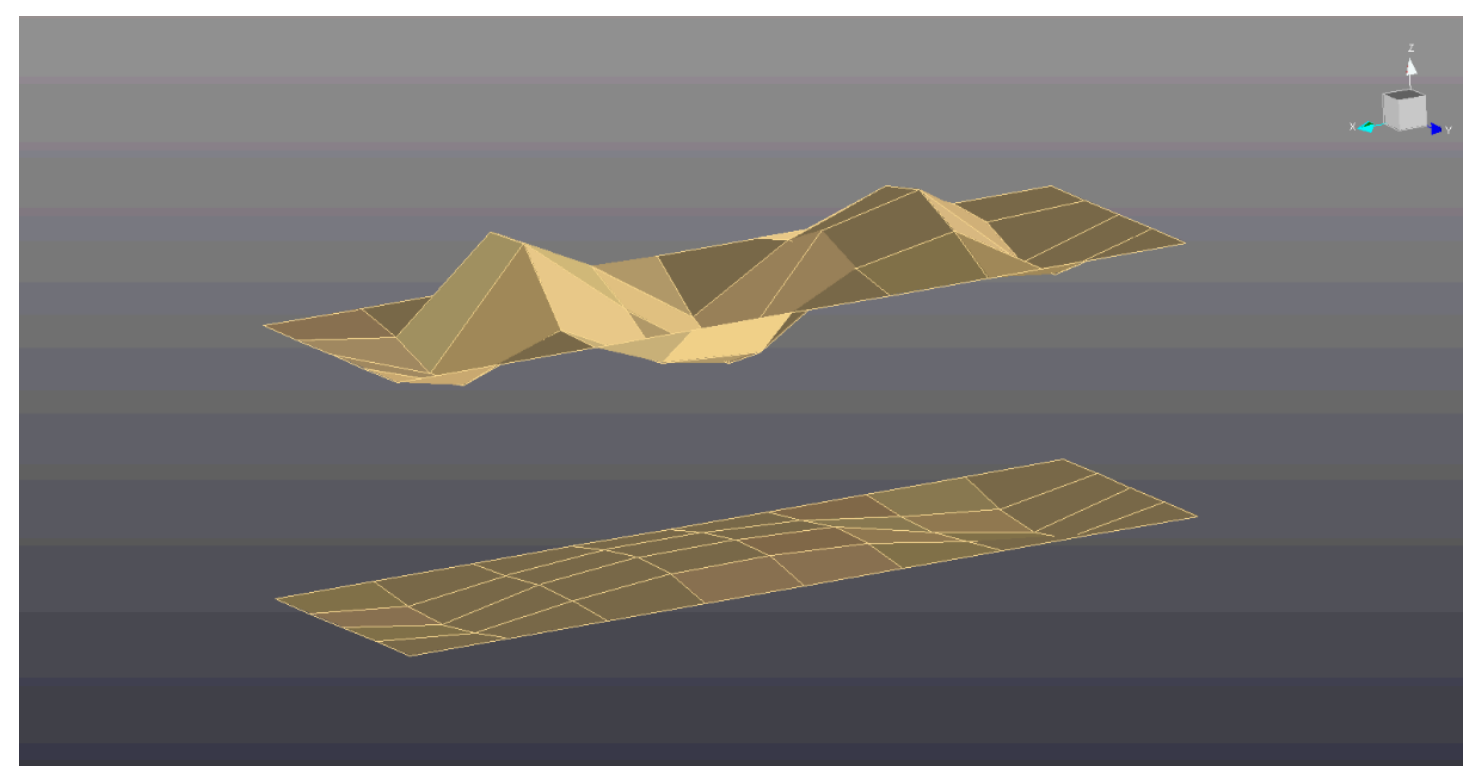

Figure 59. EMA third mode shape of $1.9 \mathrm{~mm}$ air gap $(72.0 \mathrm{~Hz})$.

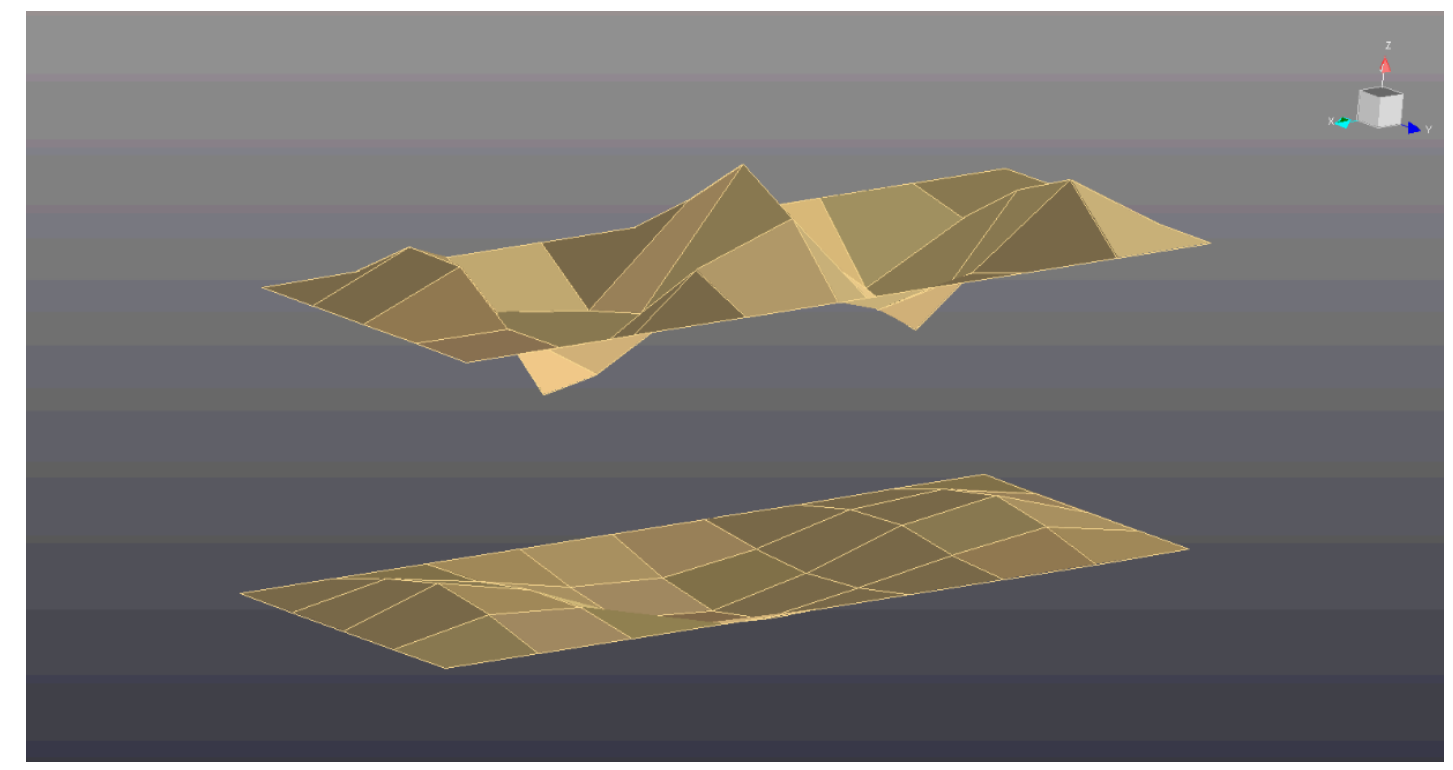

Figure 60. EMA third mode shape of $3.8 \mathrm{~mm}$ air gap $(79.0 \mathrm{~Hz})$. 


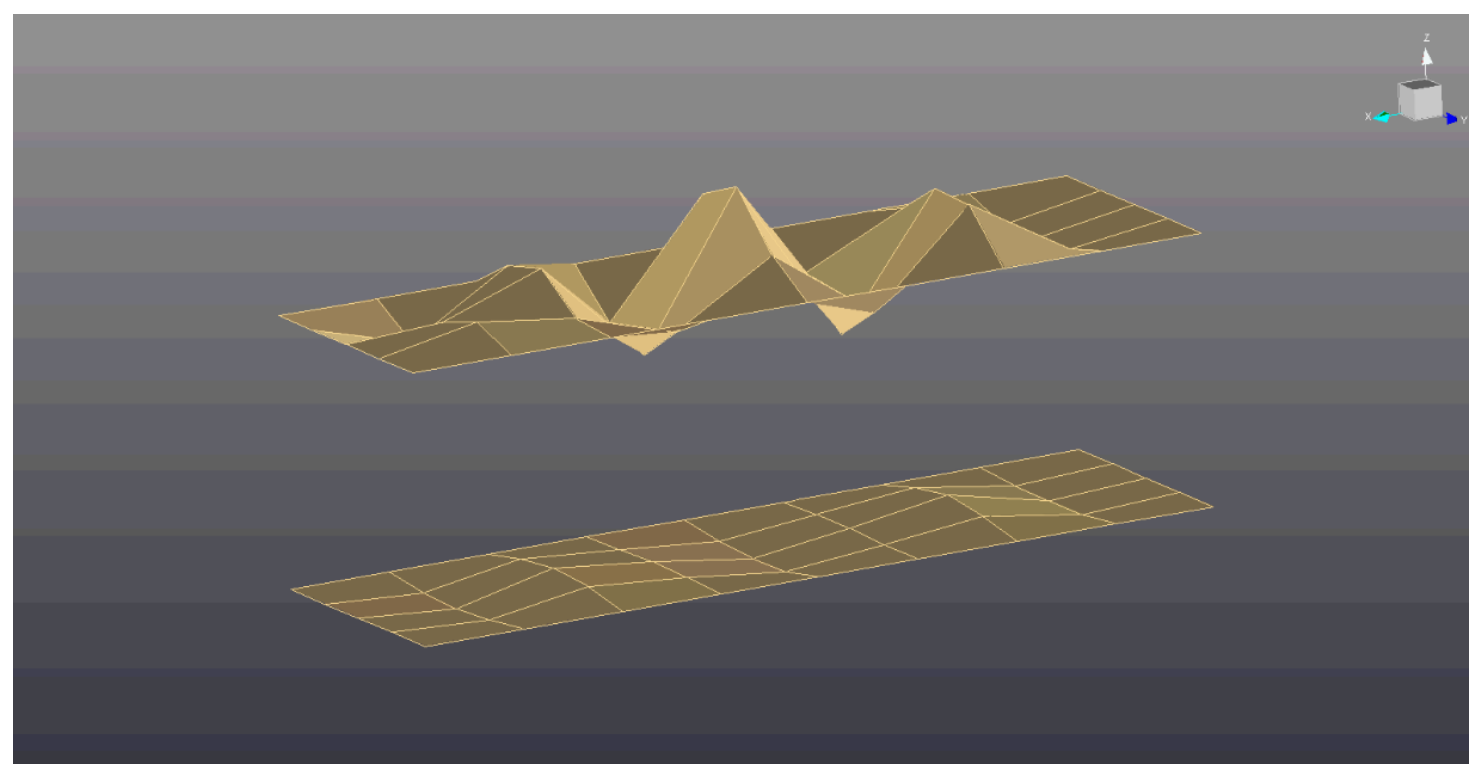

Figure 61. EMA fourth mode of $1.9 \mathrm{~mm}$ air gap $(121.7 \mathrm{~Hz})$.

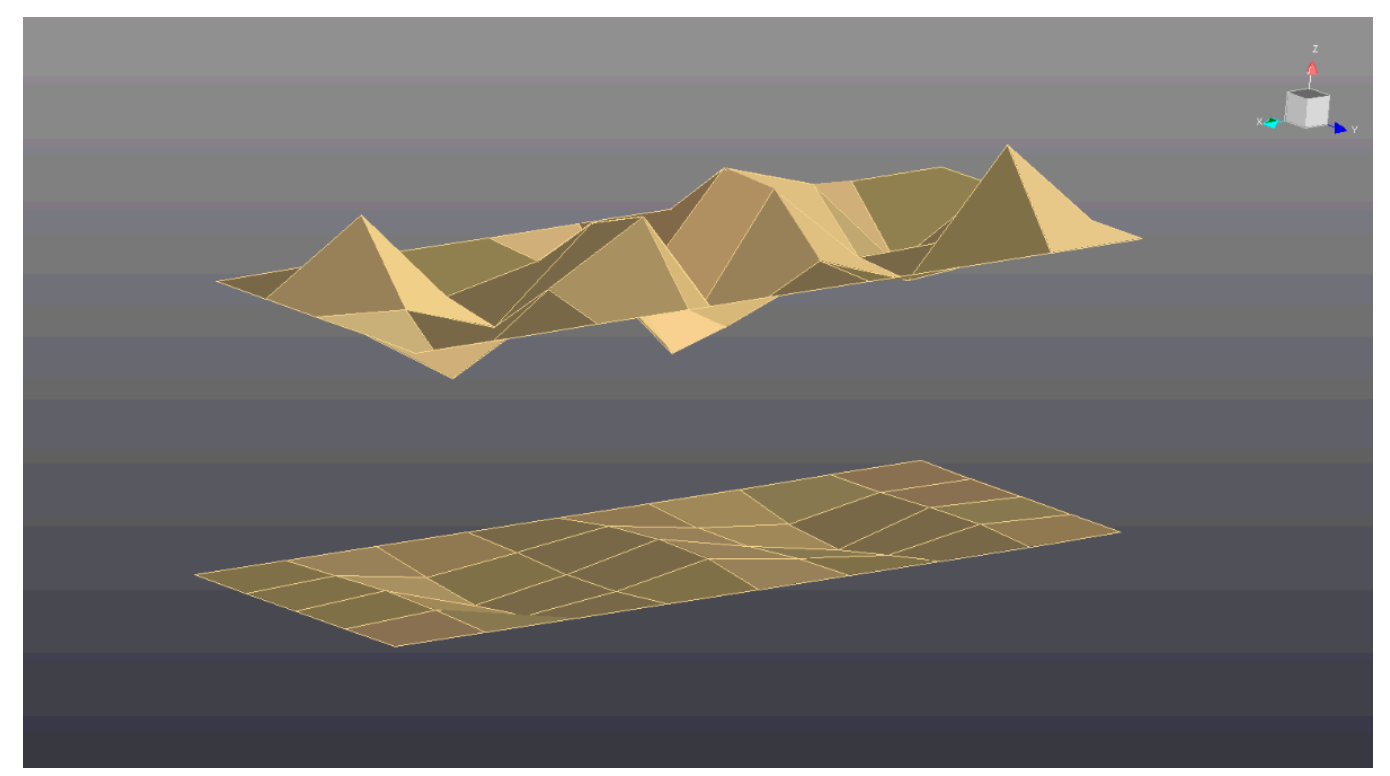

Figure 62. EMA fourth mode of $3.8 \mathrm{~mm}$ air gap $(126.7 \mathrm{~Hz})$. 


\section{APPENDIX H: MATLAB® Code for Completing MAC Calculation}

This code is the specific code used for determining the MAC values for the 1.9 mm air gap mode shapes. There were 31 mode shapes collected for this configuration. The $3.78 \mathrm{~mm}$ air gap configuration calculation included 33 mode shapes (thus there would be a different in the for loop increment). The text files containing the mode shapes were saved as 'source_1', 'source_2', etc. for the source plate and similarly 'receiver_1', 'receiver_2', etc. for the receiving plate.

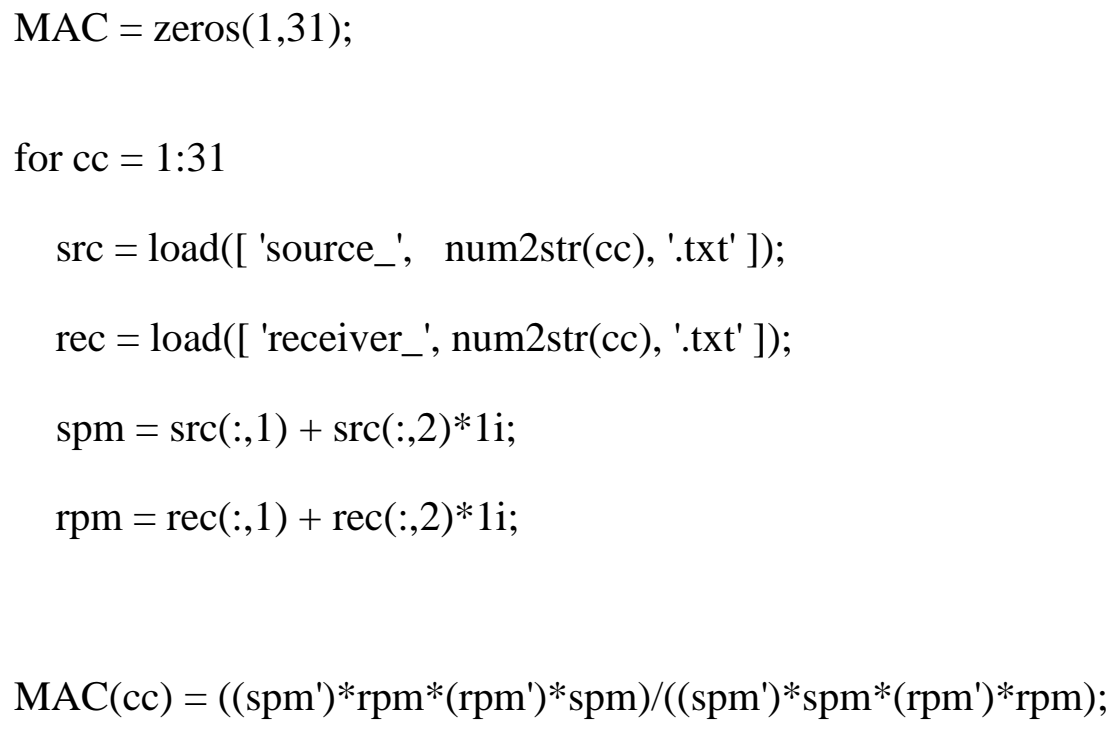

End 
APPENDIX I: MAC Values for $1.9 \mathrm{~mm}$ Air Gap Mode Shapes

\begin{tabular}{|c|c|c|}
\hline Mode & Frequency & MAC \\
\hline 1 & 34.9 & 0.130135 \\
\hline 2 & 50.4 & 0.559692 \\
\hline 3 & 70.9 & 0.037685 \\
\hline 4 & 121.9 & 0.006188 \\
\hline 5 & 160.4 & 0.066869 \\
\hline 6 & 183 & 0.014479 \\
\hline 7 & 199.4 & 0.014312 \\
\hline 8 & 223.3 & 0.044189 \\
\hline 9 & 241 & 0.018668 \\
\hline 10 & 260.2 & 0.036377 \\
\hline 11 & 292.5 & 0.045412 \\
\hline 12 & 330.4 & 0.043812 \\
\hline 13 & 355 & 0.096765 \\
\hline 14 & 374.8 & 0.066102 \\
\hline 15 & 396.6 & 0.074109 \\
\hline 16 & 434.5 & 0.424747 \\
\hline 17 & 452.4 & 0.011353 \\
\hline 18 & 475.3 & 0.052662 \\
\hline 19 & 528.5 & 0.124723 \\
\hline 20 & 579.8 & 0.033437 \\
\hline 21 & 602.8 & 0.031801 \\
\hline 22 & 634.1 & 0.215352 \\
\hline 23 & 667.2 & 0.14775 \\
\hline 24 & 707.9 & 0.11217 \\
\hline 25 & 747.5 & 0.027762 \\
\hline 26 & 761.4 & 0.018978 \\
\hline 27 & 833.8 & 0.39126 \\
\hline 28 & 883.4 & 0.042123 \\
\hline 29 & 907.4 & 0.013979 \\
\hline 30 & 940.6 & 0.500996 \\
\hline 31 & 959.5 & 0.00523 \\
\hline & & \\
\hline
\end{tabular}

Table 7. MAC values for $1.9 \mathrm{~mm}$ air gap configurations mode shapes 
APPENDIX J: MAC Values for $3.8 \mathrm{~mm}$ Air Gap Mode Shapes

\begin{tabular}{|c|c|c|}
\hline Mode & Frequency & MAC \\
\hline 1 & 40 & 0.108232 \\
\hline 2 & 57.2 & 0.379552 \\
\hline 3 & 79 & 0.047198 \\
\hline 4 & 126.6 & 0.048706 \\
\hline 5 & 141.6 & 0.123899 \\
\hline 6 & 174.9 & 0.040108 \\
\hline 7 & 198 & 0.361067 \\
\hline 8 & 237 & 0.035675 \\
\hline 9 & 254.5 & 0.068191 \\
\hline 10 & 277.5 & 0.112004 \\
\hline 11 & 302.1 & 0.018815 \\
\hline 12 & 313.8 & 0.14298 \\
\hline 13 & 374.2 & 0.178124 \\
\hline 14 & 401.8 & 0.074545 \\
\hline 15 & 449 & 0.093125 \\
\hline 16 & 483 & 0.04569 \\
\hline 17 & 506.6 & 0.034456 \\
\hline 18 & 535.6 & 0.077946 \\
\hline 19 & 552 & 0.066124 \\
\hline 20 & 577.9 & 0.033341 \\
\hline 21 & 601.9 & 0.060627 \\
\hline 22 & 615.5 & 0.047291 \\
\hline 23 & 627.1 & 0.08381 \\
\hline 24 & 657.7 & 0.007086 \\
\hline 25 & 675.2 & 0.195668 \\
\hline 26 & 764.1 & 0.020185 \\
\hline 27 & 781.4 & 0.032177 \\
\hline 28 & 839.2 & 0.05758 \\
\hline 29 & 842.3 & 0.044259 \\
\hline 30 & 851.4 & 0.048165 \\
\hline 31 & 878.4 & 0.050414 \\
\hline 32 & 929.3 & 0.171378 \\
\hline 33 & 957.3 & 0.294099 \\
\hline & & \\
\hline
\end{tabular}

Table 8. MAC values for $3.8 \mathrm{~mm}$ air gap configuration mode shapes. 


\section{CURRICULUM VITA}

NAME: $\quad$ Richard M. Phillips

CONTACT: rmphillips25@gmail.com

Work: 502-452-3815

Cell: 240-620-6529

3900 Fairfield Meadows Drive

Louisville, KY 40245

DOB: $\quad$ November 17,1988

EDUCATION

\& TRAINING:
M.S. Mechanical Engineering (exp. 12/2014)

University of Louisville

(GPA: 3.76/4.0)

2012-Present

B.S. Mechanical Engineering

University of Maryland Baltimore County

(GPA: 3.33/4.0)

2006-2011

GE Corporate Training

Edison Engineering Development Program (2011-2014)

Foundations of Leadership (2012)

Engage at GE (2012)

\section{WORK EXPERIENCE:}

\section{GE Appliances, Louisville, KY}

Design Engineer - Zoneline AC

- Part ownership of all foam parts (25 parts)

- Part ownership of all sound pack (3 parts)

- Part ownership of vent door assembly (living hinge, filter and rod mechanism)

- Evaluation leader for acoustics (transmission and operational acoustics) 
- Evaluation leader for acoustics (transmission and operational acoustics)

- Redesigned sound pack at DG phase to reduce complexity and cost - estimated $\$ 1.1 \mathrm{MM}$ savings annually and 11 parts eliminated

- Led sourced program acoustics evaluation, improving program by 3 STC

- Assisted in kit development for sourced program

- Assignment leader for 2 co-ops on the Zoneline team, mentored the co-ops to successful completion of their projects

$4^{\text {th }}$ Rotation, Range:

New Product Introduction (Free-standing Gas)

- Improved the design of door venting to pass thermal evaluation while successfully root causing several failures in the design

- Led the field test evaluation (17 ranges), led the closure of several failure items.

- Improved the design of the low end hinges to increase reliability and ensure robustness of the locking mechanism

- Evaluated and selected the best hinge for the high end product

- Developed steam clean algorithm through a multivariable design of experiment

$3^{\text {rd }}$ Rotation, Refrigeration:

Product Cost Take Out (Celaya, Mexico Product)

July 2012-January 2013

- Led DOE testing and qualification of the X11a inverter to avoid risk to production in 2014, estimated cost savings of $\$ 654 \mathrm{M}$

- Developed test plan, completed refrigerant flow calculations and created drawings for an aluminum suction tube to replace the current copper suction tube on a bottom freezer model, estimated annual savings of $\$ 120 \mathrm{M}$

- Led the execution of a new plastic overlay for annual savings of $\$ 75 \mathrm{M}$

- Designed and prototyped an 8W LED for the Bottom Freezer 20-22 model year program.

$2^{\text {nd }}$ Rotation, Water Products:

New Production Introduction (Hybrid Water Heater) January 2012-July 2012

- Ownership of the DG evaluation plan for the 60 gallon hybrid water heater

- Condenser clamp redesign to improve cycle time by 30 seconds and to ensure energy performance

- Dry fire algorithm development on 60 gallon hybrid water heater to reduce service call rate and reduce submerged heating element failure. 
$1^{\text {st }}$ Rotation, Global Products:

Platform Engineering (Zoneline AC)

July 2011-January 2012

- Confirmed compatibility of Verdant (sourced) wireless thermostat

- Designed aftermarket sound absorption parts for Zoneline AC that improved product performance by 1 STC

- Redesigned outdoor fan shroud to improve airflow (CFM) by $10 \%$

- Project management: successfully completed 8 branded product change requests while working with international team

GE Aviation, Middle River, MD

Engineering Intern

June 2010-August 2010

- CAD design of pylon components

- Updated a material database to be used by CAD and CAE engineers

\section{LABORATORY COMPETANCY:}

- Certified HVAC Technician (Type 1 EPA Clean Air Section 608) - refrigeration system recovery and charging

- Sheet metal prototyping (water jet, brake press, turret punch, spot welding)

- Experimental Modal Analysis

- Airflow testing to develop Fan/ System curves

- Smoke testing to visualize airflow

- Beginner experience in brazing

- Beginner experience in calorimetry

\section{COMPUTER SKILLS/ LANGUAGES:}

- Knowledgeable: SolidWorks, MiniTab, Microsoft Word, Excel, PowerPoint

- Basic Understanding: MATLAB, Pro-E, LabVIEW, CEEE Coil Designer

\section{ACTIVITIES/HONORS:}

- UMBC Varsity Baseball Captain (2010 and 2011 seasons)

- UMBC Varsity Baseball (2007-2011 seasons)

- Retriever Club Scholarship Award

PROFESSIONAL SOCIETY MEMBERSHIPS:

- ASHRAE Member (January 2014-present)

- ASME and ASCE student member (during undergraduate) 